\title{
A proposed terminology for the dentition of gomphodont cynodonts and dental morphology in Diademodontidae and Trirachodontidae
}

\author{
Christophe Hendrickx ${ }^{\text {Corresp., } 1}$, Fernando Abdala ${ }^{1,2}$, Jonah N Choiniere ${ }^{1}$ \\ 1 Evolutionary Studies Institute and School of Geosciences, University of the Witwatersrand, Johannesburg, Gauteng, South Africa \\ 2 CONICET-Fundación Miguel Lillo, Unidad Ejecutora Lillo, San Miguel de Tucumán, Argentina \\ Corresponding Author: Christophe Hendrickx \\ Email address: christophendrickx@gmail.com
}

Gomphodont cynodonts were close relatives of mammals and one of the Mesozoic lineages of cynodont therapsids that became extinct at the end of the Triassic. Gomphodonts were omnivorous to herbivorous animals characterized by labiolingually expanded postcanines, which allowed tooth-to-tooth occlusion. The morphology of the upper and lower postcanines presents important means of distinguishing among major lineages within Gomphodontia, i.e., Diademodontidae, Trirachodontidae, and Traversodontidae, but the dentition of most Diademodontidae and Trirachodontidae remain poorly documented. Here we present a comprehensive description of the dentition of each diademodontid and trirachodontid species, as well as detailed illustrations of each dental unit, after firsthand examination of material and $3 d$ reconstructions of postcanine teeth. Based on dental morphology, Trirachodon berryi and 'Trirachodon kannemeyeri', considered as separate taxa by some authors are here interpreted as representing different ontogenetic stages of the same species. Likewise, Sinognathus and Beishanodon, thought to belong to noncynognathian cynodonts and traversodontids by some authors, are referred to Trirachodontidae and Gomphodontia based on dental characters, respectively. Finally, we propose a standardized list of terms and abbreviations for incisors, canines and postcanines anatomical entities, with the goal of facilitating future descriptions and communication between researchers studying the gomphodont dentition. 


\section{A proposed terminology for the dentition of gomphodont}

\section{2 cynodonts and dental morphology in Diademodontidae and}

3 Trirachodontidae.

5 CHRISTOPHE HENDRICKX ${ }^{1 *}$, FERNANDO ABDALA ${ }^{1,2} \&$ JONAH CHOINIERE $^{1}$

$7{ }^{1}$ Evolutionary Studies Institute and School of Geosciences, University of the Witwatersrand,

8 Johannesburg, South Africa.

9 2Unidad Ejecutora Lillo, CONICET-Fundación Miguel Lillo, Miguel Lillo 251, San Miguel de

10 Tucumán 4000, Tucumán, Argentina.

12 Emails: christophendrickx@gmail.com, 1viutiabdala2@gmail.com, jonah.choiniere@wits.ac.za.

13 *Corresponding author.

Abstract

Gomphodont cynodonts were close relatives of mammals and one of the Mesozoic lineages of cynodont therapsids that became extinct at the end of the Triassic. Gomphodonts were omnivorous to herbivorous animals characterized by labiolingually expanded postcanines, which allowed tooth-to-tooth occlusion. The morphology of the upper and lower postcanines presents important means of distinguishing among major lineages within Gomphodontia, i.e., Diademodontidae, Trirachodontidae, and Traversodontidae, but the dentition of most Diademodontidae and Trirachodontidae remain poorly documented. Here we present a comprehensive description of the dentition of each diademodontid and trirachodontid species, as well as detailed illustrations of each dental unit, after firsthand examination of material and $3 \mathrm{~d}$ reconstructions of postcanine teeth. Based on dental morphology, Trirachodon berryi and 'Trirachodon kannemeyeri', considered as separate taxa by some authors are here interpreted as representing different ontogenetic stages of the same species. Likewise, Sinognathus and Beishanodon, thought to belong to non-cynognathian cynodonts and traversodontids by some authors, are referred to Trirachodontidae and Gomphodontia based on dental characters, 
30

respectively. Finally, we propose a standardized list of terms and abbreviations for incisors, canines and postcanines anatomical entities, with the goal of facilitating future descriptions and communication between researchers studying the gomphodont dentition.

\section{Introduction}

Gomphodont cynodonts form a radiation of Triassic therapsids known from the late Olenekian to the Norian on all continents but Australia (e.g., Battail, 1983; Abdala \& Ribeiro, 2003; Hopson, 2005, 2014; Abdala \& Gaetano, 2018; Figure 1A). Members of this clade were small to medium-sized (from approximately $30 \mathrm{~cm}$ to $2 \mathrm{~m}$ in body length), quadrupedal animals characterized by labiolingual expansion of the upper and sometimes lower postcanines (gomphodont morphology) allowing crown-to-crown occlusion (e.g., Seeley, 1895, 1908; Crompton, 1972; Reisz \& Sues, 2000; Abdala, Neveling \& Welman, 2006; Hopson, 2014). Such morphology of the postcanines suggests that gomphodonts were omnivorous or possibly exclusively herbivorous animals, feeding on hard plant material (Reisz \& Sues, 2000; Abdala, Neveling \& Welman, 2006; Liu \& Abdala, 2014). Three clades, mainly differentiated by their postcanine morphology, are currently recognized among Gomphodontia, the Diademodontidae, Trirachodontidae and Traversodontidae (Hopson, 2005; Liu \& Abdala, 2014; Hendrickx, Abdala \& Choiniere, 2016).

Diademodontidae is an early diverging lineage of gomphodonts with low taxonomic diversity at the generic and species level (Figure 1A). Two valid taxa (i.e., Diademodon and Titanogomphodon) known from the Olenekian and Anisian of southern and East Africa, Argentina and possibly Antarctica currently compose this group (Keyser, 1973; Hammer, 1995; Martinelli, de la Fuente \& Abdala, 2009; Figure 1B). A possible lazarus diademodontid from the Lower Jurassic of South Africa (Bordy et al., 2017; Abdala \& Gaetano, 2018) was described by Abdala et al. (2007) but most likely represents a non-gomphodont tetrapod (F.A. pers. obs.). The postcanine dentition of diademodontids is heterogeneous and separated into conical, gomphodont and sectorial teeth, which is considered as the most primitive condition of dental morphology among Gomphodontia (e.g., Crompton, 1972; Gow, 1978; Hopson, 2005). The upper and lower gomphodont postcanines of diademodontids display several ridges and accessory cusps whose position varies on the crown and along the tooth row. The distalmost part of the diademodontid 
60 tooth row is also characterized by a minimum of three sectorial teeth, and one or several

61 transitional postcanines gradually changing from a gomphodont morphology to a more

62 labiolingually compressed sectorial type of crown (Crompton, 1972; Hopson, 2005).

Trirachodontidae are represented by five valid species restricted to the Olenekian and

64 Anisian of Southern Africa and Asia (Abdala, Neveling \& Welman, 2006; Gao et al., 2010;

65 Sidor \& Hopson, 2018; Figure 1A, B). Trirachodontids were relatively small animals (i.e., $<1 \mathrm{~m}$ ),

66 and some had a burrowing/fossorial lifestyle (Groenewald, Welman \& Maceachern, 2001; Smith

$67 \&$ Swart, 2002). The postcanine tooth row of trirachodontids encompasses a lower number of sectorial teeth than that of diademodontids, which occur immediately distal to the gomphodont postcanines (Hopson, 2005). The gomphodont postcanine of trirachodontids shows a clearly defined centrally positioned transverse crest made of labial, central and lingual cusps and ringed by mesial and distal cingula on the rim of the tooth (Abdala, Neveling \& Welman, 2006).

The most derived and most taxonomically diverse gomphodont radiation are the

Traversodontidae, which form a major element of tetrapod communities in Gondwana during the Middle and Late Triassic (Liu \& Sues, 2010). This clade currently encompasses more than twenty taxa known from the Anisian to the Norian and possibly Rhaetian of Africa, South America, North America and Europe (e.g., Hopson, 2014; Liu \& Abdala, 2014; Figure 1A).

Traversodontids increased in body size throughout the Triassic, with younger members reaching up to two meters in length (Reisz \& Sues, 2000; Liu \& Abdala, 2014). The upper and lower postcanines of traversodontids typically encompass gomphodont teeth, and only a few taxa retained one or several sectorial postcanines at the distal rear of the tooth row in small, possibly young individuals (Liu \& Sues, 2010).

Similar to other cynodonts, the dentition of gomphodonts is the most diagnostic element of the skeleton (Liu \& Sues, 2010). Because of their high resistance compared to other parts of the skeleton due to greater density and lower permeability (Martin, 1999), teeth are also the most commonly preserved material in Gomphodontia, with dental elements known in every gomphodont taxa hitherto described. Given the postcanine diversity and complexity among gomphodonts, the dentition of these cynodonts typically receives particular attention and is often relatively well-described. Nonetheless, thorough description of the dental material is often provided for gomphodont postcanines, whereas information as well as detailed figures on the incisors, canines and conical and sectorial postcanines are omitted in the descriptions of many 
91 gomphodont taxa. In addition, we have noticed inconsistencies in the terminology and

92 abbreviations used in discussions of the dental gomphodont anatomy, with several authors

93 providing different terms for the same dental structure. The labiomesial accessory cusp seen in

94 the gomphodont postcanines of some traversodontids has, for instance, received no less than

95 eleven different terms, and more than eight terms describe the labial and labiodistal accessory

96 cusps. Such a large number of terms and abbreviations for the same dental structure leads to

97 confusion, and a clear and detailed terminology, which will greatly facilitate the description and

98 communication of the dentition of gomphodont cynodonts, remain to be provided.

99 This paper: i) proposes a standardized list of terms and abbreviations for incisors, canines

100 and postcanines anatomical entities, with the goal of facilitating future descriptions and

101 illustrations of the gomphodont dentition; and ii) provides a comprehensive description and

102 detailed illustrations of the dentition of all known diademodontid and trirachodontid taxa. Tooth

103 replacement pattern and postcanine occlusion, which were treated in detail by several authors for

104 Diademodontidae and Trirachodontidae (e.g., Crompton, 1955, 1972; Fourie, 1963; Ziegler,

105 1969; Hopson, 1971; Osborn, 1974; Sidor \& Hopson, 2018), is beyond the scope of this paper.

106 Likewise, a comprehensive description of the dentition of Traversodontidae, which will form the

107 base of another contribution (Hendrickx, Choiniere \& Abdala, in preparation), falls outside the

108 scope of this study. Finally, the evolution of the gomphodont dentition will be thoroughly

109 explored in a third contribution based on a cladistic analysis performed on a dentition-based data

110 matrix encompassing all gomphodont taxa (Hendrickx, Abdala \& Choiniere, in preparation).

111

112 Institutional abbreviations: AM, Albany Museum, Grahamstown, South Africa; AMNH,

113 American Museum of Natural History, New York, New York, USA; BP, Evolutionary Studies

114 Institute (formerly Bernard Price Institute for Palaeontological Research), University of the

115 Witwatersrand, Johannesburg, South Africa; BSP, Bayerische Staatssammlung für Paläontologie

116 und Geologie, Munich, Germany; CGP, Council for Geosciences, Pretoria, South Africa; GSN,

117 Geological Survey of Namibia, Windhoek, Namibia; IVPP, Institute for Vertebrate Paleontology

118 and Paleoanthropology, Beijing, China; MB, Museum für Naturkunde der Humboldt Universität,

119 Berlin, Germany; MHNSR-Pv, Museo de Historia Natural de San Rafael, Mendoza, Argentina;

120 NHCC, National Heritage Conservation Commission, Lusaka, Zambia; NHMUK PV, Natural

121 History Museum, London, UK; NMQR, National Museum, Bloemfontein, South Africa; NMT, 
122 National Museum of Tanzania, Dar es Salaam, Tanzania; PKUP, Peking University

123 Paleontological Collections, Beijing; SAM-PK, Iziko, the South African Museum, Cape Town,

124 South Africa; UMZC, University Museum of Zoology, Cambridge, UK.

125

126

Material and methods

127

Dental features were investigated on incisors, canines and gomphodont and sectorial

128 postcanines preserved within the upper and lower jaws as well as isolated teeth of non-

129

traversodontid gomphodonts. The dentition of 89 specimens belonging to six diademodontid and

130 trirachodontid genus-level taxa deposited in eleven scientific collections from South Africa,

131 Namibia, Germany, the United Kingdom and China were examined first-hand (Table 1). The

132 specimens were referred to a diademodontid/trirachodontid species based on a dental diagnosis

133 that will be provided for each gomphodont taxon in a forthcoming contribution (Hendrickx,

134 Abdala \& Choiniere, in preparation). Denticles, crown ornamentations and enamel texture were

135 observed with a digital microscope AM411T-Dino-Lite Pro. Only Beishanodon youngi could not

136 be examined first hand, and we relied on Gao et al.'s (2010) publication in which the dentition

137 was comprehensively described and illustrated.

138 3D-models of teeth were generated for lower and upper postcanines in all taxa but

139 Sinognathus and Beishanodon (Table 1) through photogrammetric techniques using Agisoft

140 Photoscan Standard (Version 1.3.4; Software; 2017; Retrieved from

141 http://www.agisoft.com/downloads/installer/) and the photos taken with the digital microscope

142 AM411T-Dino-Lite Pro. The batch process followed in Agisoft Photoscan to reconstruct the

143 postcanines in $3 \mathrm{~d}$ consists of four steps: i) more than 150 photos taken in all views were aligned

144 with the highest accuracy using standard options (i.e., with generic pre-selection and 40,000 and

145 4,000 key point limit and tie point limit, respectively); ii) a dense cloud was then built in ultra-

146 high quality with an aggressive depth filtering and no reuse depth map; iii) the mesh was then

147 built with a high face count and default options (i.e., a custom face count of 200,000 faces,

148 arbitrary surface type, interpolation enabled and vertex color calculated); iv) the texture was

149 finally built using the default options (i.e., generic mapping mode, texture from all cameras,

150 mosaic blending mode, texture size and count of 4,096 and 1, respectively, no color correction

151 and using the hole filling option). A total of twenty $3 \mathrm{~d}$-models are deposited and freely 
152 downloadable in the MorphoBrowser database

153 (http://pantodon.science.helsinki.fi/morphobrowser/).

154 The dental morphology of Trirachodon berryi was also investigated based on CT-scan

155 data from the specimen AM 461, a fully preserved skull and the holotype of Trirachodon

156 kannemeyeri. AM 461 was CT-scanned at the Evolutionary Studies Institute (ESI) of the

157 University of the Witwatersrand (Johannesburg) using a Nikon Metrology computed tomography

158 XTH 225/320 LC, with a voxel size of $0.0668 \mathrm{~mm}$, and generating 1778 of images of $1109 * 779$

159 pixels resolution. The postcanines were visualized and reconstructed using the software

160 VGStudio Max 3.0 available at the ESI.

161 Neotrirachodon expectatus (Tatarinov, 2002) and Redondagnathus hunti (Lucas et al.,

162 1999; Spielmann \& Lucas, 2012), classified as trirachodontids by their authors, were not

163 included in this study as they probably do not represent gomphodont cynodonts (Sidor \&

164 Hopson, 2018). Neotrirachodon, synonymized with Antecosuchus by Ivakhnenko (2011), likely

165 belongs to a bauriid therocephalian (Battail \& Surkov, 2000; Abdala, Neveling \& Welman, 2006;

166 Abdala \& Smith, 2009; Gao et al., 2010; Sues \& Hopson, 2010; Ivakhnenko, 2011) whereas

167 Redondagnathus' dental material displays several features absent in Trirachodontidae, namely: a

168 central cusp strongly mesially/distally deflected from the labial and lingual cusps and much

169 higher than the two latter cusps, no valley-like concavities separating the central cusp from the

170 labial and lingual cusps, a cingulum significantly apically higher than the other one, apically

171 pointed cingular cuspules varying dramatically in size along the cingulum, presence of a basally

172 inclined spalling surface extending below the cingulum as well as an important protuberance on

173 the basal part of the root (Sidor \& Hopson, 2018; C.H. pers. obs.). We, therefore, agree with

174 Sidor \& Hopson (2018) and consider that the teeth of Redondagnathus do not share enough

175 dental features with trirachodontids and gomphodonts to be confidently referred to these clades.

176 Likewise, CGP JSM 100, interpreted as a possible juvenile Trirachodon by Hopson (2005), was

177 not considered in this study as the specimen likely represents a new taxon of basal traversodontid

178 (C.H.; F.A. pers. obs.), a possibility also discussed by Hopson (2005). The dentition of this

179 specimen, indeed, shows several dental features absent in trirachodontids and seen in basal

180 traversodontids. They include unserrated incisors, a central cusp of transverse crest close to

181 lingual cusp in the upper postcanines, quadrangular or subrectangular lower postcanines in

182 occlusal view, a long axis of lower gomphodont postcanine parallel to the long axis of the 
183 mandibular tooth row, and a labial cusp lower than lingual cusp in lower postcanines. The

184 dentition and phylogenetic position of CGP JSM 100 will be thoroughly discussed elsewhere.

185

186 Terminology

\section{Quantitative parameters}

188 The dental positional and morphometric nomenclature follows Smith \& Dodson (2003)

189 and Hendrickx, Mateus \& Araújo (2015), with the following abbreviations being used in this

190 study:

191

\begin{tabular}{l|l}
$\begin{array}{l}\text { Crown Base } \\
\text { Length } \\
\text { (CBL) }\end{array}$ & $\begin{array}{l}\text { Maximum mesiodistal extent of the crown base at the level of the cervix (i.e., } \\
\text { the transition between the crown and the root and forming the basal extension } \\
\text { of the enamel layer; Smith, Vann \& Dodson, 2005; Hendrickx, Mateus \& } \\
\text { Araújo, 2015). }\end{array}$ \\
$\begin{array}{l}\text { Crown Base } \\
\text { Width } \\
\text { (CBW) } \\
\text { and at the level of the cervix (Smith, Vann \& Dodson, 2005). }\end{array}$ \\
$\begin{array}{l}\text { Crown } \\
\text { Height (CH) }\end{array}$ \\
$\begin{array}{l}\text { Crown Base } \\
\text { Ratio (CBR) }\end{array}$ & $\begin{array}{l}\text { Maximum apicobasal extent of the distal margin of the crown (Hendrickx, } \\
\text { Mateus \& Araújo, 2015). } \\
\text { corresponding to the quotient of CBW by CBL (CBR }=\mathrm{CBW} \div \text { CBL; Smith, } \\
\text { Vann \& Dodson, 2005). }\end{array}$ \\
$\begin{array}{l}\text { Denticle Size } \\
\text { Density }\end{array}$ & $\begin{array}{l}\text { Ratio expressing the size difference between mesial and distal denticles (Rauhut } \\
\text { \& Werner, 1995) and corresponding to the quotient of the number of denticles } \\
\text { Index (DSDI) } \\
\text { per five millimeters on the mesial carina at mid-crown (MC) by the number of } \\
\text { denticles per five millimeters on the distal carina (DC) at mid-crown (DSDI = } \\
\text { MC } \div \text { DC). }\end{array}$ \\
\hline
\end{tabular}

192

193 Proposed dental terminology

194 Crown microstructure nomenclature uses the terminology proposed by Sander (1997a,

195 1999). The anatomical nomenclature used to describe and annotate the external tooth

196 morphology (Figure 2) follows the terminology and abbreviations proposed below. The notation

197 presented by Crompton and Jenkins (1968) to describe the series of cusps (i.e., $a, b, c, d, e, f$ for

198 the lower postcanines, and $A, B, C, D, E$ and $F$, for the upper postcanines) in Thrinaxodon and 
199 Triassic mammals, and used by some authors to describe the sectorial teeth of gomphodonts

200 (e.g., Sues \& Hopson, 2010; Sidor \& Hopson, 2018) and non-mammaliaform probainognathians

201 (e.g., Oliveira et al., 2011; Soares, Martinelli \& Oliveira, 2014; Martinelli, Soares \& Schwanke,

202 2016; Martinelli et al., 2017; Pacheco et al., 2018), was incorporated into our proposed

203 terminology. All abbreviations proposed by Crompton and Jenkins (1968) must, however, be

204 italicized to not be confused with similar abbreviations referred to other dental sub-units (e.g., 'c'

205 is for the canine whereas ' $c$ ' is for the distal accessory cusp). Our terminology and the

206 abbreviations we used to annotate the figures do not also take into consideration the position of

207 the tooth within the upper or lower jaw and left or right side of the skull, as done by Crompton

208 and Jenkins (1968) and other authors (e.g., Hopson, 2005; Sidor \& Hopson, 2018).

209 Abbreviations in capital and lower case letters can nonetheless be used by authors to annotate

210 dental features from the upper and lower jaw, respectively. In the same way, the letters ' 1 ' and ' $r$ '

211 followed by the corresponding abbreviation can be used to annotate dental features from the left

212 and right jaw, respectively. For instance, 'IGPC' refers to the left upper gomphodont postcanine

213 whereas 'rmmc' refers to the mesial main cusp of the right lower postcanine.

214 For a consistent terminology, the positional terms mesial, distal, labial and lingual,

215 proposed as standard terms by Smith \& Dodson (2003), were favored, with length, width and

216 height referring to the dimension of an anatomical entity in the mesiodistal, labiolingual and

217 apicobasal directions, respectively. We also favor the following hierarchy for the combination of

218 positional terms: 1) apico- and baso- (i.e., apicocentral, apicodistal, apicomesial, apicolingual,

219 basocentral, basodistal, basomesial, basolingual, basolabial); 2) centro- (centrolabial,

220 centrolingual, centromesial, centrodistal); 3) labio- and linguo- (labiomesial, labiodistal,

221 linguomesial, linguodistal); and 4) -mesial and-distal. An exception to this relates to the

222 transverse crest, in which the centrolabial, centrolingual, labiocentral and linguocentral ridges

223 describe different entities of the crest. As for the dental formula, we propose the following

224 notation: i4/3 : c1/1 : pc7-16/7-13 (cpc1-6 : gpc2-7: tpc0-2 : spc1-4), with i for incisors, c for

225 canines, pc for postcanines, cpc for conical postcanines, gpc for gomphodont postcanines, tpc for

226 transitional postcanines, and spc for sectorial postcanines. Each dental sub-unit is separated by a

227 colon, and the numbers, or ranges (noted $\mathrm{x}-\mathrm{x}$ ), before and after the slash correspond to the

228 number of teeth from the upper and lower jaws, respectively, for each dental sub-unit. 


\begin{tabular}{|c|c|}
\hline $\begin{array}{l}\text { Accessory cusp } \\
\text { (ac) }\end{array}$ & $\begin{array}{l}\text { Minor pointed or rounded projection of dentine covered with enamel on the } \\
\text { mesial/distal ridge (i.e., the labiomesial (lamc), labiodistal (ladc), } \\
\text { linguomesial (limc) and linguodistal (lidc) accessory cusps; Figure 2C-G) } \\
\text { and/or transverse crest (i.e., the central accessory cusp (cac); Figure 2C) of } \\
\text { a gomphodont postcanine as well as on the carina (i.e., the mesial (mac) and } \\
\text { distal (dac) accessory cusps; Figure 2I) of a sectorial postcanine. }\end{array}$ \\
\hline Basin (ba) & $\begin{array}{l}\text { Deep concavity located on the occlusal surface of a gomphodont } \\
\text { postcanine, on the mesial and/or distal surfaces of the crown (i.e., the mesial } \\
(\mathrm{mb}) \text { and distal (db) basins, respectively; Figure } 2 \mathrm{C}, \mathrm{D}, \mathrm{E}, \mathrm{G}) \text {, and receiving } \\
\text { the crown's cusps and crests of postcanines of the opposite jaw during } \\
\text { occlusion. The basin seen on gomphodont postcanines is also referred as } \\
\text { 'valley' (e.g., Crompton, 1972; Godefroit \& Battail, 1997; Hopson, 2005). }\end{array}$ \\
\hline Canine (c) & $\begin{array}{l}\text { Maxillary and dentary tooth located between the distalmost incisor and the } \\
\text { mesialmost postcanine and specialized for cutting and/or piercing (Figure } \\
\text { 2A, B; Figure 3F). It is usually the largest tooth of the series. }\end{array}$ \\
\hline Carina (ca) & $\begin{array}{l}\text { A sharp, narrow, and well-delimited ridge or keel-shaped structure running } \\
\text { apicobasally on the crown and, in some case, on the root base, and typically } \\
\text { making the cutting edge of the tooth (McGraw-Hill, 2003; Brink \& Reisz, } \\
\text { 2014; Figure 2A). Incisors and canines of gomphodont cynodonts often } \\
\text { have denticulated mesial and distal carinae, whereas the carinae of sectorial } \\
\text { teeth bear accessory cusps and/or minute denticles. The carinae are also } \\
\text { referred as 'cutting edges' (e.g., Crompton, 1955; Sues \& Hopson, 2010), } \\
\text { 'cutting ridges', 'enamel ridges' (e.g., Kemp, 1980), 'serrated margins', } \\
\text { 'marginal ridges' (e.g., Hopson, 1984), 'keeled edges' and 'sectorial edges' } \\
\text { (e.g., Kammerer et al., 2012). }\end{array}$ \\
\hline $\begin{array}{l}\text { Central } \\
\text { accessory cusp } \\
\text { (cac) }\end{array}$ & $\begin{array}{l}\text { Minor pointed or rounded projection labial and/or lingual to the central cusp } \\
\text { on the transverse crest of upper gomphodont postcanine (Figure 2C). } \\
\text { Central accessory cusps correspond to the 'buccal accessory cusp' of Sues } \\
\text { et al. (1992) and the 'accessory cusps on transverse ridge' of Hopson } \\
\text { (2005). }\end{array}$ \\
\hline
\end{tabular}

Central cusp (cc) Main centrally positioned projection of dentine covered with enamel on the 


\begin{tabular}{|c|c|}
\hline & $\begin{array}{l}\text { transverse crest of the gomphodont postcanine (Figure 2C; Figure 3). The } \\
\text { central cusp is also known as the 'middle cusp' (Kemp, 1980), 'main central } \\
\text { cusp' (e.g., Crompton, 1955; Hopson, 2014; Sidor \& Hopson, 2018) and } \\
\text { 'upper central cusp'/'lower central cusp' of Hopson (2005). }\end{array}$ \\
\hline $\begin{array}{l}\text { Central ridge } \\
\text { (cri) }\end{array}$ & $\begin{array}{l}\text { Labiolingually oriented crest centrally positioned on the mesial basin of a } \\
\text { gomphodont postcanine (Figure } 2 \mathrm{E} \text { ). }\end{array}$ \\
\hline $\begin{array}{l}\text { Central valley } \\
\text { (cev) }\end{array}$ & $\begin{array}{l}\text { Depression delimited by the lingual margin of the labial cusp and the labial } \\
\text { margin of the lingual cusps on the transverse crest of the lower postcanine } \\
\text { (Figure } 2 \mathrm{G}) . \text { The central valley corresponds to the 'saddle' of Crompton } \\
\text { (1972). }\end{array}$ \\
\hline $\begin{array}{l}\text { Centrolabial } \\
\text { ridge (clar) }\end{array}$ & $\begin{array}{l}\text { Labiolingually oriented crest-like structure running on the labial surface of } \\
\text { the central cusp, following the edge of the transverse crest, and connected to } \\
\text { the labiocentral ridge of the labial cusp (Figure } 2 \mathrm{~F} \text { ). }\end{array}$ \\
\hline $\begin{array}{l}\text { Centrolingual } \\
\text { ridge (clir) }\end{array}$ & $\begin{array}{l}\text { Labiolingually oriented crest-like structure running on the lingual surface of } \\
\text { the central cusp, following the edge of the transverse crest, and connected to } \\
\text { the linguocentral ridge of the lingual cusp (Figure } 2 \mathrm{~F} \text { ). }\end{array}$ \\
\hline $\begin{array}{l}\text { Cingular cuspule } \\
\text { (cic) }\end{array}$ & $\begin{array}{l}\text { Small accessory cusp on a cingulum of a gomphodont or sectorial } \\
\text { postcanine (Figure 2D). Cingular cuspules are also referred as 'cingular } \\
\text { cusps' (e.g., Crompton, 1955; Abdala \& Ribeiro, 2003; Abdala, Neveling \& } \\
\text { Welman, 2006). }\end{array}$ \\
\hline Cingulum (ci) & $\begin{array}{l}\text { Bulge or shelf made of a succession of cingular cuspules on the rim of the } \\
\text { occlusal surface of the gomphodont postcanine and on the basolingual or } \\
\text { basolabial side of a sectorial tooth (Modified from Illiger, 1811; Owen, } \\
\text { 1840; Sander, 1997c; Langer \& Ferigolo, 2013; Figure 2G). Cingula are } \\
\text { also referred as 'crenulations' by Seeley (1894). }\end{array}$ \\
\hline $\begin{array}{l}\text { Concave surface } \\
\text { (cos) }\end{array}$ & $\begin{array}{l}\text { Apicobasally elongated concavity adjacent to the mesial and/or distal } \\
\text { carinae on the labial and/or lingual surfaces of the crown in incisors and } \\
\text { canines (Figure 2B). The presence of concave surfaces on the lingual } \\
\text { surface of the incisors and canines results in the salinon-shaped cross- } \\
\text { sectional outlines of the crown, i.e., an outline with both mesial and distal } \\
\text { carinae facing linguomesially and linguodistally, respectively, }\end{array}$ \\
\hline
\end{tabular}




\section{Conical \\ postcanine (cpe)}

Crown (co)

Cusp (cu)

\section{Denticle (de)}

Diastema (dia)

Distal accessory subsymmetrical mesial and distal crown sides, a convex labial margin, and a biconcave lingual margin (Hendrickx, Mateus \& Araújo 2015, figure 5R). Conidont tooth located in the mesialmost part of the postcanine tooth row (Figure 2A, B; Figure 3B). While Diademodon bears three or more conical postcanines (Figure 3B), trirachodontids (Figure 3 ) and some traversodontids (e.g., Boreogomphodon, possibly Andescynodon and Massetognathus, ) have one or two conical teeth, and the most derived traversodontids do not possess conical postcanine at all. Conical postcanine have also been known as 'premolars' by $19^{\text {th }}$ and $20^{\text {th }}$ century authors (e.g., Broom, 1905, 1913; Brink, 1955; Grine, 1977; Gow, 1978).

Portion of the tooth covered with enamel, typically situated above the gum and protruding into the mouth ('couronne' of Fauchard, 1728; Cuvier, 1805; Schwenk, 2000; McGraw-Hill, 2003; Figure 2I).

Pointed or rounded projection of dentine covered with enamel on the occlusal surface of a gomphodont postcanine or on the carina of sectorial teeth (Figure $2 \mathrm{G}$ ).

An elaborate type of serration being formed by a projection of dentine covered with enamel along the carina of incisors, canines and sectorial postcanines, as well as the crests of gomphodont postcanines ('dentelure' of Cuvier, 1805; Owen, 1840; McGraw-Hill, 2003; Brink \& Reisz, 2014;

Figure 2J). The denticles are also referred as 'denticulations' (e.g., Kammerer et al., 2012), and the large denticles in low number $(<15)$ on the carinae are known as 'mega-serrations'/'megaserrations' (Hopson, 1984), 'cuspules' (e.g., Abdala \& Ribeiro, 2003; Sidor \& Hopson, 2018), 'marginal cuspules' (Hopson, 1984; Sues, Hopson \& Shubin, 1992; Abdala \& Ribeiro, 2003; Abdala, Neveling \& Welman, 2006; Liu \& Abdala, 2014), 'cusps' (Kammerer et al., 2012), 'accessory cusp' and 'posterior accessory cusp' (Ranivoharimanana et al., 2011; Kammerer et al., 2012).

Space separating the last upper incisor from the canine and the upper and/or lower canine from the first postcanine (Figure 2B).

Minor pointed or rounded projection of a sectorial postcanine, distal to the 


\begin{tabular}{|c|c|}
\hline $\begin{array}{l}\text { cusp (dac, } D \text { or } \\
\text { d) }\end{array}$ & $\begin{array}{l}\text { distal main cusp (Figure 2I; Figure 3Q-R). The distal accessory cusp is also } \\
\text { referred as the 'posterior cingular cusp' (e.g., Crompton, 1963; Abdala, } \\
\text { Jasinoski \& Fernandez, 2013), 'posterior accessory cusp' (e.g., Abdala \& } \\
\text { Ribeiro, 2003; Abdala, Neveling \& Welman, 2006; Sues \& Hopson, 2010; } \\
\text { Sidor \& Hopson, 2018), 'heel cusp' (Sues \& Hopson, 2010) and 'cuspule' } \\
\text { (Liu \& Sues, 2010). The distal accessory cusp of gomphodont is } \\
\text { homologous to the 'posterior cingular cusp' (sensu Crompton, 1963) D and } \\
d \text { of the upper and lower postcanines, respectively, in Crompton and } \\
\text { Jenkins' (1968) notation. }\end{array}$ \\
\hline $\begin{array}{l}\text { Distal accessory } \\
\text { ridge (dar) }\end{array}$ & $\begin{array}{l}\text { Crest-like structure on the distal surface of the transverse crest, } \\
\text { perpendicular, diagonally oriented or even parallel from the latter (Figure } \\
2 \mathrm{H} \text {; Figure } 3 \mathrm{~A}, \mathrm{~N} \text { ). }\end{array}$ \\
\hline Distal basin (db) & $\begin{array}{l}\text { Main concavity distal to the transverse crest on the occlusal surface of a } \\
\text { postcanine (Figure 2C, D, G, H). The distal basin, which is typically } \\
\text { delimited by the distal ridge/cingulum distally, is also known as the } \\
\text { 'posterior basin' (e.g., Crompton, 1972; Hopson, 1984, 2005, 2014; } \\
\text { Godefroit \& Battail, 1997; Sues, Olsen \& Carter, 1999; Hopson \& Sues, } \\
\text { 2006; Liu \& Sues, 2010; Sues \& Hopson, 2010; Sidor \& Hopson, 2018) and } \\
\text { the 'posterior valley' (e.g., Crompton, 1972; Godefroit \& Battail, 1997; } \\
\text { Hopson, 2005). }\end{array}$ \\
\hline $\begin{array}{l}\text { Distal cingular } \\
\text { cuspule (dcc) }\end{array}$ & $\begin{array}{l}\text { Minor pointed or rounded projection on the distal cingulum (dci) of a } \\
\text { gomphodont postcanine (Figure 2G; Figure 3G). Distal cingular cusps are } \\
\text { also known as 'posterior cingular cusps' (e.g., Hopson, 2005; Abdala, } \\
\text { Hancox \& Neveling, 2005; Abdala, Jasinoski \& Fernandez, 2013) and 'heel } \\
\text { cusp' (Crompton, 1955). }\end{array}$ \\
\hline $\begin{array}{l}\text { Distal cingulum } \\
\text { (dci) }\end{array}$ & $\begin{array}{l}\text { Labiolingually oriented row of distal cingular cuspules (dcc) distal to the } \\
\text { transverse crest and typically delimiting the distal rim of the occlusal } \\
\text { surface of a gomphodont postcanine (Figure 2C, D, F). The distal cingulum } \\
\text { is also known as the 'posterior cingulum' (e.g., Crompton, 1972; Kemp, } \\
\text { 1980; Hopson, 2005; Abdala, Hancox \& Neveling, 2005; Liu \& Sues, 2010; } \\
\text { Sues \& Hopson, 2010; Martinelli, 2010; Hendrickx, Abdala \& Choiniere, }\end{array}$ \\
\hline
\end{tabular}


2016), ‘posterior marginal cingulum’ (Hopson, 2005; Sidor \& Hopson, 2018), 'posterior cingular crest' (Abdala \& Ribeiro, 2003; Kammerer et al., 2012), and 'crenulated posterior ridge' (Crompton, 1955).

\section{Distal main cusp $(\mathrm{dmc}, \boldsymbol{C}$ or $c)$}

Distal ridge (dri)

\section{Distal valley (dv)}

Enamel texture (ent)
Largest pointed or rounded projection of a sectorial postcanine distal to the main cusp (Figure 2I; Figure 3P, S). The distal main cusp is also known as the 'posterior cusp' (e.g., Hopson, 2005; Liu \& Sues, 2010; Sidor \& Hopson, 2018), and the 'posterior accessory cusp' (e.g., Crompton, 1963; Abdala \& Ribeiro, 2003; Abdala, Neveling \& Welman, 2006; Sues \& Hopson, 2010; Sidor \& Hopson, 2018). The distal main cusp is homologous to the 'posterior accessory cusp' (sensu Crompton, 1963) $C$ and $c$ of the upper and lower postcanines, respectively, in the notation proposed by Crompton and Jenkins (1968).

Labiolingually oriented crest-like structure distal to the transverse crest and delimiting the distal rim of the occlusal surface of a gomphodont postcanine (Figure 2H). Also known as the 'posterior wall' (Godefroit \& Battail, 1997; Hopson \& Sues, 2006; Hopson, 2014) and 'posterior ridge' (Crompton, 1955; Godefroit \& Battail, 1997).

Depression delimited by the distal margin of the main cusp and the mesial margin of the distal main cusp on a sectorial postcanine (Figure 2I). Pattern of sculpturing on the crown surface at a sub-millimeter scale (Hendrickx, Mateus \& Araújo, 2015; Figure 2K). The enamel surface texture of incisors, canines, and postcanines of gomphodont cynodonts shows different patterns (Hendrickx, Mateus \& Araújo 2015, figure 6). A smooth enamel texture is here defined as the absence of enamel texture so that the crown surface does not show any irregularity. A non-oriented enamel texture with no pattern is referred as irregular. Finally, the enamel surface texture is called braided if the texture is oriented and made of alternating and interweaving grooves and short, moderately elongated or long sinuous ridges that are typically apicobasally oriented on the crown (Hendrickx, Mateus \& Araújo, 2015; Figure 2K). The term 'crenulation' was used by Sidor and Hopson (2018) to describe the braided enamel 


\begin{tabular}{|c|c|}
\hline & texture seen on the canines of Cricodon. \\
\hline $\begin{array}{l}\text { Gomphodont } \\
\text { postcanine (gpc) }\end{array}$ & $\begin{array}{l}\text { Oval, quadrangular, subrectangular or subtriangular tooth in apical view } \\
\text { allowing tooth-to-tooth occlusion (Figure 2A, B; Figure 3B). Upper } \\
\text { gomphodont postcanines are typically labiolingually expanded whereas } \\
\text { lower gomphodont postcanines can be labiolingually expanded, } \\
\text { quadrangular or mesiodistally expanded. }\end{array}$ \\
\hline Incisor (i) & $\begin{array}{l}\text { Premaxillary or dentary tooth mesial to the canine and specialized for } \\
\text { cutting (Figure 2B; Figure 3F). }\end{array}$ \\
\hline $\begin{array}{l}\text { Labial cingular } \\
\text { cuspule (lace) }\end{array}$ & $\begin{array}{l}\text { Minor pointed or rounded projection on the labial cingulum of a } \\
\text { gomphodont and/or sectorial postcanine (Figure } 2 \mathrm{C} \text { ). }\end{array}$ \\
\hline $\begin{array}{l}\text { Labial cingulum } \\
\text { (laci) }\end{array}$ & $\begin{array}{l}\text { Mesiodistally oriented row of accessory cuspules on the basolabial surface } \\
\text { of a sectorial postcanine and/or delimiting the labial rim of the occlusal } \\
\text { surface of a gomphodont postcanine (Figure 2C). The labial cingulum is } \\
\text { also known as the 'external cingulum' (e.g., Crompton, 1972; Flynn et al., } \\
\text { 2000; Abdala \& Ribeiro, 2003; Abdala \& Sa-Teixeira, 2004; Hopson, 2005, } \\
\text { 2014; Abdala, Neveling \& Welman, 2006; Melo, Martinelli \& Soares, } \\
\text { 2017), 'buccal cingulum' (e.g., Sues, Olsen \& Carter, 1999; Sues \& } \\
\text { Hopson, 2010; Melo, Martinelli \& Soares, 2017), 'crenulated ridge' (e.g., } \\
\text { Crompton, 1955) and 'cingular labial crest' (Martinelli, 2010). }\end{array}$ \\
\hline Labial cusp (lac) & $\begin{array}{l}\text { Main labially positioned projection on the transverse crest of a gomphodont } \\
\text { postcanine (Figure 2C-H; Figure 3). The labial cusp is also know as the } \\
\text { 'external cusp' (e.g., Seeley, 1894; Crompton, 1972; Kemp, 1980; Flynn et } \\
\text { al., 2000; Hopson, 2005, 2014; Hendrickx, Abdala \& Choiniere, 2016; } \\
\text { Sidor \& Hopson, 2018), 'upper external cusp'/'lower external cusp' } \\
\text { (Hopson, 2005), 'main external cusp' (e.g., Hopson, 2005, 2014; Sidor \& } \\
\text { Hopson, 2018), 'main upper external cusp'/'main lower external cusp’ } \\
\text { (Hopson, 2014), 'buccal cusp' (e.g., Grine, 1977; Sues, Hopson \& Shubin, } \\
\text { 1992; Sues, Olsen \& Carter, 1999; Hopson \& Sues, 2006), 'buccal main } \\
\text { cusp' (Melo, Abdala \& Soares, 2015; Melo, Martinelli \& Soares, 2017), } \\
\text { 'posterior buccal main cusp' (Melo, Abdala \& Soares, 2015), 'labial main } \\
\text { cusp' (e.g., Godefroit \& Battail, 1997; Abdala, Barberena \& Dornelles, }\end{array}$ \\
\hline
\end{tabular}




\begin{tabular}{|c|c|}
\hline & $\begin{array}{l}\text { 2002) and 'main labial cusp' (e.g., Chatterjee, 1982; Hopson, 1984, 2005, } \\
\text { 2014; Godefroit \& Battail, 1997; Abdala, Barberena \& Dornelles, 2002; } \\
\text { Abdala \& Ribeiro, 2003; Abdala, Hancox \& Neveling, 2005; Abdala \& } \\
\text { Smith, 2009; Martinelli, 2010; Ranivoharimanana et al., 2011; Kammerer et } \\
\text { al., 2012; Liu \& Abdala, 2014). }\end{array}$ \\
\hline Labial ridge (lar) & $\begin{array}{l}\text { Mesiodistally oriented and labially positioned crest-like structure delimiting } \\
\text { the labial rim of the occlusal surface of a lower gomphodont postcanine in } \\
\text { Traversodontidae (Figure 2D). The labial ridge is also referred as the } \\
\text { 'external ridge' (e.g., Seeley, 1895; Kemp, 1980; Hopson, 1984), 'shearing } \\
\text { ridge' (e.g., Hopson, 1984), 'buccal ridge' (e.g., Sues, Olsen \& Carter, } \\
\text { 1999; Hopson \& Sues, 2006; Liu \& Sues, 2010), 'posterior ridge' } \\
\text { (Crompton, 1972) and 'buccal longitudinal crest' (Hopson \& Sues, 2006). }\end{array}$ \\
\hline $\begin{array}{l}\text { Labial valley } \\
\text { (lav) }\end{array}$ & $\begin{array}{l}\text { Depression delimited by the lingual margin of the labial cusp and the labial } \\
\text { margin of the central cusp on the transverse crest (Figure 2F). The labial } \\
\text { valley corresponds to the 'embayment' of Crompton (1972) and the 'V- } \\
\text { shaped notch' of many authors (e.g., Crompton, 1955; Sues, Olsen \& } \\
\text { Carter, 1999; Sues \& Hopson, 2010; Martinelli, 2010; Hopson, 2014). }\end{array}$ \\
\hline $\begin{array}{l}\text { Labiocentral } \\
\text { ridge (lacr) }\end{array}$ & $\begin{array}{l}\text { Labiolingually oriented crest-like structure running on the lingual surface of } \\
\text { the labial cusp, following the edge of the transverse crest, and connected to } \\
\text { the centrolabial ridge of the central cusp (Figure } 2 \mathrm{~F}, \mathrm{G} \text { ). }\end{array}$ \\
\hline $\begin{array}{l}\text { Labiodistal } \\
\text { accessory cusp } \\
\text { (ladc) }\end{array}$ & $\begin{array}{l}\text { Minor pointed or rounded projection distal to the labial cusp and located on } \\
\text { the labiodistal margin of the occlusal surface of a gomphodont postcanine } \\
\text { (Figure 2C-D, F-H). The labiodistal accessory cusp is also known as the } \\
\text { 'posterior labial cusp' (e.g., Crompton, 1955; Liu, 2007a; Martinelli, 2010; } \\
\text { Liu \& Abdala, 2014; Melo, Abdala \& Soares, 2015), 'posterolabial cusp' } \\
\text { (e.g., Abdala \& Ribeiro, 2003; Hopson, 2014), 'posterior labial accessory } \\
\text { cusp' (e.g., Kammerer et al., 2012), 'posterior external accessory cusp' } \\
\text { (Hopson, 2014), 'posterior accessory labial cusp' (e.g., Abdala, Barberena } \\
\& \text { Dornelles, 2002; Abdala \& Ribeiro, 2003; Abdala \& Sa-Teixeira, 2004; } \\
\text { Battail, 2005; Abdala, Hancox \& Neveling, 2005; Kammerer et al., 2012), } \\
\text { 'posterior buccal cusp' (e.g., Liu \& Sues, 2010; Melo, Abdala \& Soares, }\end{array}$ \\
\hline
\end{tabular}




\begin{tabular}{|c|c|}
\hline & $\begin{array}{l}\text { 2015), ‘posterobuccal cusp' (e.g., Sues, Olsen \& Carter, 1999; Hopson \& } \\
\text { Sues, 2006; Liu \& Sues, 2010; Sues \& Hopson, 2010), 'posterior buccal } \\
\text { accessory cusp' (Melo, Abdala \& Soares, 2015), ‘posterolateral accessory } \\
\text { cusp’ (Hopson, 1985) and 'posterior accessory cusp’ (e.g., Crompton, 1972; } \\
\text { Hopson, 1985). }\end{array}$ \\
\hline $\begin{array}{l}\text { Labiodistal ridge } \\
\text { (ladr) }\end{array}$ & $\begin{array}{l}\text { Mesiodistally oriented crest-like structure running on the distal surface of } \\
\text { the labial cusp and typically connected to the distal ridge/cingulum (Figure } \\
2 \mathrm{C}, \mathrm{F}) . \text { The labiodistal ridge corresponds to the 'posteroexternal ridge' of } \\
\text { Hopson (2005) and Hendrickx, Abdala \& Choiniere (2016). }\end{array}$ \\
\hline $\begin{array}{l}\text { Labiomesial } \\
\text { accessory cusp } \\
\text { (lamc) }\end{array}$ & $\begin{array}{l}\text { Main pointed or rounded projection mesial to the labial cusp and located on } \\
\text { the labiomesial margin of the occlusal surface of a gomphodont postcanine } \\
\text { (Figure 2C). The labiomesial accessory cusp is also known as the 'anterior } \\
\text { accessory cusp of upper postcanine'/'anterior accessory cusp of lower } \\
\text { postcanine' (Crompton, 1972), 'anterior labial cusp' (e.g., Crompton, 1955; } \\
\text { Liu, 2007a; Martinelli, 2010), 'anterolabial cusp' (e.g., Flynn et al., 2000; } \\
\text { Liu, 2007a; Hopson, 2014; Liu \& Abdala, 2014), 'anterolabial accessory } \\
\text { cusp' (e.g., Hopson, 2014; Liu \& Abdala, 2014; Melo, Martinelli \& Soares, } \\
\text { 2017), 'anteroexternal accessory cusp' (Hopson, 2014), 'anterior buccal } \\
\text { cusp' (e.g., Melo, Abdala \& Soares, 2015), 'anterobuccal cusp' (e.g., Sues, } \\
\text { Olsen \& Carter, 1999; Hopson \& Sues, 2006; Liu \& Sues, 2010; Sues \& } \\
\text { Hopson, 2010), 'anterior buccal accessory cusp' (Melo, 2014; Melo, Abdala } \\
\& \text { Soares, 2015), 'mesiobuccal accessory cusp' (Melo, Martinelli \& Soares, } \\
\text { 2017), and 'anterior accessory labial cusp' (e.g., Abdala, Barberena \& } \\
\text { Dornelles, 2002; Abdala \& Ribeiro, 2003; Abdala \& Sa-Teixeira, 2004; } \\
\text { Battail, 2005; Abdala, Hancox \& Neveling, 2005; Abdala \& Smith, 2009; } \\
\text { Ranivoharimanana et al., 2011; Kammerer et al., 2012). }\end{array}$ \\
\hline $\begin{array}{l}\text { Labiomesial } \\
\text { ridge (lamr) }\end{array}$ & $\begin{array}{l}\text { Mesiodistally oriented crest-like structure running on the mesial surface of } \\
\text { the labial cusp and typically connected to the mesial ridge/cingulum (Figure } \\
\text { 2C). The labiomesial ridge corresponds to the 'anterior ridge' (e.g., } \\
\text { Crompton, 1972; Hopson, 1985) and 'anteroexternal ridge' (e.g., Hopson, } \\
\text { 2005; Hendrickx, Abdala \& Choiniere, 2016). }\end{array}$ \\
\hline
\end{tabular}




\begin{tabular}{l|l}
\hline $\begin{array}{l}\text { Lingual cingular } \\
\text { cuspule (licc) }\end{array}$ & $\begin{array}{l}\text { Minor pointed or rounded projection on the lingual cingulum of a conical or } \\
\text { sectorial postcanine (Figure 2I; Figure 3O). The lingual cingular cuspules } \\
\text { are also known as the 'lingual cingular cusps' (e.g., Sidor \& Hopson, 2018). }\end{array}$ \\
$\begin{array}{l}\text { Lingual } \\
\text { cingulum (lici) }\end{array}$ & $\begin{array}{l}\text { Mesiodistally oriented row of cuspules on the basolingual surface of a } \\
\text { sectorial postcanine and/or delimiting the lingual rim of the occlusal surface } \\
\text { of a gomphodont postcanine (Figure 2I; Figure 3O). }\end{array}$ \\
\hline Lingual cusp (lic) & $\begin{array}{l}\text { Main lingually positioned projection on the transverse crest of the } \\
\text { postcanine (Figure 2C-H; Figure 3). The lingual cusp is also known as the }\end{array}$ \\
'internal cusp' (e.g., Romer, 1967; Kemp, 1980; Hopson, 1985), 'main \\
internal cusp' (e.g., Hopson, 2005, 2014; Sidor \& Hopson, 2018), 'upper \\
internal cusp'/'lower internal cusp' (Hopson, 2005), 'lingual main cusp' \\
(Melo, Martinelli \& Soares, 2017) and 'main lingual cusp' (e.g., Crompton, \\
1955; Godefroit \& Battail, 1997; Godefroit, 1999; Sues \& Hopson, 2010; \\
Melo, Martinelli \& Soares, 2017).
\end{tabular}




\begin{tabular}{|c|c|}
\hline & lingual cusp' (e.g., Abdala \& Ribeiro, 2003; Kammerer et al., 2012). \\
\hline $\begin{array}{l}\text { Linguodistal } \\
\text { ridge (lidr) }\end{array}$ & $\begin{array}{l}\text { Mesiodistally oriented crest-like structure running on the distal surface of } \\
\text { the lingual cusp and typically connected to the distal ridge/cingulum (Figure } \\
2 \mathrm{C}, \mathrm{F}) \text {. The linguodistal ridge is equivalent to the 'posterointernal ridge' of } \\
\text { Hopson (2005). }\end{array}$ \\
\hline $\begin{array}{l}\text { Linguomesial } \\
\text { accessory cusp } \\
\text { (limc) }\end{array}$ & $\begin{array}{l}\text { Main pointed or rounded projection mesial to the lingual cusp and located } \\
\text { on the linguomesial margin of the occlusal surface of a gomphodont } \\
\text { postcanine (Figure 2C, H). The linguomesial accessory cusp is also known } \\
\text { as the 'anterior accessory cusp of upper postcanine'/'anterior accessory } \\
\text { cusp of lower postcanine' (Crompton, 1972), 'anterior lingual cusp' (e.g., } \\
\text { Crompton, 1955; Abdala \& Smith, 2009; Martinelli, 2010; Melo, Abdala \& } \\
\text { Soares, 2015), 'anterior lingual accessory cusp' (Melo, 2014), } \\
\text { 'anterolingual cusp' (e.g., Hopson, 1984; Sues, Hopson \& Shubin, 1992; } \\
\text { Abdala \& Ribeiro, 2003; Abdala, Neveling \& Welman, 2006; Gao et al., } \\
\text { 2010; Sues \& Hopson, 2010; Ranivoharimanana et al., 2011; Liu \& Abdala, } \\
\text { 2014), 'anterolingual accessory cusp' (e.g., Sues \& Hopson, 2010; Hopson, } \\
\text { 2014; Liu \& Abdala, 2014; Melo, Abdala \& Soares, 2015; Sidor \& Hopson, } \\
\text { 2018) and 'anterointernal accessory cusp' (Hopson, 2014),. }\end{array}$ \\
\hline $\begin{array}{l}\text { Linguomesial } \\
\text { ridge (limr) }\end{array}$ & $\begin{array}{l}\text { Mesiodistally oriented crest-like structure running on the mesial surface of } \\
\text { the lingual cusp and typically connected to the mesial ridge/cingulum } \\
\text { (Figure } 2 \mathrm{C} \text { ). The linguomesial ridge is equivalent to the 'anterointernal } \\
\text { ridge' of Hopson (2005). }\end{array}$ \\
\hline $\begin{array}{l}\text { Longitudinal } \\
\text { ridge (lri) }\end{array}$ & $\begin{array}{l}\text { Apicobasally high and mesiodistally short convexity on the labial and/or } \\
\text { lingual surface of incisors and/or canines (modified from Hendrickx, } \\
\text { Mateus \& Araújo, 2015; Figure 2B). Longitudinal ridges are also known as } \\
\text { 'flutes'/‘fluting' (Seeley, 1894; Crompton, 1955), 'longitudinal striations' } \\
\text { (e.g., Hopson, 1984), 'vertical striations' (e.g., Liu \& Sues, 2010), and } \\
\text { 'vertical ridges' (Sues \& Hopson, 2010). }\end{array}$ \\
\hline $\begin{array}{l}\text { Main cusp (mc, } A \\
\text { or } a)\end{array}$ & $\begin{array}{l}\text { Major projection of dentine covered with enamel on the sectorial postcanine } \\
\text { (Figure } 2 \mathrm{I} \text {; Figure } 3 \mathrm{Q}, \mathrm{S} \text { ). The main cusp can be denticulated on both its } \\
\text { mesial and distal carinae. The main cusp is also known as the 'central cusp' }\end{array}$ \\
\hline
\end{tabular}




\begin{tabular}{|c|c|}
\hline & $\begin{array}{l}\text { (e.g., Liu \& Sues, 2010; Sues \& Hopson, 2010; Sidor \& Hopson, 2018), and } \\
\text { the 'central main cusp' (Sidor \& Hopson, 2018). The main cusp is } \\
\text { homologous to the cusps } A \text { and } a \text { of the upper and lower postcanines, } \\
\text { respectively, in Crompton and Jenkins' (1968) notation.. }\end{array}$ \\
\hline $\begin{array}{l}\text { Mesial accessory } \\
\text { cusp (mac, } E \text { or } \\
\text { e) }\end{array}$ & $\begin{array}{l}\text { Minor pointed or rounded projection on the mesial carina of a sectorial } \\
\text { postcanine, mesial or linguomesial to the mesial main cusp. The mesial } \\
\text { accessory cusp is homologous to the 'anterior cingular cusp' (sensu } \\
\text { Crompton, 1963) E and } e \text { of the upper and lower postcanines, respectively, } \\
\text { in Crompton and Jenkins' (1968) notation. Visible in some sectorial } \\
\text { postcanines of Thrinaxodon and possibly Cynognathus, one or several } \\
\text { mesial accessory cusps are assumed to be present in the } \\
\text { multicuspid/crenulated lower sectorial teeth of juveniles Andescynodon } \\
\text { (PVL 4390) and Massetognathus (MCZ 4267). }\end{array}$ \\
\hline $\begin{array}{l}\text { Mesial accessory } \\
\text { ridge (mar) }\end{array}$ & $\begin{array}{l}\text { Crest-like structure on the mesial surface of the transverse crest, } \\
\text { perpendicular, diagonally-oriented or parallel to the latter (Figure } 2 \mathrm{H} \text {; } \\
\text { Figure } 3 \mathrm{~A}, \mathrm{C}, \mathrm{N} \text { ). }\end{array}$ \\
\hline $\begin{array}{l}\text { Mesial basin } \\
(\mathrm{mb})\end{array}$ & $\begin{array}{l}\text { Main concavity mesial to the transverse crest on the occlusal surface of a } \\
\text { gomphodont postcanine (Figure } 2 \mathrm{C}, \mathrm{E}, \mathrm{H}) \text {. The mesial basin is also known } \\
\text { as the 'anterior excavation in the crown' (Crompton, 1955), 'anterior } \\
\text { valley' (Crompton, 1972), 'occlusal basin' (Melo, Martinelli \& Soares, } \\
\text { 2017) and 'anterior basin' (e.g., Sues, Hopson \& Shubin, 1992; Godefroit \& } \\
\text { Battail, 1997; Sues, Olsen \& Carter, 1999; Hopson \& Sues, 2006; Liu \& } \\
\text { Sues, 2010; Hopson, 2014). }\end{array}$ \\
\hline $\begin{array}{l}\text { Mesial cingular } \\
\text { cuspule (mcc) }\end{array}$ & $\begin{array}{l}\text { Minor pointed or rounded projection on the mesial cingulum of a } \\
\text { gomphodont postcanine (Figure } 2 \mathrm{C}, \mathrm{H} \text {; Figure } 3 \mathrm{E} \text { ). }\end{array}$ \\
\hline $\begin{array}{l}\text { Mesial cingulum } \\
\text { (mci) }\end{array}$ & $\begin{array}{l}\text { Labiolingually oriented row of accessory cuspules mesial to the transverse } \\
\text { crest and typically delimiting the mesial rim of the occlusal surface of a } \\
\text { gomphodont postcanine (Figure 2C). The mesial cingulum is also known as } \\
\text { the 'anterior cingulum' (e.g., Sues, Hopson \& Shubin, 1992; Abdala \& Sa- } \\
\text { Teixeira, 2004; Battail, 2005; Hopson, 2005; Hopson \& Sues, 2006; } \\
\text { Abdala, Neveling \& Welman, 2006; Kammerer et al., 2008; Gao et al., }\end{array}$ \\
\hline
\end{tabular}




\begin{tabular}{|c|c|}
\hline & $\begin{array}{l}\text { 2010; Sues \& Hopson, 2010; Liu \& Abdala, 2014; Hendrickx, Abdala \& } \\
\text { Choiniere, 2016), 'crenulated ridge' (e.g., Kemp, 1980; Abdala, Neveling \& } \\
\text { Welman, 2006), 'anterior crenulated ridge' (Crompton, 1955), 'anterior } \\
\text { marginal cingulum' (Hopson, 2005; Sidor \& Hopson, 2018), 'anterior } \\
\text { external cingulum' (Hopson, 2005) and 'anterior cingular crest' (e.g., } \\
\text { Abdala \& Ribeiro, 2003; Kammerer et al., 2012). }\end{array}$ \\
\hline $\begin{array}{l}\text { Mesial main cusp } \\
(\mathrm{mmc}, \boldsymbol{B} \text { or } b)\end{array}$ & $\begin{array}{l}\text { Largest pointed or rounded projection on the mesial carina of a sectorial } \\
\text { postcanine directly mesial to the main cusp (Figure 2I; Figure 3Q, S). The } \\
\text { mesial main cusp, as used by Sidor and Hopson (2018), is also known as the } \\
\text { 'anterior cusp' (e.g., Liu \& Sues, 2010; Sues \& Hopson, 2010; Sidor \& } \\
\text { Hopson, 2018), the 'anterior main cusp' (e.g., Abdala, Jasinoski \& } \\
\text { Fernandez, 2013), the 'anterior accessory cusp' (e.g., Crompton, 1963; } \\
\text { Abdala, Neveling \& Welman, 2006; Sues \& Hopson, 2010; Sidor \& } \\
\text { Hopson, 2018) and the 'mesial accessory cusp' (e.g., Martinelli, Soares \& } \\
\text { Schwanke, 2016). The mesial main cusp is homologous to the 'anterior } \\
\text { accessory cusp' (sensu Crompton, 1963) B and } b \text { of the upper and lower } \\
\text { postcanines, respectively, in Crompton and Jenkins' (1968) notation. }\end{array}$ \\
\hline $\begin{array}{l}\text { Mesial ridge } \\
\text { (mri) }\end{array}$ & $\begin{array}{l}\text { Labiolingually oriented crest-like structure mesial to the transverse crest } \\
\text { and typically delimiting the mesial rim of the occlusal surface of a } \\
\text { gomphodont postcanine (Figure 2C, E). Also known as 'transverse ridge' } \\
\text { (Seeley, 1894), 'anterior wall' (e.g., Hopson, 1985; Sues, Olsen \& Carter, } \\
\text { 1999; Flynn et al., 2000; Battail, 2005; Martinelli, 2010; Melo, Abdala \& } \\
\text { Soares, 2015; Melo, Martinelli \& Soares, 2017) and 'anterior crest' (Melo, } \\
\text { Abdala \& Soares, 2015). }\end{array}$ \\
\hline $\begin{array}{l}\text { Mesial valley } \\
\text { (mv) }\end{array}$ & $\begin{array}{l}\text { Depression delimited by the mesial margin of the main cusp and the distal } \\
\text { margin of the mesial main cusp on a sectorial postcanine (Figure 2I). }\end{array}$ \\
\hline Postcanine (pc) & $\begin{array}{l}\text { Maxillary or dentary tooth positioned distal to the canine. Postcanines } \\
\text { include conical, gomphodont and sectorial teeth, which can change (e.g., } \\
\text { Diademodon) from one morphology to the other (Figure 2B). }\end{array}$ \\
\hline Root (ro) & $\begin{array}{l}\text { Portion of the tooth beneath the gum and embedded in an alveolus ('racine' } \\
\text { of Fauchard, 1728; Cuvier, 1805; 'radix dentis' of Illiger, 1811; Owen, }\end{array}$ \\
\hline
\end{tabular}




\begin{tabular}{|c|c|}
\hline & 1840; Hillson, 2005; Figure 2I). \\
\hline $\begin{array}{l}\text { Sectorial } \\
\text { postcanine (spc) }\end{array}$ & $\begin{array}{l}\text { Labiolingually compressed tooth typically located in the distalmost part of } \\
\text { the postcanine tooth row, distal to the gomphodont teeth, and more rarely in } \\
\text { the anteriormost part of the postcanine tooth row, and adapted for cutting in } \\
\text { a shearing manner. Sectorial postcanines typically include a main cusp and } \\
\text { often one or several accessory cusps mesial and/or distal to the main cusp } \\
\text { (Figure } 2 \mathrm{~A}, \mathrm{~B} \text {; Figure } 3 \mathrm{~F}, \mathrm{H} \text { ). }\end{array}$ \\
\hline Serration (se) & $\begin{array}{l}\text { A projection along a ridge or keel-like structure of a tooth, whether } \\
\text { composed of enamel or by both enamel and dentine (modified from Brink } \\
\text { \& Reisz, 2014; Figure 2J). Unlike the carinae of incisors, canines and } \\
\text { sectorial teeth which bear large and elaborate serrations (i.e., denticles), the } \\
\text { serrated transverse crest and mesial and distal ridges of gomphodont } \\
\text { postcanines only have simple and minute serrations visible with a } \\
\text { microscope. Besides the well-delimited denticles of non-gomphodont } \\
\text { postcanines, these serrations should not be confused with the triangular, } \\
\text { hemi-spherical or sub-pyramidal cusps and cuspules present on the } \\
\text { transverse crest and/or cingula of gomphodont and sectorial postcanines of } \\
\text { some taxa. }\end{array}$ \\
\hline $\begin{array}{l}\text { Shouldering } \\
\text { (sho) }\end{array}$ & $\begin{array}{l}\text { Extension of the labiomesial margin of the upper postcanine forward, } \\
\text { producing a 'shoulder-like' process over the preceding postcanine } \\
\text { (modified from Romer, 1967; Abdala and Ribeiro 2003: figure 10C, D). }\end{array}$ \\
\hline $\begin{array}{l}\text { Transitional } \\
\text { postcanine (tpc) }\end{array}$ & $\begin{array}{l}\text { Labiolingually expanded sectorial postcanine sharing an intermediate } \\
\text { morphology between a gomphodont tooth and a sectorial postcanine (Figure } \\
\text { 2A; Figure 3B, D, O). Transitional postcanines are typically formed by a } \\
\text { recurved blade shape labial portion and a relatively flat lingual projection } \\
\text { (Goñi \& Goin, 1988). They are also referred as 'intermediate gomphodont' } \\
\text { (Fourie, 1963; Osborn, 1974; Grine, 1977; Goñi \& Goin, 1988), } \\
\text { 'intermediate sectorial' (Osborn, 1974; Goñi \& Goin, 1988), 'semi- } \\
\text { gomphodont'(Hopson, 1971; Crompton, 1972; Brink, 1977), 'sub- } \\
\text { gomphodont' (Hopson, 1964) and 'sub-sectorial' (Martinelli, 2010) } \\
\text { postcanines. }\end{array}$ \\
\hline
\end{tabular}




\begin{tabular}{l|l}
\hline Transverse crest & $\begin{array}{l}\text { Main labiolingually oriented ridge on the occlusal surface of the } \\
\text { gomphodont postcanine and bearing the labial, lingual and often the central } \\
\text { cusps (Figure 2C-E, H). The transverse crest is also known as the } \\
\text { 'transverse ridge' (e.g., Crompton, 1972; Hopson, 1984, 2005, 2014; } \\
\text { Godefroit, 1999; Abdala, Neveling \& Welman, 2006; Sues \& Hopson, } \\
\text { 2010; Sidor \& Hopson, 2018), 'anterior ridge' (Martinelli, 2010), } \\
\text { 'transverse anterior ridge' (Hopson \& Sues, 2006), 'anterior crest' (Liu \& } \\
\text { Abdala, 2014), 'central crest' (e.g., Hendrickx, Abdala \& Choiniere, 2016; } \\
\text { Sidor \& Hopson, 2018) and 'posterior transverse crest' (e.g., Abdala, } \\
\text { Barberena \& Dornelles, 2002; Abdala \& Ribeiro, 2003; Melo, Abdala \& } \\
\text { Soares, 2015). } \\
\text { Band like enamel wrinkle extending along most of the incisor or canine } \\
\text { length, typically from the mesial to distal carinae, perpendicular from the } \\
\text { undulation (tun) }\end{array}$ \\
$\begin{array}{l}\text { long axis of the crown (modified from Hendrickx, Mateus \& Araújo, 2015; } \\
\text { Figure 2B). }\end{array}$
\end{tabular}

231 Results

232 Diademodontidae Haughton, 1924

233 Diademodon tetragonus Seeley, 1894

234 Holotype: SAM-PK-571a (Wonderboom, subzone B, Cynognathus AZ, South Africa), two 235 isolated upper postcanines (holotype of Diademodon brachytiara; Seeley, 1894); SAM-PK-571b 236 (Burghersdorp, subzone B, Cynognathus AZ, South Africa), two isolated canines, an incomplete 237 upper jaw and a small portion of mandible (holotype of Diademodon tetragonus; Seeley, 1894). 238 Referred dental material: from Burghersdorp, subzone B, Cynognathus AZ, South Africa: AM 239 438, 458 (holotype of Gomphognathus kannemeyeri), BP/1/2522 (Luiperdskop locality), 3769, 240 3771-3773, 3776 (holotype of Cragievarus kitchingi; Cragievar locality for the four last 241 specimens), NHMUK PV R2574, R2575, R3581 (holotype of Microgomphodon eumerus), 242 SAM-PK-3426, K175, K177, K180, K183, K9968, UMCZ T.433 (Luiper Kop locality); from 243 Steynsburg, subzone B, Cynognathus AZ, South Africa, AM 3753 (holotype of Octagomphus 
244 woodi); from Winnaars Baken, subzone B, Cynognathus AZ, South Africa: AMNH FR 5518 and 2455519 (holotype of Cyclogomphodon platyrhinus), BP/1/3511, NHMUK PV R3587, R3588

246 (referred to Diademodon browni), R3765 (holotype of Diademodon entomophonus), R4092,

247 R9216, SAM-PK-8015, 11265; from Aliwal North, subzone B, Cynognathus AZ, South Africa:

248 NHMUK PV R3303 (holotype of Diademodon mastacus), R3304 (holotype of Diademodon

249 browni), R3305 (holotype of Microgomphodon oligocynus), R3308, R3724, SAM-PK-4002,

2505877 (referred to Cyclogomphodon platyrhinus), 6216, 6218, 6219; from Queenstown, subzone

251 B or C, Cynognathus AZ, South Africa: SAM-PK-?K4660, ?K4661; from Hofmeyr, subzone B

252 or C, Cynognathus AZ, South Africa: SAM-PK-K5266; from Lady Frere, subzone B,

253 Cynognathus AZ, South Africa: BP/1/1195, 3754, 3756-3758, BSP 1934 VIII 14, 15, 16, 17

254 (holotype of Gomphognathus grossarthi), 18 (holotype of Gomphognathus broomi), 19

255 (holotype of Gomphognathus haughtoni), 20, 505, BSP 1936 II 8 (holotype of Sysphinctostoma

256 smithi), MB R1004, NHMUK PV R2576-7 (holotype of Gomphognathus polyphagus), R2578,

257 UMCZ T.434, T.436 (holotype of Diademodon laticeps), T.438, T.441, T.445, T.454, T.826,

258 T.971; from Rouxville, subzone A, Cynognathus AZ, South Africa: BP/1/4529, 4647

259 (Bethel/Slootkraal localities for the two last), 4669 (Gladde Grond 530 locality), 4677

260 (Betjieskraal 36 locality); from Norwood farm, subzone C, Cynognathus AZ, South Africa:

261 BP/1/5541; from Avilion farm, subzone C, Cynognathus AZ, South Africa: BP/1/5542; from

262 unknown localities in South Africa: NHMUK PV R3767; SAM-PK-K5223 (Cape Province),

263 K5716, K8971, K9969; from the Luangwa Basin, Ntawere Formation, Zambia: BP/1/3639

264 (holotype of Diademodon rhodesiensis); from Etjo Mountain, Omingonde Formation, Namibia:

265 GSN R321, R327, R335, RK3; from San Rafael, Río Seco de la Quebrada Formation, Argentina:

266 MHNSR-Pv 357; from Beardmore Glacier region, Fremouw Formation, Antarctica: possibly

267 AMNH FR 24421.

268 Occurrence: Wonderboom, Burghersdorp, Aliwal North, Steynsburg, Winnaars Baken,

269 Queenstown and Hofmeyr, Joe Gqabi District, Walter Sisulu Municipality, Eastern Cape

270 Province, South Africa; Avilion and Norwood farms, Chris Hani District, Enoch Mgijima

271 Municipality, Eastern Cape Province, South Africa; Lady Frere, Chris Hani District; Rouxville,

272 Xhariep District, Mohokare Municipality; Free State, South Africa; Drysdall and Kitching's

273 locality 16, north of Sitwe, northern Luangwa Basin, Zambia (Peecook et al., 2018); Etjo

274 Mountain, Otjozondjupa Region, Namibia; Puesto Viejo farm house, $40 \mathrm{~km}$ southwest of San 
275 Rafael, Mendoza Province, Argentina; possibly Gordon Valley, Beardmore Glacier region,

276 Transantarctic Mountains, Antarctica.

277 Horizon: subzones B-C of the Cynognathus AZ, Burgersdorp Formation, Karoo Basin; lower

278 Ntawere Formation; lower fauna of the upper Omingonde Formation; Río Seco de la Quebrada

279 Formation, upper unit of the Puesto Viejo Group; possibly upper Fremouw Formation.

280 Age: early to late Anisian, Middle Triassic; n.b, Valencio et al. (1975) provided a ${ }^{40} \mathrm{~K} /{ }^{40} \mathrm{Ar}$

281 dating of $232 \pm 10 \mathrm{Ma}$ for the middle section of the Río Seco de la Quebrada Formation of

282 Argentina, placing this unit into the Upper Triassic (Carnian; Figure 1B). Likewise, Ottone et al.

283 (2014) obtained a ${ }^{38} \mathrm{U} / 206 \mathrm{~Pb}$ age of $235.8 \pm 2.0 \mathrm{Ma}$ for the underlying Quebrada de los Fósiles

284 Formation (Figure 1B), providing additional support to the fact that the Río Seco de la Quebrada

285 Formation is early Carnian. This unit, which has yielded remains of the basal cynognathians

286 Cynognathus (Abdala, 1996, 1999) and Diademodon (Martinelli, de la Fuente \& Abdala, 2009),

287 would thus be at least 10 million years younger than the putative age usually attributed to the

288 African Cynognathus AZ (Martinelli et al., 2017; Peecook et al., 2018; Gaetano, Mocke \&

289 Abdala, 2018 and references therein). Ottone and colleagues (2014) suggested two scenarios to

290 explain their results: i) the Cynognathus AZ and other fossiliferous units from African basins

291 (i.e., Omingonde Formation of Namibia, Manda Beds of Tanzania, Ntawere Formation of

292 Zambia) are wrongly attributed to the Anisian and should be instead assigned to the Carnian

293 (Figure 1B, in green); ii) an Anisian age of the Cynognathus AZ and other contemporaneous

294 biostratigraphic units from Southern Africa is correct and the stratigraphic duration of

295 Cynognathus and Diademodon is much longer than expected, ranging from the Anisian (Africa)

296 to the Carnian (South America).

297 Dental formula: i4/3 : c1/1 : pc7-16/7-13 (cpc1-6 : gpc2-7 : tpc0-2 : spc1-4).

298 Dental morphology: The dental morphology, postcanine microstructure, dental replacement

299 pattern and postcanine occlusion of Diademodon tetragonus are fairly well-known (Seeley,

300 1894, 1895, 1908; Watson, 1911, 1913; Broili \& Schröder, 1934; Brink, 1955, 1963, 1977;

301 Crompton, 1955, 1963, 1972; Fourie, 1963; Ziegler, 1969; Hopson, 1971; Osborn, 1974; Grine,

302 1977). Few of these studies provide, however, detailed information and illustrations on the dental

303 morphology and a thorough description of the anatomy of the incisors, canines and postcanines

304 is here provided.

305 Incisors 

specimens examined first hand. Incisors are preserved in the skulls of BP/1/3756 and BP/1/4669, the crania of AM 3753, BP/1/2522 and BSP 1934 VIII 14, and the mandible of MB R1004. The incisors of the latter specimen are, however, the only ones in natural position and visible in lingual view. Only the labial side of the teeth is visible in the other specimens, except for BSP 1934 VIII 14, in which three loose upper incisors are preserved and show their labial or lingual sides. The upper incisors of BSP 1934 VIII 14 appear to be salinon-shaped in cross-section at mid-crown and both mesial and distal carinae are denticulated. The distal carina faces distally

314 whereas the mesial carina is linguomesially displaced and almost reaches the cervix (Figure 4A,

315 C). The denticles are minute, well-delimited, apicobasally elongated to subquadrangular, and

316 their external margin, made of a thin layer of enamel, is weakly convex (Figure 4B, D). There

317 are eight and six denticles per millimeter on the mesial and distal carinae at mid-crown in BSP

3181934 VIII 14, respectively. This suggests that the distal denticles of the incisors are larger than

319 the mesial ones (DSDI > 1.2) in Diademodon. Concave surfaces adjacent to the mesial carina are 320 present on the lingual surface and marginal to the distal carina on the labial side of the crown

321 (Figure 4A). The lower incisors of MB R1004 are too badly preserved. They are mildly

322 procumbent and no constriction appears to be present between root and crown. Their

323 morphology does not seem to depart from that of the upper incisors.

\section{Canines}

Only the two partially complete isolated canines of the holotypic specimen SAM-PK-

326

327

328

329

330

331

332

333

334

335

336 $571 \mathrm{~b}$ can be examined in all views. The upper canines of AM 3753, BP/1/3756, BP/1/4669 and BSP 1934 VIII 14 and 15 are relatively well-preserved but BSP 1934 VIII 15 is the only specimen with in-situ upper canines that can be seen in both labial and lingual views. Likewise, only the lower canines of BSP 1934 VIII 505 can be observed in both labial and lingual views, yet they are poorly preserved and incomplete. The isolated canine of the holotype bear two poorly defined longitudinal ridges on both labial and lingual sides (Figure 4E). These ridges extend along the whole crown and delimit narrow labial and lingual depressions mesiodistally that extend also on the root. Although the canines of several specimens of Diademodon (e.g., BSP 1934 VIII 14, 15 and 505; BP/1/4669) do not bear any ridges, three to four faint longitudinal ridges can be seen on the canines of AM 3753 and BP/1/3756. Interestingly, SAMPK-571b, AM 3753 and BP/1/3756 with ridged canines belong to small individuals whereas 
337 large size specimens of Diademodon have canines devoid of longitudinal ridges. This strongly

338 suggests that the presence of ridges varies throughout ontogeny, as observed in the canines of

339 some traversodontids (Agustín Martinelli, pers. comm. April 2018). The mesial and distal

340 carinae of the upper canines are centrally positioned on the crown and the cross-sectional outline

341 at mid-crown is lenticular in AM 3753. Both carinae are also denticulated and the mesial carina

342 extends well-apical to the cervix in SAM-PK-571b. The denticles are well-preserved in this

343 specimen and clearly show the peculiar condition of changing sporadically in size along the

344 carinae (Figure 4F). As in the incisors, the denticles of the canines are apicobasally elongated in

345 shape and their external margin is weakly symmetrically convex. Seven and 7.5 denticles per

346 millimeter are present at mid-crown in the canine of the holotype $(\mathrm{CH} \sim 10 \mathrm{~mm})$, whereas three

347 and 3.5 to four denticles per millimeter can be counted at mid-crown in the canines of the larger

348 specimens BSP 1934 VIII $14(\mathrm{CH} \sim 14 \mathrm{~mm})$ and BP/1/4669 (CH $19 \mathrm{~mm})$, respectively. Due to

349 preservation, it is unknown whether the lower canines of BSP 1934 VIII 505 were denticulated.

350 Conical postcanines

351 The upper and lower conical postcanines vary from one in the newly born/juvenile

352 specimen BSP 1936 II 8 (Broili \& Schröder, 1936; Hopson, 1971; Brink, 1977) to six in the

353 large-sized and most probably adult specimen NHMUK PV R3308 (Hopson, 1971). As

354 described by Crompton (1955), the upper conical postcanines are straight, apically pointed, and

355 slightly labiolingually compressed or subcircular. The mesial and distal carinae of these teeth are

356 also denticulated in NHMUK PV R3308 (Crompton, 1955) and denticles appear to be present at

357 the base of the distal carina in BSP 1934 VIII 14 (Figure 4H). The upper conical teeth are,

358 however, unserrated in BP/1/3639 and possibly in MB R1004 (Figure 4G). In the latter

359 specimen, the upper conical postcanines are also mesiodistally constricted at the cervix but this

360 may result from taphonomical deformation (Figure 4G). The upper conical postcanines of

361 NHMUK PV R3308 clearly increase in width distally, and the mesial four (possibly also the

362 unpreserved fifth) crowns are monocuspid (i.e., tooth strictly conical in shape, with a single

363 centrally positioned cusp; Crompton, 1955). The sixth postcanine, considered to be a conical

364 type by Hopson (1971), departs from this morphology. Although subcircular in outline, the tooth

365 shows an important lingual projection and includes a high labial cusp and a low lingual

366 cingulum. The latter is comprised of three or more cingular cuspules linguomesially and an

367 additional cingular cuspule behind the labial cusp distally (Crompton, 1955). 
As in the upper jaw, the lower conical postcanines increase in width distally, being

369

370

371

372

373

374

375

376

377

378

379

380

381

382

383

384

385

386

387

388

389

390

391

392

393

394

395

396

397

398

weakly labiolingually compressed in the first two or three teeth and subcircular in the following crowns. No information on the first two conical teeth could be extracted from the specimens.

These lower postcanines are believed to be monocuspid like those from the cranium, and do not show any cingulum. The third and fourth lower conical postcanines preserved in AM 458 are proportionally wider than the upper conical postcanines of MB R1004 and BSP 1934 VIII 14 from the same alveoli. In AM 458, the mesial carina of conical postcanines faces linguomesially whereas the distal carina is positioned distally (Figure 4I, J). Both mesial and distal carinae are clearly denticulated in AM 458. The distal denticles are large and apically inclined whereas the mesial denticles are low and show a widely convex external margin. Cingular cuspules are visible on the linguodistal surface, at the base of the third and fourth conical postcanines of AM 458 (Figure 4J). A distal accessory cusp is also present at mid-crown height in the lower conical teeth of SAM-PK-5877 (Figure 4K).

\section{Upper gomphodont postcanines}

According to Brink (1977), the number of upper gomphodont postcanines varies between two (BSP 1936 II 8; Broili \& Schröder, 1936; Hopson, 1971) to seven (BP/1/2522; Brink, 1963).

The best-preserved upper gomphodont postcanines are from the holotypic specimen SAM-PK571a, which includes in situ teeth within the maxillae (Figure 4N-O) as well as two wellpreserved isolated postcanines from the more distal portion of the jaw (Figure 4L-M). With a CBR ranging from one to 1.7 , most of the upper gomphodont postcanines are wider than the lower gomphodont postcanines. Gomphodont postcanines of Diademodon are characterized by the presence of several accessory ridges and bumps on the mesial and distal surfaces of the transverse crest. The mesial and distal accessory ridges vary in length, orientation and extension along the tooth row so that each gomphodont postcanine has a unique morphology along the jaw. All upper postcanines, however, bear a large labial cusp longer and slightly higher than the lingual cusp (Figure 4L, N). A smaller and lower yet well-demarked labiodistal accessory cusp always follows the labial cusp. The mesial and distal crests of the labial cusp appear to be weakly denticulated, with the largest denticles being present in the basal portion of the cusp. The lingual cusp is always adjacent to a linguomesially accessory cusp, and the latter is as long and tall as the lingual cusp. In the fourth right gomphodont postcanine of BSP 1934 VIII 14, the linguomesial accessory cusp is in fact much longer than the lingual cusp (Figure 4P) and is 
399 followed by a second shorter linguomesial accessory cusp. The presence of accessory ridges and

400 bumps on the transverse crest makes it difficult to delimit the central cusp in SAM-PK-571a,

401 which seems to be centrally positioned on the crest (Figure 4L, M). Both mesial and distal

402 margins of the upper gomphodont postcanines are delimited by one or several accessory cusps

403 forming a cingulum (Figure 4L). The size, position and height of these cingular cuspules vary in

404 each upper postcanine along the tooth row (see below). The isolated upper postcanines of the

405 holotype bear a single mesial cingular cuspule (Figure 4M) and perhaps some other minor

406 cingular cuspules, whereas the distal cingulum is made of four to five cuspules increasing in

407 height and width lingually (not clearly visible in Figure 4L, see $3 \mathrm{~d}$ model). The distal basin is

408 longer than but as deep as the mesial basin. The root is more than twice as long as the crown and

409 bears a deep, wide and centrally positioned depression on its distal surface.

410 The upper gomphodont postcanines from the anterior half of the maxilla (Figure 4N, O)

411 follow the same pattern of ridges and cusps seen in the isolated upper postcanines, i.e., they have

412 two main labial and lingual cusps adjacent to two prominent labiodistal and linguomesial

413 cingular cuspules, respectively. The labial and lingual cusps have, however, the same height. The

414 labiodistal accessory cusp is significantly lower and shorter than the labial cusp, whereas the

415 linguomesial accessory cusp is longer and as high or higher than the lingual cusp. The transverse

416 crest of these postcanines bears accessory ridges and bumps on the mesial surface only, the distal

417 surface being smooth (Figure 4N). In one of the two in-situ upper postcanines, the mesial surface

418 shows an accessory ridge running perpendicular to the transverse crest and parallel to a second,

419 poorly marked ridge, as well as a single accessory bump on its linguomesial portion. The central

420 cusp of the transverse crest is long, low and appears to bear some poorly defined serrations on its

421 labial and lingual crests. Some portions of the mesial and distal cingula and labiomesial,

422 labiodistal, linguomesial and linguodistal ridges also show a beaded appearance and are finely

423 serrated in the three best-preserved upper postcanines. The distal basin of the distalmost

424 preserved postcanine is narrow, well defined and bounded by the distal cingulum. This basin is,

425 however, shallow and poorly defined in the preceding tooth (Figure $4 \mathrm{~N}$ ) and absent in the

426 mesialmost preserved postcanine. The mesial basin of the two first postcanines has also been

427 worn out, a feature shared with Titanogomphodon. Similar to the isolated upper postcanines, the

428 mesial margins of the in-situ postcanines have a single and weakly lingually deflected cingular

429 cuspule. Likewise, the distal cingulum is formed by four cingular cuspules that increase in width 
430 and height lingually. Two distal cingular cuspules are seen on the linguodistal margin of the 431 preceding tooth (Figure 4N). A higher number of cingular cuspules can, however, been counted 432 on the cingula of other Diademodon specimens, with five, possibly six, cingular cuspules in the 433 mesial cingulum of the best-preserved right upper postcanine of NHMUK PV R3303, and five to 434 six cingular cuspules in the distal cingulum of the largest left and right upper postcanines of 435 NHMUK PV R3765. Although the width and height of the mesial cingular cuspules also increase 436 lingually in NHMUK PV R3303, the cingular cups of the distal carina decrease in size either 437 towards the center of the cingulum or sporadically along the cingulum in NHMUK PV R3765.

\section{Lower gomphodont postcanines}

439 The number of lower gomphodont postcanines appears to vary between three (juvenile 440 specimen BSP 1936 II 8; Broili \& Schröder, 1936; Hopson, 1971) to five (large-sized/adult 441 specimens BSP 1934 VIII 505 and SAM-PK-177), or even possibly more. Two lower 442 gomphodont postcanines from the posterior portion of an incomplete left mandible of the 443 holotype SAM-PK-571a are also among the best-preserved lower postcanines known (Figure 444 5A-E). The best-preserved lower postcanine, which is the most distal one, is longer than wide 445 and the lingual cusp is as wide but slightly shorter and lower than the labial cusp (Figure 5A, C).

446 It is difficult to know whether accessory cusps were present. Based on the size of the cusps, the 447 linguomesial and labiodistal accessory cusps appear to be present and may not correspond to 448 cingular cuspules. These two cusps are lower and shorter than the lingual and labial cusps 449 (Figure 5A, B). It is unknown whether the lingualmost cingular cuspule of the mesial cingulum 450 is homologous to the linguomesial accessory cusp (Figure 5A, B). The mesial and distal 451 accessory ridges are prominent, higher than the low and poorly delimited transverse crest and 452 diagonally oriented from it. Three accessory ridges can be counted on the mesial surface of the 453 transverse crest and one on the distal surface (Figure 5A). A second much shorter distal ridge 454 extending linguodistally is present at the level of the distal basin. Three protuberant and well455 delimited mesial cingular cuspules composed the mesial cingulum whereas the distal cingulum 456 encompasses four smaller and poorly delimited cingular cuspules (Figure 5A, C). As observed in 457 some upper postcanines, the mesial and distal edges of the labial cusp are denticulated (Figure 458 5E). The second more mesial lower gomphodont postcanine is more sub-circular in outline and 459 the mesial and distal accessory ridges on the transverse crest are not so prominent. We assume 460 the presence of a labiodistal and linguomesial accessory cusps in this tooth, but the mesialmost 
461 and distalmost cingular cuspules are as wide and as well-delimited as these two putative

462 accessory cusps. Both labial and lingual cusps are incomplete and it is unknown whether they

463 had the same width and height.

464 The lower gomphodont postcanines of the large majority of other more mature specimens

465 of Diademodon preserving the lower dentition (e.g., BMNH R3588; BSP 1934 VIII 16, 505; MB

466 R1004; GSN R321) are worn out and only the distalmost mandibular postcanines of AM 458,

467 AM 3753 and SAM-PK-5877 are complete enough to provide some information on their

468 morphology. In all specimens, the labial cusp is the largest, and is significantly longer, wider and

469 higher than the lingual cusp. The transverse crest connecting the two cusps forms a narrow ridge

470 bearing a low and poorly defined central cusp. One or two large pointed mesial cingular cuspules

471 are visible in the three specimens, mesial to the lingual cusp (Figure 5D). Based on their size,

472 these cingular cuspules may correspond to the linguomesial accessory cusps of more derived

473 gomphodonts. A wide and high centrally positioned mesial cingular cuspules is well-visible in

474 SAM-PK-5877 (Figure 5D) but worn out in AM 458 and AM 3753. The central cingular

475 cuspules are wider than the mesial cuspules directly mesial to the lingual cusp but narrower than

476 the preceding one situated on the linguomesial margin of the lower postcanine. The distal

477 cingulum, well-preserved in the left and right distalmost lower postcanines of SAM-PK-5877,

478 bears four to six well-delimited cingular cuspules (Figure 5D). These distal cingular cuspules

479 extend on the labiodistal ridge of the labial cusp in the left postcanine where they increase in

480 length mesially. As in the holotype, several accessory ridges of variable length and orientation

481 (i.e., perpendicular, diagonally oriented or parallel to the transverse crest) are present on the

482 mesial and distal surfaces of the transverse crest in SAM-PK-5877, AM 458 and AM 3753. In

483 SAM-PK-5877, one of the mesial accessory ridges reaches the largest mesial cingular cuspules

484 (Figure 5D).

485 Transitional postcanines

486 The transitional upper and lower postcanines, which are relatively well preserved in MB

487 R1004, SAM-PK-K177 and AM 3753, have an intermediate morphology between the distalmost

488 gomphodont and the sectorial postcanines. They are subcircular, weakly labiolingually

489 elongated, drop-shaped or oval in outline. These teeth show a large recurved cusp on the labial

490 portion of the crown homologous to the labial cusp and the main cusp of gomphodont and

491 sectorial postcanines, respectively. A lingual cingulum formed by three to five well-delimited 
492 and strongly protruding cingular cuspules are also visible (Figure 5F, G). Labiodistally oriented

493 ridges connecting the main cusp to one or several of these cingular cuspules can be seen in some

494 specimens (Figure 5F). One or two distal accessory cusps are also present distal to the main cusp,

495 with the one directly mesial to the main cusp being likely homologous to the labiodistal

496 accessory cusp of gomphodont postcanines of Diademodon and possibly other trirachodontids

497 and traversodontids. Two transitional postcanines can be observed in the lower jaw of SAM-PK-

$498 \mathrm{~K} 177$ (Figure 5F). Although incomplete, the main cusp of those two teeth appears to be

499 linguomesially oriented and subcircular in outline. The transitional upper postcanines (the

500 'intermediate gomphodont of Osborn 1974) were lost in some specimens of Diademodon such as

501 BSP 1934 VIII 14 in which they probably were replaced by gomphodont postcanines, following

502 the replacement model proposed by Hopson (1971) and Osborn (1974).

503 Sectorial postcanines

$504 \quad$ The upper and lower sectorial postcanines always bear a recurved main cusp followed by

505 a distal main cusp, or, more commonly, one distal main cusp and a smaller distal accessory cusp

506 (Figure 5H-I). The distal accessory cusp of the sectorial teeth is either of the same length or

507 slightly shorter than the distal main cusp. Some teeth also bear a minute mesial main cusp on the

508 basal third of the mesial margin of the main cusp (Figure 5H). The mesial and distal carinae of

509 the main cusp are usually denticulated along the whole crown height. The specimen BP/1/4529

510 shows the unique feature of having both mesial and distal denticles divided into two parts, i.e., a

511 large sub-denticle apically and a smaller one basally (Figure 5J, K). The distal main and distal

512 accessory cusps are also denticulated in this specimen (Figure 5J). A lingual cingulum composed

513 of six to seven cuspules is clearly present in the mesial lower sectorial teeth of AM 3753, MB

514 R1004 and SAM-PK-K177. This cingulum is, however, absent in the upper sectorial postcanines

515 of BSP 1934 VIII 14 and in the distalmost upper and lower sectorial teeth of MB R1004.

516 Crown enamel surface texture and microstructure

517 Histological studies of the postcanine of Diademodon tetragonus were done by Grine

518 (1977, 1978), Osborn \& Hillman (1979) and Sander (1997b). The enamel microstructure of this

519 taxon was revealed to be prismless and columnar (the synapsid columnar enamel SCE of Sander,

520 1997b), and to include incremental lines and enamel tubules. The enamel surface texture (sensu

521 Hendrickx, Mateus \& Araújo, 2015) of incisors, canines and postcanines is braided and

522 apicobasally oriented.

Peer) reviewing PDF | (2018:02:25716:2:0:NEW 28 Feb 2019) 


\section{Titanogomphodon crassus Keyser, 1973}

524 Holotype: GSN R323, an incomplete cranium missing the mesial tip of the rostrum.

525 Referred dental material: None.

526 Occurrence: Northern slope of Etjo Mountain, Otjozondjupa Region, Namibia.

527 Horizon: Etjo Beds, upper levels of the upper Omingonde Formation.

528 Age: late Anisian-Ladinian?, Middle Triassic. The upper fauna from the upper Omingonde

529 Formation is correlated to that from the Dinodontosaurus AZ of Brazil and the Chañares

530 Formation of Argentina (Abdala \& Smith, 2009; Abdala et al., 2013; Martinelli et al., 2017).

531 Given that the Chañares Formation was recently dated to the lower Carnian (Marsicano et al.,

532 2016), the upper fauna from the Omingonde Formation might also be from the lowermost part of

533 the Upper Triassic.

534 Dental formula: i?/? : c?/? : pc>7/? (cpc?: gpc>3: tpc1 : spc3).

535 Dental morphology: Keyser (1973) described the dentition of Titanogomphodon in relative

536 details given the poor preservation of the teeth. The holotypic specimen GSN R323 preserves the

537 distal portion of the three distalmost gomphodont postcanines as well as a transitional postcanine

538 and the first and third sectorial teeth (Figure 6).

\section{Upper gomphodont postcanines}

$540 \quad$ As noted by Keyser (1973), the transverse crest of the gomphodont postcanine, which

541 connects the labial and lingual cusps (both unpreserved in all gomphodont postcanines of GSN

542 R323), is slightly mesially displaced (Figure 6B). As seen in Diademodon upper postcanines, a

543 faint mesial accessory ridge can be observed in the distalmost gomphodont tooth (Figure 5A, C).

544 Unlike Keyser's (1973) description of the upper gomphodont postcanines, no labiodistal

545 accessory cusp or distinct cuspules forming a distal cingulum can be observed in the preserved

546 teeth (Figure 6A). Nonetheless, the damaged right mesialmost gomphodont postcanine appears

547 to show a labiomesial accessory cusp, mesial to the unpreserved labial cusp as well as a mesial

548 cingular cuspule (Figure 6D, F). Many portions of the enamel and dentine surface of this tooth

549 are, however, missing and the presence of these two accessory cusps/cingular cuspules needs to

550 be confirmed. Similar to some upper postcanines of Diademodon that have been worn out, and

551 unlike trirachodontid postcanines, the mesial and distal basins are absent in all preserved

552 postcanines of Titanogomphodon.

553 Transitional and sectorial postcanines

Peer) reviewing PDF | (2018:02:25716:2:0:NEW 28 Feb 2019) 
According to Keyser (1973), Titanogomphodon is diagnosed by the diagonal orientation

555

556

557

558

559

560

561

562

563

564

565

566

567

568

569

570

571

572

573

574

575

576

577

578

579

580

581

582

of the sectorial postcanines, of which the long axis is linguomesially oriented. Such orientation

of the sectorial teeth indeed contrasts with the mesiodistally oriented upper sectorial postcanines of other gomphodont cynodonts such as Diademodon, Langbergia, Trirachodon, Andescynodon and Boreogomphodon, in which the long axis is parallel to the labial margin of the upper jaw. As in Diademodon and unlike trirachodontids, a transitional postcanine is present between the gomphodont and sectorial teeth. Little information can be extracted from the transitional and sectorial postcanines due to wear and the incompleteness of the crowns. No main and accessory cusps, or cingular cuspules are preserved in the sectorial postcanines and only a concavity centrally positioned on the lingual surface of the crown and root is present in the two sectorial teeth (Figure 6A, E).

\section{Trirachodontidae Romer, 1967}

\section{Langbergia modisei Abdala, Neveling \& Welman, 2006}

Holotype: NMQR 3255 (from Langberg), an incomplete cranium.

Referred dental material: from Goedgedacht: NMQR 3251; from Langberg: NMQR 3256, BP/1/5362; from Rexford Store: NMQR 3268, BP/1/5363; from Eerste Geluk: NMQR 3280, 3281; from Bosrand: BP/1/5400, 5401, 5404; from Driefontein: BP/1/5666; from Moerbeidal:

CGP/1/33; from Palmiet Fontein: CGP/1/120; from Kaaimansgat: SAM-PK-11481.

Occurrence: (from Abdala, Neveling \& Welman (2006), Table 1) Langberg 556 and

Driefontein, Paul Roux, Thabo Mofutsanyane District, Free State Province, South Africa;

Rexford Store 433, Bethlehem, Thabo Mofutsanyane District; Eerste Geluk 131, Kestell, Thabo

Mofutsanyane District; Goedgedacht 15, Marquard, Thabo Mofutsanyana District; Bosrand 12,

Senekal, Thabo Mofutsanyane District; Moerbeidal 648, Kaaimansgat 146 and Hugo's Kop 620, Rouxville, Xhariep District, Free State Province, South Africa; Palmiet Fontein 94, Tarkastad, Chris Hani District, Eastern Cape Province, South Africa;.

Horizon: subzone A of the Cynognathus Assemblage Zone (AZ), Burgersdorp Formation, Beaufort Group, Karoo Supergroup.

Age: late Olenekian, Early Triassic.

Dental formula: i4/3 : c1/1 : pc7-9/8 (cpc1-2: gpc3-7?: spc2-4). 
583 Dental morphology: The dentition of Langbergia modisei has been well-described by Abdala,

584 Neveling \& Welman (2006). Here we provide additional information based on firsthand

585 examination of the best-preserved specimens.

586 Incisors

587 The mesial carina of the incisors does not seem to be denticulated, whereas the distal

588 carina is denticulated and bears around 30 denticles per $5 \mathrm{~mm}$ (contra Abdala, Neveling \&

589 Welman, 2006; Figure 7A-C). The denticles of the first right lower incisor of NMQR 3251 have

590 a symmetrically convex external margin and are poorly delimited. They are apicobasally

591 elongated and change sporadically in size along the carina (Figure 7A, B). The largest denticles

592 are at mid-crown and the denticles do not extend up to the crown apex and the root (Figure 7A,

593 B). The distal denticles of the fourth upper incisor of NMQR 3281 and SAM-PK-11481 share the

594 same morphology, with the largest denticles at mid-crown and the basalmost and apicalmost

595 denticles extending far above the root (Figure 7C) and below the crown apex, respectively. A

596 concave surface adjacent to the distal carina is also present on the labial surface of the third?

597 right incisor in SAM-PK-11481. Based on the first and best-preserved lower incisor of NMQR

5983280 , the mesial carina faces mesially whereas the distal carina is distally, almost linguodistally

599 positioned, giving a lenticular to D-shaped cross-sectional outline at mid-crown. The distal

600 profile of the upper incisors of this specimen is sigmoid in labial view, with the basal one-third

601 and the apical two-thirds of the crown being convex and concave, respectively. The incisors are

602 apically recurved and some of them are weakly mesiodistally constricted at the cervix.

603 Canines

604 Both upper and lower canines of Langbergia modisei have denticulated carinae

605 (BP/1/5362; NMQR 3251, 3268) with a denticle density ranging from 20 to 32 denticles per 5

$606 \mathrm{~mm}$. In NMQR 3251 and 3268, the mesial and distal denticles of the canines do not extend to the

607 cervix basally, but do reach the crown apex in NMQR 3251. Similar to the incisors, the mesial

608 and distal denticles change sporadically in size along the carinae and have a symmetrically to

609 asymmetrically convex external margin (Figure 7F, G). The denticles of the canines tend to be

610 better delimited and mesiodistally longer than those of the incisors so that denticles are

611 apicobasally elongated and sometimes subquadrangular in shape. Despite the fact of changing

612 randomly in size, the basal and apicalmost denticles are smaller than those of the mid-crown on

613 both mesial and distal carinae. Faint longitudinal ridges delimiting mesiodistally short, flat facets 
614 can be observed on the labial surface of the canines of BP/1/5362 (Figure 7H) and SAM-PK-

615 11481. In the latter specimen, the mid-crown cross-sectional outline of the upper canine is

616 roughly salinon-shaped (sensu Hendrickx, Mateus \& Araújo, 2015), with a wide convex labial

617 margin showing a weakly concave labiodistal surface, and a biconcave lingual margin, of which

618 the mesial concavity is longer than the distal one (Figure 7E). A concave surface is also present

619 on the mesial and distal surfaces of the erupting right and left upper canines of NMQR 3268,

620 respectively. The cross-sectional outline of the canine of NMQR 3251 is, however, parabolic at

621 mid-crown. This indicates that there is variation in cross-sectional outline in the canines. No

622 transverse undulations could be observed on the upper and lower canines of the specimens

623 examined. The enamel surface texture of NMQR 3268 is clearly braided and curves basally close

624 to the carinae (Figure $7 \mathrm{I})$.

625 Gomphodont postcanines

626 As noted by Abdala, Neveling \& Welman (2006), the first upper and lower postcanines

627 differ in their morphology. The first upper postcanine of NMQR 3251 is significantly smaller

628 than the more distal ones, has a sub-circular cross-sectional outline and only bears a single main

629 cusp, a morphology that is similar to the conical postcanines of Diademodon. In NMQR 3255,

630 the first upper postcanine has an oval cross-sectional outline and is only slightly smaller than the

631 other gomphodont postcanines. Given the incomplete preservation of the first upper postcanines

632 on both sides, it is unknown whether they were monocuspid as well. The morphology of the first

633 lower postcanine appears to be more complex. It includes a main centrally positioned and a

634 slightly labially displaced cusp (Figure 7N), which is homologous to the central cusp of more

635 distal gomphodont postcanines based on its size, position and morphology. This main cusp is

636 bordered by a small apically pointed mesial accessory cusp and a low lingual cingulum formed

637 by at least three minute cingular cuspules (Figure $7 \mathrm{~N}$ ), a morphology reminiscent to that of

638 sectorial postcanines seen in diademodontids and trirachodontids. Because the distal portion of

639 this tooth is missing, it is unknown whether an accessory cusp was present distal to the main

640 cusp.

641 Unlike other trirachodontids, the upper and lower gomphodont postcanines of Langbergia

642 roughly share the same morphology, i.e., they are elliptical in cross-section, slightly

643 labiolingually elongated and their long axis is slightly to strongly linguomesially oriented

644 (Abdala, Neveling \& Welman, 2006). This diagnosis applies to the specimens with upper and 
645 lower postcanines visible in apical view (i.e., NMQR 3251 and NMQR 3255), with the exception 646 of NMQR 3268. Indeed, although the upper and lower gomphodont postcanines of NMQR 3251

647 and NMQR 3255 share a crown base ratio (CBR) varying between 1.3 and 1.45, the upper

648 gomphodont postcanines of NMQR 3268 are more labiolingually elongated, with a CBR around

6492 in the widest teeth. Likewise, the long axis of the upper postcanines of NMQR 3268 is

650 perpendicular to the long axis of the cranium. It is unknown whether these dental differences are

651 ontogenetic, intra- or interspecific, and NMQR 3268 is here tentatively kept within the species $L$.

652 modisei based on the absence of a maxillary platform, a labiolingually narrow and prominent

653 central cusp, and the stratigraphic distribution of the specimen (i.e., Cynognathus subzone A).

654 Both upper and lower gomphodont postcanines of Langbergia increase in size up to the

655 penultimate tooth, which is slightly larger than the last gomphodont postcanine. The long axis of

656 the upper gomphodont postcanines is roughly parallel in all teeth in NMQR 3251, 3255 and

6573268 , with very little variation along the tooth row. In the lower postcanines, however, it changes

658 in orientation, with the long axis being strongly mesially oriented in the first two postcanines,

659 then almost parallel to the long axis of the mandibular tooth row in the last gomphodont tooth.

660 All gomphodont postcanines bear a high, wide, centrally positioned central cusp bordered

661 labially and lingually by the labial and lingual cusps, respectively (Figure 7J-M). The central

662 cusp always appears to be higher and wider than both labial and lingual cusps. It is separated

663 from these two cusps by a deep and narrow valley extending basally at a certain distance above

664 the mesial and distal basins (Figure 7L). The labial, central and lingual cusps that form the

665 transverse crest are not perfectly aligned on the same plane of elongation of the postcanine. The

666 long axis of the central cusp either follows that of the transverse crest or is diagonally oriented to

667 it (Figure 7J, K, M). Likewise, the labial cusp of the upper postcanines is significantly deflected

668 mesially from the diagonally oriented axis of the transverse cusp whereas the lingual cusp of the

669 lower postcanines is weakly deflected distally in some teeth (Figure 7J, K, M). The lingual and

670 central cusps are, however, aligned in the same plane of elongation of the postcanine while the

671 labial cusp remains mesially displaced from that plane. A cingulum formed by three to four large

672 and sometimes strongly protruding cingular cuspules delimits both the mesial and distal margin

673 of the upper and lower gomphodont postcanines in NMQR 3251 and NMQR 3255. The

674 labiomesial and linguodistal cusps are the largest accessory cusps of the cingula in the upper

675 gomphodont postcanines whereas the labiomesial, linguomesial and linguodistal are the largest 
676 in the lower postcanines. Although incomplete and badly preserved, the upper postcanines of

677 NMQR 3268 do not seem to bear these large accessory cusps on the cingula. The mesial and 678 distal cingula instead comprise a large number of small cingular cuspules, as seen in Cricodon 679 and Trirachodon. Due to the incompleteness of the upper postcanines of NMQR 3268, it is 680 unknown whether the cingular cuspules extend along the whole width of the crown or are 681 restricted to a certain part of the cingulum. A similar morphology is seen in the mesial cingulum 682 of the last right upper gomphodont of SAM-PK-11481, in which the cingular cuspules also form 683 low and poorly delimited convexities. The whole morphology of this gomphodont postcanine, 684 which is strongly diagonally oriented and whose labiomesial portion is the only one not hidden 685 by the matrix, in fact departs from that seen in the gomphodont teeth of NMQR 3251, 3255 and 686 3268. The labial cusp of the crown in SAM-PK-11481 appears to form a minute projection 687 separated from the central cusp by a much wider and higher cusp. It is, however, possible that the wider cusp directly adjacent to the central cusp is in fact the labial cusp, and that the small cusp, which is connected to the mesial cingulum by a low ridge, corresponds to a cingular cuspule mesial to the labial cusp. The cingular cuspules, however, increase in width towards the center of the crown at least on the distal cingulum in this specimen. The mesial and distal basins, delimited

692 by the transverse crest and the cingulum, are deep and mesiodistally short in Langbergia (Figure

$6937 \mathrm{~J}, \mathrm{~K}, \mathrm{M}$ ). As observed for the canines, the enamel texture of the gomphodont postcanines is

694 braided and apicobasally oriented.

\section{Sectorial postcanines}

The sectorial postcanines always include a main recurved cusp followed by one distal main cusp and, in some teeth, a distal accessory cusp distally, and one or no mesial main cusp

698 (Figure 7O, P). The mesial margin of the main cusp is denticulated on the apical third of the crown in BP/1/5362 (Figure 7P). The denticles are poorly defined, low, apicobasally elongated projections on the carina. As in the denticles of the incisors and canines, they sporadically change in size and their external margin is symmetrically to asymmetrically convex. The distal main cusp is the longest whereas the distal accessory cusp is significantly smaller and sometimes appears as a minute projection. The mesial main cusp is often large, projects apically and strongly protrudes from the basal third of the crown (Figure 70). The distal main cusp also projects distally in some specimens. As observed by Abdala, Neveling \& Welman (2006), a 
707 postcanine of NMQR 3255 (Figure 7Q). The mesialmost cingular cuspule is long and followed

708 distally by two short cusps, a much longer one, and then a medium sized one. A sigmoid and

709 basally inclined cingulum formed by several minute cingular cuspules is also visible on the

710 lingual surface of the third lower sectorial postcanine of NMQR 3251. In the latter specimen, the

711 last upper sectorial crown is significantly shorter and slightly lower than the preceding one. It is

712 a tricuspid postcanine in which the main cusp, distal main cusp and distal accessory cusp projects

713 basodistally and decrease in height and length distally (Figure 70). The distal main cusp is a

714 subtriangular prominence at mid-crown height whereas the distal accessory cusp is a minute

715 projection in the basalmost part of the crown (Figure 7O).

\section{Cricodon metabolus Crompton, 1955}

717 Holotype: UMZC T905 (from Njalila, Manda Beds, Tanzania), incomplete upper and lower 718 jaws with several loose teeth.

719 Referred dental material: from Avilion farm, subzone C, Cynognathus AZ, South Africa:

720 BP/1/5540, 5835, 6159; from Norwood farm, subzone C, Cynognathus AZ, South Africa:

721 BP/1/6102; from Sitwe, Ntawere Formation, Zambia: NHCC LB28; from Ruhuhu Basin, Manda

722 Beds, Tanzania: NMT RB227, NHMUK PV R36800; from Aliwal North, subzone B,

723 Cynognathus AZ, South Africa: NHMUK PV R3722, SAM-PK-6212, 5881 $a$ and $b$.

724 Occurrence: Stockley's bone locality B11, Njalila, Tanzania; Outcrop Z40 (Z51 according to

725 Sidor \& Hopson, 2018), Ndatira River, Litumba Ndyosi District, Ruhuhu Basin, Tanzania (Smith

726 et al., 2018); Outcrops Z29, Z81, near the village of Lutimba Kuhamba, Litumba Kuhamba

727 District, Tanzania (Sidor \& Hopson, 2018; Smith et al., 2018); Outcrop L23, 5 km west of Sitwe,

728 Eastern Province, Zambia; Avilion and Norwood farms, Bamboeshoek Valley, Sterkstroom,

729 Chris Hani District, Enoch Mgijima Municipality, Eastern Cape Province, South Africa; Aliwal

730 North, Joe Gqabi District, Walter Sisulu Municipality, Eastern Cape Province, South Africa.

731 Horizon: middle to upper Lifua Member, Manda Beds; subzones B and C of the Cynognathus

732 Assemblage Zone (AZ), Burgersdorp Formation, Beaufort Group, Karoo Supergroup; upper

733 Ntawere Formation.

734 Age: early to late Anisian, Middle Triassic.

735 Dental formula: $14 / 3: \mathrm{c} 1 / 1: \mathrm{pc} 9-10 / 11$ (cpc0 : gpc7-9 : spc0-2).

736 Dental morphology: The dentition of the holotypic specimen of Cricodon metabolus was 737 described by Crompton (1955) and additional information was given by Abdala, Hancox \& 
738 Neveling (2005) and Sidor and Hopson (2018) based on referred specimens. Although Sidor and

739 Hopson (2018) recently comprehensively described the well-preserved dentition of an immature

740 Cricodon metabolus (NMT RB227) from Zambia, a detailed examination of the holotype and

741 referred material deposited in South Africa and England enable us to provide additional

742 information on the dental morphology of this taxon. BP/1/5540, 5835, 6102, 6159, NHMUK PV

743 R3722, R36800, SAM-PK-6212, 5881a (represented by a badly crushed snout and the anterior

744 portion of a mandible) and $5881 \mathrm{~b}$ (preserving the left maxillary tooth row with five upper

745 gomphodont postcanines) are here tentatively referred to Cricodon metabolus based on the large

746 size, the low denticle density of the incisors and canines, the drop-shaped outline of the

747 distalmost upper postcanines, the step-like disposition of distalmost upper gomphodont

748 postcanines, and the long axis of lower postcanines perpendicular to the mandibular tooth row.

749 We, however, note important differences in the cranial, mandibular and dental anatomy of the

750 holotype and referred specimens NMT RB227, BP/1/6102, SAM-PK-5881 (e.g., length of the

751 diastema between the canine and the first upper/lower postcanine, morphology of the first upper

752 postcanines and last gomphodont postcanines, lateral extension of the platform marginal to the

753 dental series). If these differences could be ontogenetic, we do not exclude the possibility that

754 these referred specimens represent one or several new trirachodontid species. Conversely,

$755 \mathrm{BP} / 1 / 5538$ from the subzone C Cynognathus AZ of the Avilion farm (Sterkstroom District) is

756 confidently excluded from this taxon. This specimen, represented by the posterior portion of the

757 snout and orbits with the three last gomphodont and the first sectorial postcanines preserved,

758 differ from Cricodon by: i) longer and more ovoid upper distal gomphodont postcanines (CBR of

7591.5 vs. CBR of 1.85 to 2.5 typical of Cricodon); ii) no step-like disposition of the

760 antepenultimate and penultimate upper gomphodont postcanines; iii) upper postcanines with a

761 large labiomesial accessory cusp and no distal cingulum (contra Abdala, Hancox \& Neveling,

762 2005); iv) sectorial upper postcanines with a large strongly pointed and strongly apically

763 recurved main cusp and two distal accessory cusps. BP/1/5538 may also belong to a new

764 gomphodont taxon.

765 Incisors

766 The mesial and distal carinae of the partially erupted first left lower incisor of the

767 holotype UMZC T905 are clearly denticulated and include apicobasally elongated to

768 subquadrangular and weakly apically inclined denticles with a symmetrically convex external 
769 margin (Figure 8A, B). Both mesial and distal denticles decrease in size apically and reach the 770 crown apex, although the tip of the apex remains unserrated. There are around 1.75 denticles per $771 \mathrm{~mm}$ (denticle density of $\sim 9 / 5 \mathrm{~mm}$ ) in the basalmost erupted part of the mesial and distal carinae, 772 and 3.5 denticles per $\mathrm{mm}$ at the apex. The upper incisors of BP/1/6102 and BP/1/5540 share the 773 same denticle density, with 7 to 10 denticles per $5 \mathrm{~mm}$ in the distal carina (Figure 8C, D). This

774

775

776

777

778

779

780

781

782

783

784

785

786

787

788

789

790

791

792

793

794

795

796

797

798

799 contrasts with the much higher density of denticles $(>20 / 5 \mathrm{~mm}$ at mid-crown) on the incisors of other trirachodontids. The mesial carina and denticles of BP/1/6102 are not visible and are most likely covered by sediment. Only the apical denticles of the first left upper incisor can be seen on the mesial carina of BP/1/5540. These mesial denticles are apicobasally elongated, have a flat external margin and extend one millimeter below the crow apex. The denticles of the distal carina of $\mathrm{BP} / 1 / 6102$ and $\mathrm{BP} / 1 / 5540$ also extend from the cervix to the base of the crown apex (Figure $8 \mathrm{C}$ ). In BP/1/6102, the distal denticles decrease in size apically and basally from the mid-crown height, and are apicobasally elongated at mid-crown and in the apical part of the crown and almost subquadrangular in the basal third of the carina (Figure 8D). On the other hand, the distal denticles of BP/1/5540 are apically inclined and subquadrangular on most of the carina. The denticles of the third replacing upper incisor of NHCC LB28 are more prominent distally than mesially, and the distal denticles also increase in size from the apex towards the base of the crown in both upper and lower incisors (Sidor \& Hopson, 2018). The external margin of the denticles in BP/1/5540 is symmetrically to asymmetrically convex and weakly parabolic. The interdenticular space is apicobasally wide in the basal denticles and narrow in the mid-crown and apical denticles in BP/1/6102 whereas it is wide in most of the denticles in $\mathrm{BP} / 1 / 5540$. The distal denticles of the incisors change sporadically in size along the carina in Cricodon. The mesial carina faces mesially whereas the distal carina is oriented linguodistally in the first two and distally in the last two upper incisors. The incisors are recurved, with a strongly convex mesial profile and a straight to slightly concave distal profile. Although the incisors from all BP specimens referred to Cricodon do not seem to be constricted at the cervix, a constriction appears to be present in the lower incisors of NHCC LB28, giving a spatulate outline to the crowns (Sidor \& Hopson, 2018). No information can be provided on the cross-sectional outline of the incisors, yet the labial is convex and the lingual flat in NHCC LB28 (Sidor \& Hopson, 2018). The root of the incisors of this specimen are long, taper apically and have an oval cross-sectional outline that is narrower mesiodistally than labiolingually (Sidor \& Hopson, 2018). 


\section{Canines}

801 The morphology of the canines of Cricodon is based on the upper and lower canines of

802 NHCC LB28, the upper canines of BP/1/6102, BP/1/5540 and NHMUK PV R3722, and the

803 lower canines of SAM-PK-5881a, as the canines are not preserved in the holotype (Crompton,

804 1955). As noted by Abdala, Hancox \& Neveling (2005) and Sidor \& Hopson (2018), both

805 carinae of the lower canine are denticulated (Figure 8E). The denticles are slightly bigger than

806 those of the incisors, with 6 to 7 denticles per $5 \mathrm{~mm}$ on the distal carinae at mid-crown in

$807 \mathrm{BP} / 1 / 6102$ and BP/1/5540 (Figure 8G-I), and 9 to 11 in NHCC LB28 (Sidor \& Hopson, 2018).

808 The denticle density of the smaller specimens NHMUK PV R3722 and SAM-PK-5881 $a$ vary

809 between 12.5 and 14 denticles per $5 \mathrm{~mm}$. The distal denticles are larger than the mesial ones in

$810 \mathrm{BP} / 1 / 6102, \mathrm{BP} / 1 / 5540$ and NHCC LB28, with a denticle density of 8.6 in the mesial carina and

8116.8 in the distal carina in $\mathrm{BP} / 1 / 6102$ (Figure $8 \mathrm{G}, \mathrm{H}$ ), 8 and 6.6 denticles/5mm in $\mathrm{BP} / 1 / 5540$, and

8129 to 11 and 15 to 19/5mm in NHCC LB28 (Sidor \& Hopson, 2018). Although Sidor \& Hopson

813 (2018) consider a difference in mesial and distal denticle densisty as a diagnostic feature in

814 Cricodon, we note, however, no size discrepancy between the mesial and distal denticles in the

815 upper and lower canines of NHMUK PV R3722 and SAM-PK-5881a. The denticles are

816 apicobasally elongated in the mesial and distal carinae of NHMUK PV R3722 and SAM-PK-

$8175881 a$, and apicobasally elongated to subquadrangular in the distal carina of BP/1/6102 and

$818 \mathrm{BP} / 1 / 5540$. Similar to the incisors, there is a sporadic variation in denticle size along the carina,

819 with a minute denticle followed by a much larger one in some portion of the carina. The

820 interdenticular space is particularly wide in the mid-crown denticles of the distal carina in

$821 \mathrm{BP} / 1 / 5540$ (Figure 8I). The cross-sectional outline is lenticular at mid-crown in the upper canines

822 of BP/1/6102 and NHCC LB28 (Sidor \& Hopson, 2018; figure 2C), and weakly salinon-shaped

823 in the lower canine of SAM-PK-5881a (Figure 8F) due to the presence of concave surfaces

824 adjacent to both carinae (Figure 8E). In the latter specimen, several transverse undulations are

825 present on the lingual surface of the lower canine at mid-crown (Figure 8E). Short transverse

826 undulations ('crenulations' sensu Sidor \& Hopson, 2018) are also present in the replacement

827 upper canines of NHCC LB28 (Sidor \& Hopson, 2018). Unlike the postcanines, the surface

828 texture of the incisors and canines appears to be irregular and non-oriented.

829 Upper gomphodont postcanines 
831 LB28 and SAM-PK-5881a. In NHCC LB28, the first two postcanines are sectorial, a condition

832 only seen in the putative juvenile specimens of Trirachodon BP/1/4534 and 4535 among

833 Gomphodontia (Sidor \& Hopson, 2018; C.H. pers. obs.). Both sectorial postcanines are

834 particularly small compared to the more distal ones, and diagonally oriented from the long axis

835 of the upper postcanine tooth row. They include a centrally positioned main cusp and a mesial

836 and distal main cusps (Sidor \& Hopson, 2018). The mesial main cusp occupies one fourth of the

837 main cusp length and projects at three-fourths of the crown (Sidor \& Hopson, 2018). The distal

838 main cusp is larger, longer (i.e., one half of the main cusp length) and better separated from the

839 main cusp (Sidor \& Hopson, 2018). This distal main cusp also lies more basal than the mesial

840 main cusp, around one half of the crown height. A small cingular cuspule is present on the

841 lingual side of the second postcanine, basal to the mesial valley separating the main cusp from

842 the mesial main cusp. The sectorial postcanines are swollen just beneath the cusps and decrease

843 in mesiodistal length towards the root (Sidor \& Hopson, 2018).

844 The upper postcanines 3 to 10 of NHCC LB28 are gomphodont, with their long axis

845 perpendicular to that of the tooth row. The postcanines increase in mesiodistal length,

846 labiolingual width and elongation up to the seventh tooth, then decrease in size and elongation

847 more distally (Sidor \& Hopson, 2018). The third and fourth upper postcanines are slightly

848 smaller and shorter than those from the ninth and tenth alveoli (Sidor \& Hopson 2018, table 1).

849 Likewise, postcanines eight to ten are significantly smaller than the three preceding postcanines,

850 and are labially deflected from them, so that their labiolingual width are in line with the labial

851 two thirds of postcanines five to seven. In apical view, all upper gomphodont postcanines are

852 roughly pear-shaped, with the labial third of the crown being significantly mesiodistally shorter

853 than the lingual two-thirds. Postcanines eight to ten, in fact, display a mesiodistal constriction

854 labially, at one third of the crown (Sidor \& Hopson, 2018). Each upper gomphodont postcanine

855 includes a labiolingually oriented and centrally positioned transverse crest comprising a labial,

856 lingual and central cusps, all separated by shallow valleys (Sidor \& Hopson, 2018). Minute

857 central accessory cusps are also present on the transverse crest, on each side of the central cusps,

858 as seen in the eighth unworn postcanine. The central cusp is labiolingually elongated and

859 lingually deflected, whereas the labial and lingual cusps are mesiodistally long and have a

860 lenticular cross-sectional outline, with their pointed extremity directed towards the central cusp 
861 (Sidor \& Hopson, 2018). The labial cusp, which is slightly longer than the lingual cusp, is the

862 tallest of the three cusps, whereas the lingual and central cusps share the same height (Sidor \&

863 Hopson, 2018). The upper gomphodont postcanines are ringed by mesial and distal cingula,

864 which enclose shallow and short mesial and distal basins, respectively. Both cingula extend on

865 the lingual two-thirds of the crown, the labial third being devoid of cingular cuspules. The mesial

866 cingulum lies more basal than the distal one and joins the base of the labiomesial ridge of the

867 labial cusp in postcanines 3 to 5 (Sidor \& Hopson, 2018). There are around six cuspules on each

868 mesial and distal cingula in postcanines 5 to 7 (eight on the mesial cingulum of the fifth

869 postcanine), with the largest cingular cuspules being in the lingual portion of the crown, adjacent

870 to the lingual cusp. Postcanines nine and ten, however, have a lower number of cingular cusps,

871 with five and three cuspules on the distal cingulum, respectively, and three and two in the

872 preserved portion of the mesial cingulum, respectively (Sidor \& Hopson, 2018). Similar to the

873 more mesial postcanines, the cingular cuspules of postcanines nine and tenth are restricted to the

874 lingual portion of the cingula, with the most lingual cuspules being the largest. As seen in the

875 holotype, the enamel surface texture of the upper gomphodont postcanines is apicobasally

876 oriented and braided (Sidor \& Hopson, 2018).

877 The first upper postcanine of SAM-PK-5881 $a$ is incomplete, worn and its labial part is

878 hidden by matrix, but clearly shows a gomphodont morphology. No mesial and distal basins can

879 be seen but they might have been worn out. The more distal upper postcanines, which are

880 relatively worn, share the same morphology and only their size and labiolingual elongation

881 increase distally. The mesial margin of the second and third upper postcanines is slightly

882 concave and follows the convexity of the distal margin of the preceding crown.

883 All isolated and in-situ upper gomphodont postcanines of the holotype UMCZ T905,

884 which belong to the distal half of the maxilla, are labiolingually expanded and ovate in outline,

885 with a CBR of 2.5, 2.3, 2 and 1.85 for the sixth, seventh, eighth and ninth left postcanines,

886 respectively. These morphology contrasts with those of the eighth to tenth upper postcanines of

887 NHCC LB28, in which CBR does not exceed 1.5 (Sidor \& Hopson 2018, table 1). The long axis

888 of postcanines sixth to nine of the holotype is roughly perpendicular to the long axis of the tooth

889 row, and only the last gomphodont tooth is labiomesially oriented. A striking feature of the upper

890 tooth row of Cricodon is the step-like disposition of the antepenultimate and penultimate

891 gomphodont postcanines, so that each of these two teeth is at the level of the base-crown or root 
892 of the preceding postcanine. This feature is also present in NHCC LB28 (Sidor \& Hopson 2018, 893 figure 3A), SAM-PK-5881b, SAM-PK-6212 and BP/1/6102. The upper gomphodont teeth are 894 slightly mesiodistally constricted at the labial one-third of the crown, giving an asymmetrical 895 outline of the postcanine in apical view, with the labial one-third of the tooth being shorter than 896 the lingual one (Figure 8J). A similar constriction can be seen in the ninth upper gomphodont 897 postcanine. The constriction is, however, slightly more pronounced on the distal surface of the 898 eighth postcanine and particularly well-developed on the distal margin of the sixth and seventh teeth. A wide concavity occupying the labial third of the crown can be seen on the distal surface of these two postcanines. The upper gomphodont postcanines include a low and centrally

901

902

903

904

905

906

907

908

909

910

911

912

913

914

915

916

917

918

919

920

921

922 positioned transverse crest, which is straight (Figure 8J), sigmoid or weakly parabolic in outline, with the concavity directed distally, in apical view. The transverse crest is made of a wide and lingually displaced central cusp bordered by two prominent labial and lingual cusps. No preserved upper postcanines bear fully complete labial, central and lingual cusps but the labial cusp appears to be as high as the central cusp, and as high as or slightly higher than the lingual cusp. As described by Crompton (1955), the labial and lingual ridge of the central cusp are denticulated, with the widest denticles being close to the apex (Figure $8 \mathrm{~N}$ ). The denticles of the central cusp are wide, with a weakly convex external margin. Denticles are also clearly visible on the mesial, distal and central ridges of the labial and lingual cusps, being particularly numerous and well-developed on the labiomesial and labiodistal ridges of the labial cusp (Figure 80). Unlike the central cusp, the denticles of the mesial, distal and central ridges of the labial and lingual cusps diminish in size apically. Similar to the denticles of incisors and canines, they are apicobasally elongated and change sporadically in size. Their external margin is, however, flattened or weakly convex (Figure 8O). The denticles on the labiomesial and labiodistal ridges either extend along the whole cusp up to its apex, or are restricted to the basal half of the cusp.

The mesial and distal cingula of the upper postcanines bear a large number $(>7)$ of small and well-delimited cingular cuspules along most, if not all, the width of the mesial and distal rims of the crown (Figure 8J, N). Unlike more mesial teeth, the distal cingulum of the ninth left upper postcanine does not extend to the labial cusp. The same can be said of the mesial cingulum of a loose left upper postcanine. The cingular cuspules sporadically vary in size along the crown, yet the widest cuspules are found in the central and/or lingual parts of the cingulum. We counted ten cingular cuspules on the mesial cingulum and seven distal in the ninth left upper gomphodont 
923 postcanine, and seven cuspules in the preserved labial half of the distal cingulum of the eight left

924 upper postcanine. The preserved portion of the mesial and distal cingula of the upper

925 gomphodont postcanine sampled by Hendrickx, Abdala \& Choiniere (2016) includes nine and

926 eleven cingular cuspules, respectively. Unlike to the ninth left upper postcanine, the widest

927 cingular cuspules of this isolated tooth are seen in the labial portion of the distal cingulum and in

928 the centrolabial and lingual parts of the mesial cingulum (Figure $8 \mathrm{~N}$ ). The mesial cingulum is

929 parabolic or weakly sigmoid and slopes basolabially in mesial view. The distal cingulum, on the

930 other hand, is symmetrically parabolic or biconcave. In two loose upper postcanines, the

931 denticulated labiodistal ridge of the labial cusp does not connect to the distal cingulum as the

932 lingual extremity of the latter extends on the labiodistal surface of the labial cusp, so that the

933 lingualmost distal cingular cuspules are situated apical to the labiodistal ridge.

934 The upper postcanines of the holotype and two specimens with the same specimen

935 number (SAM-PK-5881) largely follow the same morphology, yet a few differences can be

936 noted. Although the CBR of the largest upper postcanine (i.e., third right gomphodont

937 postcanine, CBR of 2.3) of SAM-PK-5881 $a$ falls within the range of values obtained in the

938 holotype, the upper postcanines of SAM-PK-5881 $b$ are more ovoid, with a CBR beyond 1.7. In

939 addition, the long axis of the last upper postcanine is not diagonally oriented in SAM-PK-5881b.

940 A deep and narrow concavity is also present in the central portion of the distal cingulum of the

941 two distalmost upper postcanines in this specimen, so that the cingulum of these crowns is

942 conspicuously biconvex (Figure 8M). The upper postcanine roots of SAM-PK-5881b, well

943 visible in mesial and labial views, are apicobasally long, three time the height of the crown in at

944 least the first gomphodont postcanine, and weakly taper apically. The cervical line separating the

945 crown from the root is roughly horizontal and particularly neat in this specimen due to the light

946 brown-orange coloring the crowns, which contrasts with the white color of the roots.

947 Lower gomphodont postcanines

948 As described by Crompton (1955), the upper and lower gomphodont postcanines of the

949 holotype roughly share the same morphology, but their crown base ratio is significantly lower in

950 the lower teeth, varying from 1.2 to 1.6 (Figure $8 \mathrm{~K}$ ). Similar to the upper postcanines, the first

951 lower postcanine, preserved in SAM-PK-5881 $a$, is weakly elongated labiolingually and includes

952 a transverse crest made of labial, central and lingual cusps and ringed by the mesial and distal

953 cingula (Figure 8L). The central cusp of the lower postcanine is, however, long and wide at its 
954 base and surrounded by merged mesial and distal basins, forming a subcircular groove. Three

955 cuspules are preserved on the lingual part of the mesial cingulum and four on the labial portion

956 of the distal one, and both cingula probably bore between six to eight cuspules. A mesiodistal

957 constriction is present at the cervix in the first postcanine, which is also constricted at the same

958 level on its labial surface. The morphology of the second to fifth lower postcanines of SAM-PK-

$9595881 a$ follow that of the more well-preserved distal teeth of the holotype. The size and CBR of

960 these teeth increase up to the fifth lower postcanines (CBR of 1.6), then decrease more distally.

961 The transverse crest is positioned at mid-length of the crown and perpendicular to the long axis

962 of the mandible in all lower postcanines of SAM-PK-5881 $a$. Only the fourth left lower

963 gomphodont tooth of this specimen preserves the distal cingulum formed by five cingular

964 cuspules, three labiolingually wide in the labial two-thirds and two small cuspules adjacent to the

965 unpreserved lingual cusp.

966 A comparative analysis of the upper and lower postcanines of the holotype provides

967 major differences between them. Similar to the postcanines of the cranium, the lower

968 gomphodont postcanines include a transverse crest composed of a labial, central and lingual

969 cusps ringed by the mesial and distal cingula. Yet, unlike the upper postcanines, large cingular

970 cuspules appear to be present linguomesially and labio- and linguodistally in the lower

971 gomphodont teeth (Figure 8K). These cuspules are most likely homologous to the putative

972 labiodistal, linguomesial and linguodistal accessory cusps of Langbergia. Similar to the upper

973 postcanines, the transverse crest is diagonally oriented from the long axis of the postcanine tooth

974 row in the last lower gomphodont tooth, and perpendicular to this axis in more mesial

975 postcanines, as seen in the eight right (Figure 8K) and what are assumed to be the fifth and sixth

976 left lower postcanines (n.b., Crompton (1955) interpreted these two teeth as corresponding to the

977 seventh and eight lower postcanines, yet based on their size and the height of the preserved

978 portion of the dentary, they are considered here as the fifth and sixth). Unlike the last upper

979 gomphodont postcanine, the transverse crest of the ninth lower postcanine is only mildly

980 diagonally oriented (Figure $8 \mathrm{~K}$ ). The central cusp forms a centrally positioned dome on the

981 transverse crest and, as the upper postcanines, its labial and lingual ridges are denticulated. It is

982 unknown whether the central, mesial and distal ridges of the labial and lingual cusps also bore

983 denticles in the eighth and ninth right lower gomphodont postcanines, but the mesial and distal

984 ridges of the labial cusp of the fifth? left lower postcanine is clearly serrated. The labial, central 
985 and lingual cusps all share the same height in the eighth right lower postcanine, the only one

986 having these cusps complete. Unlike the upper postcanines, the labiodistal surface is angular in

987 apical view in the eighth and ninth right lower postcanines, the best preserved of the mandible,

988 with the labiodistal margin connecting to the labial surface of the crown at a slightly obtuse angle

989 (Figure 8K). The mesial and distal margins of the fifth and sixth left and right lower postcanines

990 are, however, gently convex, with no angular corner. There are ten mesial and seven distal

991 cingular cuspules on the cingula in the ninth right lower postcanine, the only lower crown

992 preserving the majority of these elements. Both cingula extend along the whole width of the

993 postcanine, and the smallest cingular cuspules are found in the central portions of the cingulum.

994 The mesial and distal cingula are badly preserved in the fifth? and sixth? left lower gomphodont

995 teeth but the labialmost cingular cusps are particularly large on both cingula. In the fifth? left

996 postcanine, the labiomesial cingular cuspule is significantly larger than the labiodistal one, and

997 strongly protrudes apically, as seen in Langbergia. The distal cingulum is almost complete in this

998 tooth and preserves six cingular cusps increasing in width and height lingually. Both upper and

999 lower postcanines of the holotype show a braided and apicobasally oriented enamel surface

1000 texture best visible on the mesial and distal surface of the central cusp (Figure 8N).

1001 The preserved lower gomphodont postcanines of the referred specimens NHMUK PV

1002 R36800 and NHCC LB28, on the distal portion of a mandible, have some differences with those

1003 of the holotype. As in the latter, there is a decrease in size and elongation in the distalmost

1004 postcanines of the mandible in NHMUK PV R36800, yet the last two lower gomphodont

1005 postcanines are particularly small and subcircular in outline in NHMUK PV R36800. As seen in

1006 the last lower gomphodont tooth of the holotype, the long axis of the antepenultimate lower

1007 gomphodont postcanine is slightly diagonally oriented from the labial margin of the mandible.

1008 The long axis of the two last gomphodont lower postcanines is, however, perpendicular to the

1009 long axis of the mandibular tooth row. The transverse crest of the preserved lower postcanines

1010 comprises three high subtriangular cusps, of which the central cusp is the widest, even in the

1011 subcircular postcanines. The labial, lingual and central cusps appear to share the same height.

1012 Unlike the holotype, the labiodistal margin of the lower gomphodont postcanines of NHMUK

1013 PV R36800 is not angular but smoothly convex, whereas the linguodistal surface is concave in

1014 the third and second gomphodont teeth. Six distal cingular cuspules decreasing in size toward the

1015 central part of the cingulum can be counted in the antepenultimate gomphodont postcanine. 
1016 Likewise, there are at least seven mesial cingular cuspules in the last gomphodont postcanine,

1017 and their size diminishes towards the mid-width of the crown. As in the holotype, the enamel

1018 surface texture, well-visible on the surface of the central cusp of NHMUK PV R36800 is

1019 braided.

1020 Unlike the lower gomphodont postcanines of the holotype, the eighth right lower tooth,

1021 the only lower gomphodont postcanine preserved in NHCC LB28, is subrectangular in outline in

1022 apical view, with a nearly straight lingual surface and a biconvex distal margin (Sidor \& Hopson

1023 2018). As seen in the ninth right lower postcanine of the holotype, the crown shows a weakly

1024 diagonally oriented transverse crest made of labial, lingual and central cusps, as well as a notch

1025 in the labiodistal corner of the crown, behind the labial cusp. The central cusp is centrally

1026 positioned on the crown and 1.5 wider than the subequal width of the labial and lingual cusps.

1027 On the transverse crest, the labial is the highest cusp and the central the lowest (Sidor \& Hopson

1028 2018). The mesial and distal basins surround the transverse crest and are bounded by the cingula,

1029 respectively. The mesial cingulum is restricted to the labial two-thirds of the crown and

1030 comprises seven cingular cuspules whose width changes sporadically along the cingulum. From

1031 labial to lingual, there are three small cuspules, two large and elongate ones, and two minute

1032 cuspules on the mesial cingulum (Sidor \& Hopson 2018). The distal cingulum includes a larger

1033 number of cuspules (i.e., eight or nine), with the widest cuspules located in the labial portion of

1034 the cingulum distal to the labial cusp, as seen in the holotype. The mesial basin extends from the

1035 labiomesial surface of the lingual cusp to the labialmost mesial cingular cuspules, whereas the

1036 distal basin extends from the distal side of the lingualmost distal cingular cuspule to the notch on

1037 the labiodistal surface of the crown (Sidor \& Hopson 2018).

1038

1039 Sectorial postcanines

1040 An isolated sectorial postcanine (Figure 8P-Q) belonging to the holotype was illustrated

1041 and briefly described by Hendrickx, Abdala \& Choiniere (2016). This tooth most likely

1042 represents the shearing-type crown underlying the ninth right upper postcanine described by

1043 Crompton (1955). The postcanine consists of a mesiodistally long main cusp adjacent to a poorly

1044 developed mesial main cusp, and a well-developed subtriangular and apically pointed distal main

1045 cusp. Given this morphology, we assume that this is the distalmost tooth of the sectorial tooth

1046 row, probably the tenth right upper postcanine, as suggested by Crompton (1955). The mesial 
1047 and distal carinae are denticulated along the apical portion of the main cusp and the serrations

1048 extend across the apex of the cusp (Figure 8P-Q). The denticles are low, apicobasally elongated

1049 and show a symmetrically convex external margin. There is no trace of a cingulum on the labial

1050 or lingual margins of the crown.

1051 The lower sectorial postcanines partially visible in the left and right eleventh alveoli of

1052 NHCC LB28 and comprehensively describe by Sidor and Hopson (2018), provide for the first

1053 time information on the sectorial postcanines from the mandibular region of Cricodon. Unlike

1054 the upper postcanine of the holotype, the lower sectorial tooth is significantly longer, wider and

1055 lower. It is diagonally oriented at an angle of $45^{\circ}$ from the rest of the jaw and includes a large

1056 subtriangular main cusp, two smaller distal and mesial main cusps, and a distal accessory cusp

1057 (Sidor \& Hopson 2018). The mesial main cusp is a low but long convexity lying much lower

1058 than the distal main cusp. It is separated from the main cusp by a low valley and is slightly

1059 lingually deflected from the main and distal main cusps. The latter occupies the distal fourth of

1060 the crown and forms a low subtriangular prominence protruding vertically. It is followed by the

1061 distal accessory cusp, an even lower convexity on the distal margin of the distal main cusp.

1062 Unlike the preserved upper sectorial postcanine of the holotype, the lower sectorial tooth of

1063 NHCC LB28 includes a prominent lingual cingulum enclosing a shallow and labiolingually

1064 narrow lingual basin (Sidor \& Hopson 2018). The lingual cingulum comprises five cingular

1065 cuspules, i.e., a small mesialmost one followed distally by three mesiodistally long cuspules,

1066 which increase in length distally (Sidor and Hopson 2018, figure 5F). A fifth cingular cuspule is

1067 present at the distal extremity of the cingulum but too incomplete to provide information on its

1068 size. The cingulum extends from the mesial main cusp to the distal accessory cusp, as revealed

1069 by the presence of a cingular cuspule distal to the distal accessory cusp in the left postcanine

1070 (Sidor \& Hopson 2018). Two lower sectorial postcanines are also present in NHMUK PV

1071 R36800 but they are poorly preserved. The first sectorial postcanine is being replaced by a

1072 mesiodistally elongated gomphodont? postcanine with a narrow and apically pointed lingual

1073 cusp and a much longer and higher central cusp. Both lower sectorial postcanines include a large

1074 recurved main cusp bounded mesially and distally by small mesial and distal main cusps.

1075 Although the mesial main cusp of the first sectorial tooth appears to form a relatively large

1076 convexity, that of the second sectorial postcanine corresponds to a small protuberance at one

1077 third of the crown height, slightly more basal than the distal main cusp. The latter is unpreserved 
1078 in the first sectorial postcanine and incomplete in the second one. Based on the preserved portion

1079 of the cusp, the distal main cusp is much longer and more prominent than the mesial main cusp

1080 in this tooth. No lingual cingulum or denticulated carinae appear to be visible in these two lower

1081 sectorial postcanines but their presence cannot be ruled out.

1082 Crown microstructure

1083 Hendrickx, Abdala \& Choiniere (2016) recently explored the enamel and dentin

1084 microstructure in two isolated gomphodont and sectorial postcanines of the holotypic specimen

1085 of Cricodon metabolus. This study revealed that the enamel microstructure of this taxon is

1086 prismless and composed of discontinuous columnar divergence units (SCE). Abundant tubules

1087 and around 19 irregularly spaced striae of Retzius were also observed in the enamel layer, which

1088 is 11.5 times thicker in gomphodont postcanines $(176.5 \mu \mathrm{m}$ in average in horizontal section)

1089 compared to sectorial teeth $(15.4 \mu \mathrm{m}$ in average in horizontal section). The dentin layer of the

1090 Cricodon postcanine includes a large amount of tubules and approximately 100 incremental

1091 growth lines of von Ebner were counted in the gomphodont tooth.

\section{Trirachodon berryi Seeley, 1894}

1093 Holotype: NHMUK PV R3579 (from Lady Frere, subzone B, Cynognathus AZ, South Africa),

1094 the mesial portion of the cranium with poorly preserved teeth.

1095 Referred dental material: from Burghersdorp, subzone B, Cynognathus AZ, South Africa: AM

1096434 (Cragievar locality), 461 (holotype of Trirachodon kannemeyeri), BP/1/3775 (Cragievar

1097 locality), NHMUK PV R2807, SAM-PK-987; from Aliwal North, subzone B, Cynognathus AZ,

1098 South Africa: NHMUK PV R3306, R3307, R3350, R3721 (holotype of Trirachodon browni),

1099 SAM-PK-873 (holotype of Trirachodon minor), 5880; from Winnaars Baken, subzone B,

1100 Cynognathus AZ, South Africa: BP/1/3511, 4258, 5050, SAM-PK-12168 (= K5821), K170,

1101 K171, K7888; NMQR 1399; from Lady Frere, subzone B, Cynognathus AZ, South Africa: BSP

11021934 VIII 21, 22, 23; from Rouxville, subzone A, Cynognathus AZ, South Africa: BP/1/4658,

11034661 (Leewspuit locality), CGP/1/33 (Moerbeidal locality), SAM-PK-K10157, K10161,

1104 K10176, K10207, K10411; from Kestell, subzone A, Cynognathus AZ, South Africa: NMQR

1105 3279; from Bergville, subzone A, Cynognathus AZ, South Africa: CGP/1/79 (= CGP JNN 2000-

1106 7-2A); from unknown localities in South Africa: SAM-PK- K142, K4801, K4803, NMQR 122;

1107 from Etjo Mountain, Omingonde Formation, Namibia: GSN R327. 
1108 Occurrence: Lady Frere, Chris Hani District, Emalahleni Municipality, South Africa;

1109 Burghersdorp, Aliwal North, and Winnaars Baken, Joe Gqabi District, Walter Sisulu

1110 Municipality, South Africa; Lemoenfontein 44 and Moerbeidal, Rouxville, Xhariep District, Free

1111 State Province, South Africa; Bergville, Thabo Mofutsanyane district, Maluti-a-Phofung

1112 Municipality, Free State Province, South Africa; western buttress of Etjo Mountain,

1113 Otjozondjupa Region, Namibia.

1114 Horizon: subzone A and B of the Cynognathus AZ, Burgersdorp Formation, Beaufort Group,

1115 Karoo Supergroup; lower? assemblage of the upper Omingonde Formation.

1116 Age: late Olenekian-early Anisian, Middle Triassic.

1117 Dental formula: $14 / 3: \mathrm{cl} / 1$ : pc6-12/8-9 (cpc1 : gpc4-10 : spc0-2).

1118 Dental morphology: The dentition of Trirachodon has received particularly little attention

1119 compared to other gomphodonts, and information on the dental anatomy of this taxon mostly

1120 rely on the rather limited descriptions and illustrations of Seeley (1894) and Broili \& Schröder

1121 (1934). Firsthand examination of Trirachodon specimens with the best-preserved dental material

1122 now allows for a comprehensive description of the dentition of this taxon. Dental differences in

1123 the specimens referred to T. berryi and T. kannemeyeri, considered to be separated species by

1124 several authors (e.g., Sidor \& Hopson, 2018), are also considered in the discussion.

1125 Incisors

1126 The incisors, well-preserved in the specimens CGP/1/79 (= CGP JNN 2000-7-2A),

1127 SAM-PK-K171, SAM-PK-12168 and BP/1/4658, have denticulated mesial and distal carinae at

1128 least in the first upper and lower incisors of SAM-PK-12168 (Figure 9A-C) and SAM-PK-K171,

1129 respectively. Mesial denticles are also visible in the third upper incisor of BP/1/4658 and an

1130 isolated upper? incisor of CGP/1/79. No denticles could be seen in the lower incisors of

$1131 \mathrm{BP} / 1 / 4658$ and 4661 and some upper and lower incisors of CGP/1/79. It is unknown whether the

1132 absence of denticles in some upper and lower incisors is a genuine condition of Trirachodon.

1133 The presence of unserrated canines in some specimens would, however, suggests so. The mesial

1134 denticles of SAM-PK-12168 are well-separated, apicobasally elongated and almost

1135 subquadrangular at the base of the carina (Figure 9B), whereas those of CGP/1/79 are poorly

1136 defined, particularly low and apicobasally subrectangular all along the carina. As other

1137 diademodontids and trirachodontids, they sporadically change in size and their external margin is

1138 weakly symmetrically to asymmetrically convex. Unlike Cricodon, which features much larger 
1139 denticles, there are 6 and 10 mesial denticles per $\mathrm{mm}$ in the Trirachodon specimens SAM-PK-

114012168 and BP/1/4658, respectively. The largest denticles are situated apically, and given the fact

1141 that the apex and basal portions of the crown is missing, it is unknown whether the denticles

1142 reached the apex and cervix. The distal denticles of the first and second incisors of SAM-PK-

114312168 are incipiently developed and form poorly delimited convexities changing sporadically in

1144 size along the carina (Figure 9C). These denticles appear to extend well-above the cervix and get

1145 flared at mid-crown. Some upper and lower incisors are weakly mesiodistally constricted at the

1146 cervix, conferring a folidont (i.e., leaf-shaped) morphology to the crown. The cross-sectional

1147 outline of the upper and lower mesial incisors is D- to salinon-shaped, with the mesial carina

1148 positioned mesially and the distal carina facing linguodistally (Figure 9D, E). The incisors from

1149 the distal half of the jaw appear to have a more semi-circular cross-sectional outline, with the

1150 distal carina facing distally. Similar to Langbergia, a concave surface adjacent to the distal

1151 margin of the crown is visible on the labial surface of the second? upper incisor of SAM-PK-

115212168.

1153 Canines

1154 The canines of the specimens of Trirachodon CGP/1/79, SAM-PK-K171, 12168, K10157

1155 and $\mathrm{BP} / 1 / 4658,4661$ and 3511 have both mesial and distal carinae denticulated. Unserrated

1156 canines are, however, present in the specimens BSP 1934 VIII 21 and 22 as well as SAM-PK-

1157 K7888. The denticles are minute, sometimes barely discernable, and always apicobasally

1158 elongated (Figure 9H). They sporadically change in size along the carina and have symmetrically

1159 to asymmetrically convex external margins. In some specimens, the denticles are incipiently

1160 developed or restricted to a small portion of the crown (e.g., BP/1/3511, SAM-PK-12168). The

1161 denticles of the canines are larger than those of the incisors, with mesial and distal denticle

1162 density ranging from three to nine denticles per $\mathrm{mm}$ in the canines. In $\mathrm{BP} / 1 / 4658$, the mesial

1163 carina is lingually deflected whereas the distal carina is centrally positioned on the distal margin

1164 of the crown. An apicobasally long concave surface adjacent to the distal carina is clearly present

1165 on the labial and sometimes lingual sides of the canine in BSP 1934 VIII 22, CGP/1/79, SAM-

1166 PK-K171, 12168, K10157 and BP/1/4658, 4661. A similar concave surface adjacent to both

1167 carinae on the lingual side can be seen in the lower canine of SAM-PK-K171. Transverse

1168 undulations and several faint longitudinal ridges can be observed on the labial surface of the

1169 right canine of BP/1/4661 (Figure 9F, G). Flat or mesiodistally convex surfaces meeting at acute 
1170 corners are instead visible on the labial surface of one or both canines of SAM-PK-12168 and

$1171 \mathrm{CGP} / 1 / 79$. The cross-sectional outline of the incisor is elliptical, lenticular or salinon-shaped at

1172 mid-crown, indicating some important variation in cross-sectional outline in Trirachodon. The

1173 enamel surface texture of BP/1/4661 and CGP/1/79 is clearly braided and apicobasally oriented,

1174 curving basally adjacent to the carinae (Figure 9G). The texture of the enamel appears to be

1175 smooth in the canines of the other specimens.

1176 Upper gomphodont postcanines

1177 The morphology of the upper postcanines is based on the specimens BSP 1934 VIII 21,

1178 SAM-PK-K171, SAM-PK-K4801, NHMUK PV R3307 and BP/1/4658. As in Cricodon and

1179 Sinognathus, the upper postcanines are labiolingually expanded and ovate in outline. They

1180 increase in size and elongation distally up to the antepenultimate or penultimate gomphodont

1181 tooth. The first upper postcanine is the smallest and, with a CBR ranging from 1.1 to 1.6, the

1182 least labiolingually elongated of the upper gomphodont tooth row. This tooth is missing, badly

1183 preserved or in occlusion and obscured by the lower postcanines in all specimens examined first

1184 hand but CT-scan data of AM 461 provides some information on its morphology. The tooth is

1185 subconical, i.e., the crown is simple, slightly labiolingually elongated, labiolingually constricted

1186 at the cervix and bears a centrally positioned central cusp but no labial and lingual cusps nor a

1187 mesial and distal cingula.

1188 The CBR of the more distal upper postcanines varies from 1.4 to 2.4 and the outline of

1189 the crown in apical view only slightly changes along the tooth row. In BSP 1934 VIII 21 and

$1190 \mathrm{BP} / 1 / 4658$, the postcanines from the mesial half of the upper postcanines are reniform (sensu

1191 Hendrickx, Mateus \& Araújo, 2015), with a weakly to strongly concave mesial margin. This

1192 outline results from the presence of a distal 'shouldering' between each tooth, which are in close

1193 contact in these two specimens. In SAM-PK-K171 and SAM-PK-K4801, the reniform outline is

1194 restricted to the third and fourth upper postcanines, yet the mesial margin is only weakly concave

1195 in the fourth tooth. Although the distal margin of the upper postcanines from the mesial half of

1196 the Trirachodon crown is typically convex, this distal margin is sigmoid in BSP 1934 VIII 21

1197 due to the presence of a narrow concavity on the lingual third of the distal surface of the crown.

1198 This dental feature is, however, restricted to this specimen. The more distal upper postcanines of

1199 Trirachodon are roughly ovate in outline, but a weak mesiodistal constriction occurs at the labial

1200 third of the crown in SAM-PK-K171, SAM-PK-K4801, and NHMUK PV R3307 (Figure 9I, K- 
1201 M). This constriction, created by the presence of a concavity on the labial third/half of the distal 1202 margin of the postcanine, leads to an asymmetrical crown-shape, in which the labial third is 1203 shorter than the lingual two-thirds of the postcanine (Figure 9I, K-M). Such a concavity is 1204 particularly pronounced in the last upper gomphodont postcanines. It is, however, absent in the postcanines of BSP $1934 \mathrm{VIII} 21$ and BP/1/4658 so that the upper postcanines are subsymmetrical in shape in these two specimens (Figure 9J).

As other trirachodontids, the upper postcanines of Trirachodon consist of a mesial and distal cingula extending on the mesial and distal rims of the crown as well as a labiolingually elongated transverse crest. The latter is made of a labial, central and lingual cusps and bounded mesially and distally by the wide mesial and distal basins, respectively (Figure 9I-K). The transverse crest is centrally positioned on the crown in the postcanines from the mesial half of

1212 the upper tooth row in BP/1/4658, SAM-PK-K171 and NHMUK PV R3307, and distally

1213 deflected in BSP 1934 VIII 21. Unlike Cricodon, the transverse crest runs diagonally on the

1214 crown in the distalmost gomphodont postcanines. The diagonal orientation of the transverse 1215 crest, particularly noticeable in NHMUK PV R3307, SAM-PK-K171 and SAM-PK-K4801,

1216 results from the distal deflection of the labial cusp, which points apicodistally in these specimens

1217 (Figure 9I, K-M). The central cusp is closer to the lingual cusp in most specimens, and centrally

1218 positioned on the transverse crest in SAM-PK-K4801. The central cusp is typically

1219 apicolingually inclined in distal view, so that the valley bordering the central cusp on the

1220 transverse crest is deeper between the central and labial cusps. The latter consists of a three-faced

1221 pyramidal structure, in which the edges form the labiomesial, labiodistal and labiocentral ridges.

1222 The lingual cusp shares the same shape, with a labiodistally shorter linguocentral ridge. Similar

1223 to Cricodon, the labiomesial and labiodistal ridges of the labial cusp are denticulated in at least

1224 one postcanine of SAM-PK-K171 and SAM-PK-K4801. The linguomesial, linguodistal,

1225 centrolabial and centrolingual ridges do not, however, appear to have serrations. The mesial and

1226 distal cingula typically bear a low number (i.e., $<6$ ) of cingular cuspules restricted to a certain

1227 portion of the cingulum or along the whole width of the cingulum (Figure 9M-N). We counted 1228 three, four and five cingular cuspules on the mesial cingulum of the best-preserved postcanines 1229 of NHMUK PV R3307, SAM-PK-K171 and BSP 1934 VIII 21, respectively, and three to four, 1230 four, five, and six to seven distal cingular cuspules in SAM-PK-K171, BSP 1934 VIII 21, SAM-

1231 PK-K4801 and NHMUK PV R3307, respectively. The size of the cingular cuspules varies 
1232 sporadically along the cingulum and does not follow any pattern along the tooth row. We,

1233 however, note that the widest cingular cuspules are often located in the middle or lingual part of

1234 the crown. When restricted to a certain portion of the postcanine, the cingular cuspules variously

1235 occupy the central, lingual or labial part of the crown. Large cingular cuspules have been

1236 observed in the labiomesial, labiodistal, linguomesial and linguodistal sides of the fully complete

1237 postcanines. Given the fact that none of these large cingular cuspules are present in all

1238 postcanines of the tooth-row, they may not be homologous to the accessory cusps of some

1239 gomphodonts. The presence of labiomesial, labiodistal, linguomesial and linguodistal accessory

1240 cusps in the upper gomphodont postcanines Trirachodon cannot, however, be ruled out.

1241 The morphology of the distalmost upper gomphodont postcanine of the holotype and

1242 referred specimens NHMUK PV R3579 and BSP 1934 VIII 21, respectively, which represent the

1243 specimens of Trirachodon with the highest number of gomphodont postcanines (i.e., 11 and 12,

1244 respectively), departs from that of the more mesial upper postcanines. In NHMUK PV R3579,

1245 the last postcanine is half the size of the preceding teeth, elliptical, long and short (CBR of 1.3)

1246 and displays a centrally positioned transverse crest ringed by the mesial and distal basins and

1247 cingula. The transverse crest includes a long and wide labial cusp, a lingually displaced central

1248 cusp and a narrow lingual cusp. The labial cusp, of which the base is preserved, was the largest

1249 and likely the highest of all three, while the central and lingual cusps appears to have the same

1250 height. The mesial cingulum seems to encompass four cingular cuspules, in which the widest,

1251 which may correspond to the labiomesial accessory cusp, is directly mesial to the labial cusp.

1252 Two particularly wide distal cingular cusps adjacent to the labial and lingual cusps may also

1253 represent the labio- and linguodistal accessory cusps of other gomphodont upper postcanines.

1254 Unlike NHMUK PV R3579, the last upper postcanine of BSP 1934 VIII 21 appears to be

1255 strongly labiolingually elongated and includes a long, high and lingually deflected central cusp

1256 and a much shorter, apically pointed labial cusp (Figure 9O). Unlike NHMUK PV R3579 and

1257 more mesial gomphodont postcanines, this tooth does not have a lingual cusp nor a distal basin

1258 and cingulum. Given that the mesial portion of the tooth is still embedded in matrix, it is

1259 unknown whether the mesial basin and cingulum were present or not. The root is twice as long as

1260 the crown at mid-width of the tooth, tapers apically and has a basolingually inclined lingual

1261 margin and sub-vertical labial border (Figure 90). The basolingual portions of the crown and 
1262 root of BSP 1934 VIII 21 also show an extensive parallelogram-shaped wear facet on its distal

1263 surface.

1264 Lower gomphodont postcanines

1265 Well-preserved lower gomphodont postcanines are present in SAM-PK-K171, SAM-PK-

$1266 \mathrm{~K} 4801$ and BP/1/4658. The first postcanine, only seen in BP/1/4658 (Figure 10D), is

1267 significantly smaller than the more distal postcanines, as witnessed by the particularly small size

1268 of the alveoli in SAM-PK-K171. Its morphology does not differ from that of more distal

1269 gomphodont postcanines (Figure 10D). Similar to Langbergia and unlike Cricodon, the long axis

1270 of the lower gomphodont postcanines is linguomesially oriented and never perpendicular to the

1271 mandibular tooth row (Figure 10A-C). The linguomesial inclination of the first and last

1272 gomphodont teeth is more pronounced than the others in BP/1/4658 and SAM-PK-K171. The

1273 lower postcanines decrease in size from the middle of the mandibular tooth row in $\mathrm{BP} / 1 / 4658$, so

1274 that the last gomphodont tooth is as small as the first postcanine. As in Langbergia and unlike

1275 Cricodon, such decrease in size occurs from the penultimate lower postcanine in SAM-PK-K171

1276 and SAM-PK-K4801. The lower gomphodont postcanines share the same morphology than that

1277 of upper postcanines, yet they are symmetrical in the transverse and sagittal axes and narrower,

1278 with a CBR varying from 1.3 to 1.6 (Figure 10A-C). The central cusp is centrally positioned on

1279 the crown and occupies most of the transverse crest width. As in other trirachodontids, this cusp

1280 is bordered by the labial and lingual cusps, and the three cusps all share the same height. The

1281 mesial and distal basins are deep and both surround the dome-like central cusp mesially and

1282 distally, respectively (Figure 10A-C). The mesial and distal cingula are symmetrically concave

1283 and parabolic in shape in mesial and distal views. They include a variable number of cingular

1284 cuspules extending between the labial and lingual cusps. There are two to three and four cingular

1285 cuspules on the mesial cingulum in the best-preserved lower postcanines of SAM-PK-K171

1286 (Figure 10A, E) and SAM-PK-K4801 (Figure 10B-C), respectively, and four distal cingular

1287 cuspules in both specimens. Six to seven cingular cuspules appear to be present on the distal

1288 cingulum of the fifth right and left postcanines of $\mathrm{BP} / 1 / 4658$, respectively, while more than

1289 seven distal cuspules were present on the sixth left lower tooth. Unlike Cricodon, the widest

1290 cuspules typically occur in the center or labial portions of the crown. The last lower gomphodont

1291 postcanine of SAM-PK-K4801 (Figure 10C) has the peculiarity of having a particularly high

1292 transverse crest, higher than that of more mesial postcanines. The central cusp strongly protrudes 
1293 apically and is higher than both the labial and lingual cusps. The distal cingulum comprises six

1294 well-separated cingular cuspules whereas the mesial cingulum includes three cuspules in its

1295 labial half (Figure 10C). The last lower postcanine of SAM-PK-K171 and BP/1/4658 share the

1296 same morphology with the other lower postcanines. The enamel texture of Trirachodon's upper

1297 and lower postcanines, clearly visible on the mesial and distal surfaces of the central cusp, is

1298 braided and apicobasally oriented.

1299 Sectorial postcanines

$1300 \quad$ One or two upper and lower sectorial teeth are borne by the specimens SAM-PK-K4801, 1301 SAM-PK-K171, SAM-PK-12168, BP/1/4658, BP/1/4661, BP/1/3511, and CGP/1/79. The first

1302 right upper sectorial tooth of SAM-PK-K4801 is simpler and shorter than the second one (Figure 1303 10F). It includes a main distally positioned and recurved cusp followed mesially by a smaller 1304 mesial main cusp. This mesial main cusp is symmetrically convex and projects from the mesial 1305 surface at one third of the crown. The single or distalmost upper sectorial postcanine shares the 1306 same morphology, i.e., it comprises a main cusp, a mesial main cusp at one half of the crown and 1307 two distal cusps, the distal main and distal accessory cusps, both occupying the distal third of the 1308 crown (Figure 10F). The main cusp typically occupies the two-fifths to three-fifths of the crown 1309 length. It consists of a subtriangular, apicodistally pointed or strongly recurved (Figure 10F) 1310 projection, and its external margin is strongly parabolic and asymmetrically convex. The mesial 1311 main cusp can be minute and forms a tiny bump on the mesial surface of the main cusp, or a 1312 large, apically pointed projection similar in size or slightly longer than the distalmost accessory 1313 cusp. The distal main and distal accessory cusps are straight, decrease in size distally, and either

1314 point apically or apicodistally. The distal main cusp either forms a low, weakly pointed and 1315 mesiodistally long convexity or a high and mesiodistally short projection. No cingular cuspule 1316 were observed on the labial and lingual margin of the upper sectorial postcanines of

1317 Trirachodon. Variation in the morphology of the last sectorial appears to occur between the left 1318 and right sides of the cranium, as seen in SAM-PK-K4801. In this specimen, the mesial main 1319 cusp of the last upper sectorial postcanine consists of a poorly-developed bump on the right side 1320 (Figure 10F) and a large and strongly protruding projection on the left side. Likewise, the distal 1321 main cusp of this sectorial postcanine is mesiodistally short and high on the right side (Figure 1322 10F) and long and low on the left side. 
1323 The morphology of the single or first lower sectorial postcanine is significantly different

1324 from that of the upper sectorial teeth. The crown is particularly wide, especially in $\mathrm{BP} / 1 / 4658$

1325 (CBR of 0.6 to 0.65 ). The crown consists of a large and high apically pointed main cusp

1326 bordered by two small apically projected mesial and distal main cusps (Figure 10I). The distal

1327 main cusp is larger than the mesial one in SAM-PK-K171 and BP/1/4658. The three cusps are

1328 bounded lingually by a mesiodistally concave cingulum made of minute cingular cuspules

1329 (Figure 10G). This lingual cingulum either extends along the whole length of the crown or is

1330 restricted to the mesial half of the postcanine, as seen in SAM-PK-K171. A labial cingulum is

1331 also present on the lower sectorial postcanine and occupies the whole length, as seen in the right

1332 lower postcanine of BP/1/4658 (Figure 10I), or a small portion of the distal surface of the crown 1333 only, as in SAM-PK-K4801 (Figure 10H).

1334 The second lower postcanine, only well-preserved on the left jaw of BP/1/4658 (Figure

1335 10I-J), is narrower, with an CBL of 0.54 . The tooth includes a main cusp occupying slightly

1336 more than the mesial half of the crown, as well as a distal main cusp and a distal accessory cusp.

1337 No mesial main cusps appear to be present in the second left and right lower sectorial

1338 postcanines. The distal main cusp points apically and is not recurved (Figure 10I-J). The main

1339 cusp, of which only the base is visible, was likely significantly higher than the distal main cusp

1340 on the left side of the jaw. The distal main cusp of the second right sectorial postcanine is,

1341 however, much larger and probably only slightly lower than the main cusp. The distal main cusp

1342 consists of a symmetrically parabolic convexity while the distal accessory cusp is a minute and

1343 pointed projection (Figure 10I-J). A lingual cingulum bearing several minute cuspules extends

1344 along the whole length of the crown (Figure 10J). The second right lower sectorial postcanine of

$1345 \mathrm{BP} / 1 / 4658$ is significantly shorter than the preceding one (65\% smaller) and is being replaced by

1346 another sectorial postcanine (Figure 10I-J). This tooth erupts distally from the second sectorial

1347 postcanine, and its morphology is reminiscent to that of the upper sectorial postcanines in that it

1348 has an apically recurved main cusp. No mesial or distal main cusps appear to be present on this

1349 erupting postcanine but they might be hidden by the matrix. The main cusp has an unserrated

1350 mesial carina twisting lingually and no cingulum is present at the base of the lingual surface of

1351 the crown (Figure 10J).

1352 Dental morphotypes in Trirachodon berryi 
1353 As noticed by previous authors such as Sidor and Hopson (2018), two dental

1354 morphotypes of Trirachodon can be observed. AM 461, SAM-PK-K171, SAM-PK-12168,

1355 NHMUK PV R3307 (included in 'Cricodon kannemeyeri' by Sidor and Hopson (2018), see

1356 Discussion below), as well as CGP/1/79, SAM-PK-K4801, BP/1/4661 and BP/1/3511, share a

1357 combination of dental features not seen in other specimens of Trirachodon, i.e., denticulated

1358 canines, less than ten upper postcanines comprising one or two upper and lower sectorial teeth,

1359 transversely asymmetrical distal upper gomphodont postcanines, in which the lingual half of the

1360 crown is longer than the labial one, a diagonally oriented transverse crest on the crown, and a

1361 slightly apicodistally pointed labial cusp. These specimens indeed differ from NHMUK PV

1362 R3579, BSP 1934 VIII 21 to 23 and SAM-PK-K7888 (classified among Trirachodon berryi by

1363 Sidor and Hopson (2018), see below), characterized by the following dental features: unserrated

1364 canines, more than nine upper postcanines, no sectorial teeth, transversely symmetrical distal

1365 upper postcanines (i.e., labial and lingual halves of the crown of the same length, apically

1366 pointed labial cusp, and non-diagonally oriented transverse crest on the crown) and last upper

1367 gomphodont postcanine being significantly smaller than the preceding tooth.

1368 It should, however, be noted that the specimen NHMUK PV R3307 does not have a

1369 sectorial postcanine on the right portion of the maxilla while a particularly low number of upper

1370 postcanines (i.e., seven) is present in this specimen. The absence of a diagonally oriented

1371 transverse crest in the upper postcanines of BSP 1934 VIII 21 could also be explained by the fact

1372 that the labial cusp of some gomphodont postcanines is worn out. All specimens classified in the

1373 morphotype of Trirachodon berryi do not preserve incisors and only two of them (i.e., BSP 1934

1374 VIII 21, SAM-PK-K7888) bear canines. The latter are, however, incomplete and/or badly

1375 preserved and the absence of denticles could be explained by the fact that they have been worn

1376 out from the carinae due to the advanced age of the individuals (see Discussion). We also note

1377 that $\mathrm{BP} / 1 / 4658$ appears to represent a transitional form between the dental morphotypes of $T$.

1378 berryi and 'T. kannemeyeri', as this specimen includes finely denticulated canines,

1379 subsymmetrical and non-mesiodistally constricted upper gomphodont postcanines with a non-

1380 diagonally oriented transverse crest and a complete distal cingulum (present at least in the fifth

1381 right upper postcanine), penultimate and last upper gomphodont postcanines with a CBR $>2$,

1382 seven upper postcanines, as well as one upper sectorial postcanines and two lower tricuspid

1383 sectorial postcanines bearing a lingual cingulum. We propose that the dental differences between 
1384 these two morphotypes are ontogenetic and not interspecific, as some authors suggest, an

1385 hypothesis developed in the Discussion section.

\section{Sinognathus gracilis Young, 1959}

1387 Holotype: IVPP V2339, an almost complete skull.

1388 Occurrence: Peipanching Shihpi, Wuhsiang-Yüshe area, Shanxi Province, China.

1389 Horizon: upper Ermaying Formation.

1390 Age: late Anisian, Middle Triassic.

1391 Dental formula: $\mathrm{i} 4 / 2: \mathrm{c} 1 / 1: \mathrm{pc6} / 7$ (cpc? : gpc5 : spc?).

1392 Dental morphology: The dentition of Sinognathus gracilis, briefly described by Young (1959)

1393 due to the lack of preparation of the skull, has received a relatively good description from Sun

1394 (1988) following a re-preparation of the postcanines teeth. Firsthand examination of the holotype

1395 provides a few additional details on the dental material of this taxon.

\section{Incisors and canines}

1397 The incisors, poorly preserved in IVPP V2339, do not show a constriction at the level of 1398 the cervix (Figure 11A). Minute denticles can be seen at the base and apex of the distal carina of 1399 the fourth left upper incisor (Figure 11B, C). We counted eight denticles per mm on this tooth.

1400 No other incisor appears to bear serrations. The cross-section through the root base of the first 1401 left upper incisor is subcircular (Figure 11D). The root base of the left and right upper canines, 1402 the crown base of the right lower canine as well as the root, crown base and a small portion of 1403 the mesial part of the left lower canine are preserved (Figure 11E, F). None of these portions of

1404 the canines show serrations (Figure 11F) and it is unknown whether denticles are unpreserved or 1405 absent. The cross-sectional outline through the root base of the left upper canine is roughly 1406 lenticular (Figure 11G). The left lower canine is mostly projected apically, whereas the right 1407 canine appears to be weakly procumbent. The root base of the left lower canine is slightly longer 1408 than the crown base. The root is two-thirds the height of the crown and tapers basally (Figure 1409 11E).

\section{Gomphodont postcanines}

1411 All postcanines are in occlusion. Information on their morphology can, however, be

1412 extracted from the right upper postcanines, of which the lingual portion has been prepared and is 1413 visible in medioventral view (Figure 11J-L), and from a mid-crown sagittal section through the 
1414 upper and lower postcanines of the left jaw side of the skull (Figure 11H, I, N). Some parts of the

1415 labial portion of the right lower postcanines can also be seen in labial view (Figure 11M). As

1416 described by Sun (1988), the upper postcanines are labiolingually elongated and consist of a

1417 labiolingually oriented and slightly distally positioned transverse crest. The latter is apically high

1418 and comprises labial, central and lingual cusps of the same height. A small valley separates the

1419 central and lingual cusps in the best-prepared upper postcanine (Figure 11J-L). The central cusp

1420 is wide, the widest of the three cusps, and centrally located on the transverse crest. The mesial

1421 and distal ridges, visible in the sagittal cross-section through the fourth left upper postcanines,

1422 bound the mesial and distal margins of the gomphodont postcanines (Sun, 1988). These ridges

1423 are not visible in the lingual portion of the exposed upper postcanines, yet poorly preserved

1424 cingular cuspules appear to be present on what would then be the distal cingulum of the third

1425 upper postcanine (Figure 11K). A linguomesial accessory cusp may have been present in the

1426 upper gomphodont postcanine (Figure 11K). No other accessory cusps are visible in the upper

1427 postcanines. The mesial basin is longer than the distal one, and both basins are horizontal and

1428 shallow.

1429 Few details on the lower gomphodont postcanines of the holotype can be observed. They

1430 are labiolingually elongated and bear an apically high transverse crest bounded by the mesial and

1431 distal basins. Both basins are mesiodistally concave, yet the distal basin is horizontally

1432 positioned and shallow whereas the mesial basin is basally inclined and shorter. The transverse

1433 crest is slightly mesially deflected and includes labial, central and lingual cusps roughly sharing

1434 the same height. A faint mesial ridge is present at the rim of the lower postcanine. Remnants of

1435 mesial cuspules appear to be present on this ridge (Figure 11M), but future CT-data of better

1436 preserved postcanines will corroborate this information. Based on the sagittal cross-section

1437 through the left lower postcanines, no distal ridge or cingulum appears to be present.

1438 The sixth right upper postcanine was interpreted as a sectorial by Sun (1988). The crown

1439 is, however, incomplete, with the labial and central portion missing, and only an horizontal

1440 cross-section through the root can be seen in ventromedial view (Figure 110). A closer look at

1441 the cross-sectional outline reveals that the sixth upper tooth was a gomphodont and not a

1442 sectorial postcanine. This is corroborated by the fact that the preserved portion of this crown

1443 shows a labiolingually oriented transverse crest in the middle of the crown (Figure 11O-P),

1444 whereas no sectorial postcanines bear such a ridge in gomphodont cynodonts. In addition, 
1445 sectorial teeth/alveoli are typically labially positioned from the long axis of the tooth row in all 1446 gomphodont cynodonts (with the possible exception of Beishanodon; see discussion below), at

1447 the level of the labial half of the gomphodont postcanines. The preserved portion of the sixth

1448 upper postcanine is, however, at the same level as the lingual half of the preceding tooth (Figure

1449 11P). Based on firsthand examination of the specimen IVPP V2339, nothing support the

1450 presence of sectorial postcanines in Sinognathus.

1451 Beishanodon youngi Gao et al., 2010

1452 Holotype: PKUP V3007, an incomplete cranium.

1453 Occurrence: Beishan locality, Quarry-3, in Beishan Hills, northern Gansu Province, China.

1454 Horizon: Lower Triassic dark shales, Beishan fossil beds, Hongyanjing Formation.

1455 Age: late Olenekian, Middle Triassic.

1456 Dental formula: i4/? : c1/? : pc8/? (cpc2 : gpc7 : spc?).

1457 Dental morphology: The dentition of this taxon, which is only known from six upper

1458 gomphodont postcanines, has been well-described by Gao et al. (2010). Because we have not had 1459 the opportunity to examine the holotypic specimen of Beishanodon, we rely on Gao et al.'s

1460 (2010) text and figures to describe the dentition of this taxon.

\section{Incisors and canines}

1462 There are four upper incisors separated from the canine by a diastema whose length 1463 corresponds to that of two incisor alveoli. As noted by Gao et al. (2010), the outline of the

1464 incisor alveoli suggest that the root and crown base of the upper incisors were particularly 1465 labiolingually expanded and slightly mesiodistally shorter, especially in the first two incisors.

1466 The canine alveoli is positioned lateroposteriorly from the paracanine fossa, and its long axis is

1467 diagonally and labiomesially oriented from that of the cranium. A short diastema of the length of 1468 the first postcanine lies between the canine and postcanines.

\section{Upper postcanines}

1470 The postcanine tooth row is straight, extends posteriorly to the level of the anterior 1471 margin of the orbit, and its long axis is directed towards the center of the subtemporal fenestra 1472 (Gao et al., 2010). Based on the size of the alveoli, the teeth increased in width and length up to 1473 the fifth postcanine, and the two last alveoli seem to have roughly the same size. Only the four 1474 first right and the fifth and sixth left upper postcanines are preserved. The first postcanine is the 
1475 smallest of the tooth row and corresponds to a conical crown with a subcircular cross-sectional 1476 outline. A large cusp lies directly labial to the apex of this tooth (Gao et al., 2010). The second to

1477 fourth postcanines are gomphodont in shape and elliptical in outline, with their long axis 1478 perpendicular to the long axis of the tooth row but linguodistally oriented from that of the skull. 1479 The CBR of the preserved teeth varies between 1.25 to 2 . The gomphodont postcanine includes a 1480 labiolingually oriented, weakly distally deflected, and labiolingually curved transverse crest, 1481 with the apex of the concavity directed distally in apical view. The transverse crest is made of 1482 labial, central and lingual cusps, with the central cusp being located in the labial half of the 1483 crown, close to the labial cusp (contra Gao et al., 2010). A distal cingulum comprising up to ten 1484 cingular cuspules can be seen at the rim of the fourth right postcanine (Gao et al., 2010). The 1485 gomphodont postcanines do not seem to include any accessory cusps, and only the labiomesial 1486 and labiodistal ridges are clearly visible on the labial cusp in these teeth. It is unknown whether 1487 one or several upper sectorial postcanines were present in the distalmost portion of the tooth row, 1488 but the shape of last right alveolus, which is longer than wide, would suggest that there was a 1489 sectorial postcanine in that position.

1491 Discussion

1492 The dentition of diademodontid and trirachodontid gomphodonts, which has one of the 1493 most complex occlusal pattern among non-mammaliaform cynodonts (Crompton, 1972), show a

1494 large variety of dental features previously unknown or undescribed. The following homologous 1495 dental characters were shown to be present and relatively common in the dentition of non1496 traversodontid gomphodonts: i) concave surfaces adjacent to the carinae in the incisors and 1497 canines; ii) transverse undulations, longitudinal ridges and a sporadic variation in denticles size 1498 along the carinae in the canines; iii) denticulated carinae in the incisors, canines and sectorial 1499 postcanines; iv) denticulated labial cusps, mesial and distal cingular cuspules, and a braided 1500 enamel surface texture in the gomphodont postcanines; and v) lingual and labial cingula in the 1501 sectorial postcanines. In diademodontids, we revealed the presence of denticles changing 1502 sporadically in size along the carinae in the canines, lingual cingular cuspules in the conical 1503 postcanines, denticulated labial cusp in the gomphodont postcanines and bi denticulated denticles 1504 in the sectorial postcanines in Diademodon, and a labiomesial accessory cusp as well as mesial 1505 cingular cuspules, in the upper gomphodont postcanines of Titanogomphodon. The presence of 
1506 these dental characters in Titanogomphodon, however, needs confirmation with better-preserved

1507 specimens. In trirachodontids, we described for the first time denticulated carinae in the incisors

1508 and sectorial postcanines as well as longitudinal ridges in the canines of Langbergia, concave

1509 surfaces adjacent to the carinae in the canines and a biconvex distal cingulum in the upper

1510 postcanines of Cricodon, transverse undulations and longitudinal ridges in the canines as well as

1511 labial and lingual cingular cuspules in the lower sectorial postcanines of Trirachodon, and

1512 denticulated incisors and no sectorial postcanines in Sinognathus.

\section{The affinities of the Chinese gomphodonts}

1514 According to Gao et al. (2010), the placement of Beishanodon within Trirachodontidae is

1515 supported by an ovoid-elliptical outline of the upper postcanines and a long axis of the

1516 postcanine tooth row directed toward the center of the subtemporal fenestra. The upper

1517 postcanines of Beishanodon also share with trirachodontids a low transverse crest made of a

1518 labial, central and lingual cusps combined with a distal cingulum comprising a large number of

1519 cingular cuspules. The dentition of this taxon is nonetheless unusual for a trirachodontid in many

1520 aspects: the upper postcanine are particularly labiolingually narrow in relation to the skull length

1521 (the distance between the anteriormost point of the snout and the posteriormost point of the

1522 occipital condyles) and only Diademodon shares a low upper postcanine CBW/skull length ratio

1523 (Figure 12). The first conical postcanine has a large labial cusp (Gao et al., 2010), a feature

1524 absent in other gomphodont taxa. In addition, the transverse crest of the postcanines three and

1525 four is located near the distal border of the tooth, presenting an occlusal basin that resembles a

1526 traversodontid postcanine. According to figure 6A from Gao et al. (2010), the central cusp of the

1527 second right postcanine is also strongly labiodistally positioned, a feature absent in all other

1528 trirachodontids. Finally, the sectorial postcanine(s), if present, would be weakly lingually

1529 deflected from the long axis of the tooth row (Gao et al. 2010, figure 5 and 6a) whereas all

1530 gomphodont cynodonts have their sectorial postcanine labial to this axis.

1531 Although the latest cladistic analyses on gomphodont cynodonts (i.e., Liu \& Abdala,

1532 2014; Sidor \& Hopson, 2018) recovered Beishanodon and Sinognathus within the clade

1533 Trirachodontidae + Traversodontidae, these two taxa were recently suggested to be

1534 probainognathians by Sidor \& Hopson (2018) and basal probainognathians closely related to

1535 Aleodon brachyrhamphus by Hopson (2014) and Hopson \& Sidor (2015). Nonetheless, the 
1536 dentition of Aleodon, the only non-tritylodontid probainognathian with labiolingually elongated

1537 and ovoid postcanines (Crompton, 1955; Abdala \& Giannini, 2002; Martinelli et al., 2017),

1538 strongly differs from that of Beishanodon and Sinognathus in the following features: i) upper

1539 postcanine tooth row curved, with a long axis of the posterior portion directed towards the lateral 1540 part of the subtemporal fossa; ii) postcanines strongly protruding from the alveoli; iii) second

1541 and, in some cases, third upper postcanines subcircular and significantly smaller than the

1542 following teeth; iv) no transverse crest, central cusps or mesial and distal cingula in the

1543 postcanines; v) labial cusp significantly larger (i.e., longer, wider and higher) than the lingual

1544 'cusp' (when present) in the upper postcanines; and vi) postcanines with a wide lingual platform

1545 extending from the sectorial/labial portion of the crown. Sidor and Hopson (2018) note that the

1546 two Chinese cynodonts also share probainognathian cranial characters such as the presence of a

1547 widely bowed zygomatic arch and the absence of a parietal foramen and a zygomatic/suborbital

1548 process of the jugal, three cranial features absent in basal cynognathians (i.e., Cynognathus,

1549 diademodontids, trirachodontids, and basal traversodontids) according to these authors. The

1550 zygomatic arch is, however, poorly anteroposteriorly convex in Sinognathus (IVPP V2339),

1551 showing the same convexity than some trirachodontid specimens (e.g., NMQR 3255, CGP/1/79).

1552 In fact, the temporal fenestra of Sinognathus is subrectangular in dorsal view, as in Langbergia

1553 and Trirachodon and unlike Lumkuuia, Chiniquodon and Aleodon. If a parietal foramen is indeed

1554 present in all African trirachodontids (including the Trirachodon specimen AM 461; Benoit pers.

1555 comm. 2018), it is however absent in the basal traversodontids Pascualgnathus (MLP 65-VI-18-

1556 1; PVL 4416) and Andescynodon (PVL 3836, 3840; Liu \& Powell, 2009). Likewise, a suborbital

1557 process of the jugal is absent in the basal traversodontid Scalenodon (Abdala, Neveling \&

1558 Welman, 2006) and more derived forms such as Boreogomphodon and Massetognathus (Abdala,

1559 Neveling \& Welman, 2006; Sues \& Hopson, 2010). For those reasons, we consider both

1560 Beishanodon and Sinognathus to be confidently classified among gomphodont cynognathians.

1561 Sidor \& Hopson's (2018) phylogeny recovered Sinognathus and Beishanodon among basal

1562 traversodontids, close to Pascualgnathus. Nevertheless, Sinognathus lacks the shearing planes

1563 between the outer surface of the main cusp of the lower and the inner surfaces of the main cusps

1564 of the upper postcanines characteristic of Traversodontidae. Likewise, the transverse crest of

1565 Sinognathus is centrally positioned on the crown, forms a low ridge and lacks the deep labial

1566 valley present in traversodontids. Consequently, this Chinese gomphodont is here confidently 
1567 classified as a trirachodontid, pending a phylogenetic analysis to support this hypothesis, which 1568 will be conducted in a forthcoming contribution (Hendrickx, Abdala \& Choiniere, in 1569 preparation). Finally, given the presence of a single conical postcanine, six upper gomphodont

1570 postcanines comprising a distal cingulum and a low transverse crest made of a labial, central and 1571 lingual cusps, a straight postcanine tooth row directed towards the centromedial portion of the 1572 temporal fenestra, and possibly one or two sectorial postcanines, we tentatively refer

1573 Beishanodon to Trirachodontidae. If correct, this reveals that diademodontids and some 1574 trirachodontids convergently evolved large skulls compared to the upper postcanine width, which remained particularly small in mature individuals.

\section{Dental differences between Trirachodon berryi and 'Trirachodon kannemeyeri'}

Two species of Trirachodon, T. berryi and 'T. kannemeyeri', were distinguished by

1578 Seeley (1894) based on the snout expansion and the number and labiolingual elongation of the maxillary teeth. Although these two taxa were synonymized by Hopson \& Kitching (1972) (along with Trirachodon minor, Trirachodontoides berryi and Inusitatodon smithi) and Abdala, Neveling \& Welman (2006), they were considered as separate species by Kitching (1977) and more recently by Hopson \& Sidor (2015) and Sidor \& Hopson (2018). According to the two latter authors, T. berryi includes the specimens NHMUK PV R3579, BSP 1934 VIII 21 to 23 and SAM-PK-K7888, whereas the specimens AM 461, SAM-PK-K171, SAM-PK-12168 (= SAMPK-K5821), and NHMUK PV R3307 belong to 'T. kannemeyeri'. SAM-PK-11481 is also included in the latter taxon by Sidor \& Hopson (2018), yet, as stated by Abdala, Neveling \& Welman (2006), SAM-PK-11481 is here referred to Langbergia based on the absence of a maxillary lateral platform, the curvature of the ventral margin of the dentary, and the presence of a high central cusp separated from labial cusp by a narrow valley and strongly protruding cingular cuspules. Future CT-scanning and reconstruction of the occluded dentition of this specimen will corroborate referral to this taxon.

Sidor \& Hopson (2018) list the following apomorphic characters in the dentition of

1593 Trirachodon berryi: i) the upper gomphodont postcanines are slightly less than twice as wide as

1594 long (i.e., CBR < 2) and are transversely symmetrical in apical view; ii) the mesial and distal 1595 cingula are usually complete and typically bear small cingular cuspules; iii) the sectorial upper postcanines are absent; and iv) the last upper gomphodont postcanine is transversely expanded, 
1597 and about two-thirds the transverse diameter of the preceding tooth, with reduced labial and

1598 lingual cusps. Sidor \& Hopson (2018) also suggest that the dentition of ' $T$. kannemeyeri' and

1599 Cricodon are closer than that of Trirachodon berryi, so that these authors propose the new

1600 combination Cricodon kannemeyeri. According to Sidor and Hopson (2018), shared

1601 synapomorphies between Cricodon metabolus and 'Cricodon kannemeyeri' are: i) transversely

1602 expanded upper and lower gomphodont postcanines with one or two sectorial teeth at the rear of

1603 the tooth row; ii) distal upper gomphodont postcanines more than twice as wide as long (i.e.,

1604 CBR > 2) and transversely asymmetrical in apical view, with the lingual half of the crown

1605 usually being mesiodistally longer than the labial half of the crown; iii) cingular cuspules varying

1606 in size, with some being particularly large; iv) mesial and, less frequently, distal cingula often

1607 incomplete, and sometimes even absent; v) distalmost one or two postcanines sectorial and

1608 formed by three main cusps oriented mesiodistally and often with a narrow lingual cingulum.

1609 We, however, note that a single character (i.e., the presence of one or two sectorial postcanines;

1610 character 59) in Sidor \& Hopson's (2018) datamatrix unites Cricodon metabolus and 'Cricodon

1611 kannemeyeri' and differentiate them from Trirachodon berryi.

1612 Although Sidor \& Hopson (2018) note that the mesial and distal cingula are usually

1613 complete and bear small cingular cuspules in T. berryi, the distal cingulum is complete and

1614 includes a large number of cingular cuspules in NHMUK PV R3307 and SAM-PK-K4801.

1615 Likewise, important variations in size in the mesial and distal cingular cuspules, which are as

1616 large as other Trirachodon specimens, can be noticed in BSP 1934 VIII 21. Seeley (1894) and

1617 Sidor \& Hopson (2018) also observe difference in the elongation of the upper gomphodont

1618 postcanines between these species, yet the CBR of the penultimate upper gomphodont

1619 postcanine of BSP 1934 VIII 21 is 2.3 whereas the crown of SAM-PK-K171 from the same

1620 position has a CBR of 2.

1621 As stated before, we agree with Sidor and Hopson (2018) that two morphotypes can be

1622 observed among the specimens referred to Trirachodon berryi and 'T. kannemeyeri' but we

1623 interpret them as ontogenetic variations. 'C. kannemeyeri' sensu Sidor and Hopson (2018) can be

1624 considered as an younger ontogenetic stage of $T$. berryi. In adults of this sequence: i) the last

1625 sectorial postcanines were replaced by transversely symmetrical gomphodont postcanines; and ii)

1626 two to three upper gomphodont postcanines, with the last one bearing a large central cusp, and

1627 reduced labial cusp and lingual cusps (Figure 90), were added in the distal portion of the tooth 
1628 row. Such dental replacement and increase in the number of gomphodont teeth throughout 1629 ontogeny are common in gomphodont cynodonts and were observed in the closely related 1630 trirachodontid Cricodon metabolus (Crompton, 1955) as well as the basal traversodontids 1631 Scalenodon angustifrons (Crompton, 1955) and Andescynodon mendozensis (Goñi \& Goin, 1632 1988).

1633 Given that both morphotypes of $T$. berryi and 'C. kannemeyeri' are represented by large1634 sized specimens with a skull of more than ten centimeters (see Abdala, Neveling \& Welman 1635 (2006), Table 4; C.H. pers. obs.), this suggests that the largest specimens referred to ' $C$. 1636 kannemeyeri' were subadult/non-fully grown individuals in which: i) the maximum size was 1637 reached; and ii) the sectorial postcanines remained to be replaced by gomphodont postcanines

1638 latter in their life. Specimens classified as T. berryi would consequently represent fully grown, 1639 most likely old, individuals in which all sectorial postcanines were replaced by gomphodont 1640 postcanines. This hypothesis is supported by size and wear in the postcanines. All specimens 1641 belonging to T. berryi have skulls of more than nine centimeters (see Abdala, Neveling \& 1642 Welman (2006), Table 4) and show extensive wear in the upper and lower gomphodont 1643 postcanines (e.g., NHM R3579, BSP 1934 VIII21-23; SAM-PK-K7888; Sidor \& Hopson 2018,

1644 Figure 10C). On the other hand, wear is barely present or less extensive on the upper and lower 1645 gomphodont postcanines of specimens belonging to 'C. kannemeyeri' (e.g., SAM-PK-K171, 1646 NHMUK PV R3307), which includes individuals whose skull length varies from 5.2 to ten 1647 centimeters (see Abdala, Neveling \& Welman (2006), Table 4; C.H. pers. obs.). An exception to 1648 this is BP/1/4658 which bears seven worn out upper and lower postcanines, and one upper and 1649 two lower sectorial teeth. As stated before, BP/1/4658 appears to represent a transitional form 1650 between the dental morphotypes of T. berryi and ' $C$. kannemeyeri' and likely belongs to a 1651 subadult individual. Consequently, all specimens previously referred to the species ' $C$.

1652 kannemeyeri' are here interpreted as younger individuals of T. berryi.

1653

1654 Conclusions

1655 The teeth of diademodontids and trirachodontids are morphologically complex and show 1656 particularly important positional, ontogenetic and intraspecific variations. Even the most 1657 comprehensive descriptions of the dentition of these gomphodont cynodonts have inadvertently 1658 omitted dental features that might provide taxonomic and phylogenetic information. The main 
1659 differences between the dentition of diademodontids and trirachodontids include: i) the presence 1660 of a at least one transitional postcanine between gomphodont and sectorial teeth in the upper and 1661 lower tooth row; ii) one or several accessory ridges on the mesial and/or distal surfaces of the

1662 transverse crest; and iii) the absence of mesial and distal basins in some upper gomphodont

1663 postcanines in diademodontids; and i) the presence of labial and lingual cusps of the same height

1664 in the lower postcanines; ii) the absence of shearing planes between the outer surface of the main

1665 cusp of the lower and the inner surfaces of the main cusps of the upper postcanines in

1666 trirachodontids. Based on the morphology of the dentition, Trirachodon berryi and $T$.

1667 kannemeyeri more likely correspond to two morphotypes of the same species, with $T$.

1668 kannemeyeri representing younger individuals of T. berryi. The Chinese cynodonts Sinognathus

1669 and Beishanodon are here confidently reassigned to the Gomphodontia based on dental

1670 characters, with Sinognathus being referred to Trirachodontidae, whereas Beishanodon is

1671 tentatively ascribed to this clade. This study reveals the importance of describing the dentition of

1672 gomphodonts comprehensively and providing as much information as possible on the

1673 morphological varation of the complete dentition as well as crown ornamentations and surface

1674 texture, with the goal of enhancing the identification of isolated gomphodont teeth and clarifying

1675 the phylogenetic position of gomphodont taxa, an objective that we wish to tackle in subsequent

1676 contributions.

1677

1678 Acknowledgements

1679 The cynodont material was examined in several institutions of South Africa, Namibia,

1680 Germany, the UK, Argentina, and China and access to the material was possible thanks to

1681 Johann Neveling (CGP), Helke Mocke (GSN), Mathew Lowe (UCMZ), Sandra Chapman

1682 (NHMUK), Gertrud Rößner and Femke Holwerda (BSPG), Zheng Fang (IVPP), Elize Butler and

1683 Jennifer Botha-Brink (NMQR), Zaituna Erasmus (SAM), Bernard Zipfel and Sifelani Jirah

1684 (ESI). We are particularly thankful to Helke Mocke (GSN) for giving us access to unpublished

1685 material. We also thank Christian Kammerer (NCSM) and Christian Sidor (University of

1686 Washington) for taking for us and sharing photos of the dentition of Diademodon and Cricodon,

1687 Christian Sidor for sharing an unpublished manuscript describing new material of Cricodon from

1688 Zambia, and Mike Day (NHM) and Johann Neveling (CGP) for providing information on the 
1689 locality and horizon on some specimens. We would like to express our utmost thanks to José

1690 Eduardo Camargo Martínez for allowing us to use his artwork for the black silhouettes of

1691 cynodonts. Our thanks finally go to the Agustín Martinelli, Christian Sidor and Kirstin Brink for

1692 their helpful comments and suggestions, which considerably improved the quality of this

1693 manuscript. C. H. dedicates this work to O. Mateus.

1694

\section{References}

1696 Abdala F. 1996. Redescripción del cráneo y reconsideración de la validez de Cynognathus minor 1697 (Eucynodontia-Cynognathidae) del Triásico Inferior de Mendoza. Ameghiniana 33:115$1698 \quad 126$.

1699 Abdala F. 1999. Elementos postcraneanos de Cynognathus (Synapsida-Cynodontia) del Triásico 1700 Inferior de la Provincia de Mendoza, Argentina. Consideraciones sobre la morfología del 1701 húmero en cinodontes. Revista Española de Paleontología 14:13-24.

1702 Abdala F., Barberena MC., Dornelles J. 2002. A new species of the traversodontid cynodont 1703 Exaeretodon from the Santa Maria Formation (Middle/Late Triassic) of southern Brazil.

1704 Journal of Vertebrate Paleontology 22:313-325. DOI: 10.1671/02724634(2002)022[0313:ANSOTT]2.0.CO;2.

1706 Abdala F., Damiani R., Yates A., Neveling J. 2007. A non-mammaliaform cynodont from the

1707 Upper Triassic of South Africa: a therapsid Lazarus taxon? Palaeontologia Africana $1708 \quad 42: 17-23$.

1709 Abdala F., Gaetano LC. 2018. The Late Triassic record of cynodonts: Time of innovations in the mammalian lineage. In: Tanner LH ed. The Late Triassic World. Topics in Geobiology. Springer International Publishing, 407-445.

1712 Abdala F., Giannini NP. 2002. Chiniquodontid cynodonts: systematic and morphometric considerations. Palaeontology 45:1151-1170. DOI: 10.1111/1475-4983.00280. 
1714 Abdala F., Hancox PJ., Neveling J. 2005. Cynodonts from the uppermost Burgersdorp

1715 Formation, South Africa, and their bearing on the biostratigraphy and correlation of the

1716 Triassic Cynognathus Assemblage Zone. Journal of Vertebrate Paleontology 25:192-

1717 199. DOI: 10.1671/0272-4634(2005)025[0192:CFTUBF]2.0.CO;2.

1718 Abdala F., Jasinoski SC., Fernandez V. 2013. Ontogeny of the Early Triassic cynodont

1719 Thrinaxodon liorhinus (Therapsida): dental morphology and replacement. Journal of

1720 Vertebrate Paleontology 33:1408-1431. DOI: 10.1080/02724634.2013.775140.

1721 Abdala F., Marsicano CA., Smith RMH., Swart R. 2013. Strengthening Western Gondwanan

1722 correlations: A Brazilian Dicynodont (Synapsida, Anomodontia) in the Middle Triassic

1723 of Namibia. Gondwana Research 23:1151-1162. DOI: 10.1016/j.gr.2012.07.011.

1724 Abdala F., Neveling J., Welman J. 2006. A new trirachodontid cynodont from the lower levels of 1725 the Burgersdorp Formation (Lower Triassic) of the Beaufort Group, South Africa and the 1726 cladistic relationships of Gondwanan gomphodonts. Zoological Journal of the Linnean Society 147:383-413. DOI: 10.1111/j.1096-3642.2006.00224.x.

Abdala F., Ribeiro AM. 2003. A new traversodontid cynodont from the Santa Maria Formation (Ladinian-Carnian) of southern Brazil, with a phylogenetic analysis of Gondwanan traversodontids. Zoological Journal of the Linnean Society 139:529-545. DOI:

Abdala F., Sa-Teixeira AM. 2004. A traversodontid cynodont of African affinity in the South American Triassic. Palaeontologia Africana 40:11-22.

1734 Abdala F., Smith RMH. 2009. A Middle Triassic cynodont fauna from Namibia and its 1735 implications for the biogeography of Gondwana. Journal of Vertebrate Paleontology 29:837-851. DOI: 10.1671/039.029.0303. 
1737 Battail B. 1983. La phylogénie des cynodontes gomphodontes. Acta Palaeontologica Polonica $1738 \quad 28: 19-30$.

1739 Battail B. 2005. Late Triassic traversodontids (Synapsida: Cynodontia) in southern Africa. $1740 \quad$ Palaeontologia Africana 41:67-80.

1741 Battail B., Surkov MV. 2000. Mammal-like reptiles from Russia. In: Benton MJ, Shishkin MA, 1742 Unwin DM, Kurochkin EN eds. The Age of Dinosaurs in Russia and Mongolia. 1743 Cambridge: Cambridge University Press, 86-119.

1744 Bordy E., Sciscio L., Abdala F., McPhee B., Choiniere J. 2017. First Lower Jurassic vertebrate burrow from southern Africa (upper Elliot Formation, Karoo Basin, South Africa). Palaeogeography, Palaeoclimatology, Palaeoecology 468:362-372. DOI: 10.1016/j.palaeo.2016.12.024.

1748 Brink AS. 1955. A study on the skeleton of Diademodon. Palaeontologia Africana 3:3-39.

1749 Brink AS. 1963. Two cynodonts from the Ntawere formation in the Luangwa valley of Northern $1750 \quad$ Rhodesia. Palaeontologia Africana 8:77-96.

1751 Brink AS. 1977. A model of tooth replacement in the "mammal-like reptile" Diademodon. South 1752 African Journal of Science 73:138.

1753 Brink KS., Reisz RR. 2014. Hidden dental diversity in the oldest terrestrial apex predator 1754 Dimetrodon. Nature Communications 5:1-9. DOI: 10.1038/ncomms4269.

1755 Broili F., Schröder J. 1934. Beobachtungen an wirbeltieren der Karrooformation. IX. Uber den 1756 Schadel von Gomphodontosuchus Seeley. Sitzungsbericht der Bayerischen Akademie der Wissenschaften 1:115-182. 
1758 Broili F., Schröder J. 1936. Beobachtungen an Wirbeltieren der Karrooformation. XXII. Ein

1759 neuer Galesauride aus der Cynognathus-Zone. Sitzungsbericht der Bayerischen Akademie

1760 der Wissenschaften:269-282.

1761 Broom R. 1905. 6. On some points in the anatomy of the theriodont reptile Diademodon.

1762 Proceedings of the Zoological Society of London 75:96-102. DOI: 10.1111/j.1469-

1763 7998.1905.tb08366.x.

1764 Broom R. 1913. On evidence of a mammal-like dental succession in the cynodont reptiles.

$1765 \quad 32: 465-468$.

1766 Chatterjee S. 1982. A new cynodont reptile from the Triassic of India. Journal of Paleontology

$1767 \quad 56: 203-214$.

1768 Cohen KM., Finney SC., Gibbard PL., Fan J-X. 2018. The ICS international chronostratigraphic 1769 chart. Episodes 36:199-204.

1770 Crompton AW. 1955. On some Triassic cynodonts from Tanganyika. Proceedings of the 1771 Zoological Society of London 125:617-669. DOI: 10.1111/j.1096-3642.1955.tb00620.x.

1772 Crompton AW. 1963. Tooth replacement in the cynodont Thrinaxodon liorhinus. Annals of the $1773 \quad$ South African Museum 46:479-521.

1774 Crompton AW. 1972. Postcanine occlusion in cynodonts and tritylodontids. Bulletin of the 1775 British Museum (Natural History). Geology 21:29-71.

1776 Crompton AW., Jenkins FA. 1968. Molar occlusion in late triassic mammals. Biological Reviews 43:427-458. DOI: 10.1111/j.1469-185X.1968.tb00966.x.

1778 Cuvier G. 1805. Leçons d'Anatomie Comparée: La Première Partie des Organes de la 1779 Digestion. Crochard.

1780 Fauchard P. 1728. Le Chirurgien Dentiste, ou Traité des Dents. Chez Jean Mariette. 
1781 Flynn JJ., Parrish JM., Rakotosamimanana B., Ranivoharimanana L., Simpson WF., Wyss AR.

1782 2000. New traversodontids (Synapsida: Eucynodontia) from the Triassic of Madagascar.

1783 Journal of Vertebrate Paleontology 20:422-427. DOI: 10.1671/02721784 4634(2000)020[0422:NTSEFT]2.0.CO;2.

1785 Fourie S. 1963. Tooth replacement in the gomphodont cynodont, Diademodon. South African $1786 \quad$ Journal of Science 59:211-213.

1787 Gaetano LC., Mocke H., Abdala F. 2018. The postcranial anatomy of Diademodon tetragonus 1788 (Cynodontia, Cynognathia). Journal of Vertebrate Paleontology 0:e1451872. DOI: $1789 \quad 10.1080 / 02724634.2018 .1451872$.

1790 Gao K-Q., Fox RC., Zhou C-F., Li D-Q. 2010. A new nonmammalian eucynodont (Synapsida: 1791 Therapsida) from the Triassic of Northern Gansu Province, China, and its biostratigraphic 1792 and biogeographic implications. American Museum Novitates:1-25. DOI: 10.1206/649.1.

1793 Godefroit P. 1999. New traversodontid (Therapsida: Cynodontia) teeth from the Upper Triassic 1794 of Habay-la-Vieille (southern Belgium). Paläontologische Zeitschrift 73:385-394. DOI: 10.1007/BF02988049.

1796 Godefroit P., Battail B. 1997. Late Triassic cynodonts from Saint-Nicolas-de-Port (north-eastern 1797 France). Geodiversitas 19:567-631.

1798 Goñi RG., Goin FJ. 1988. Morfología dentaria y biomecánica masticatoria de los cinodontes 1799 (Reptilia, Therapsida) del Triásico Argentino; I, Andescynodon mendozensis Bonaparte $1800 \quad$ (Traversodontidae). Ameghiniana 25:139-148.

1801 Gow CE. 1978. The advent of herbivory in certain reptilian lineages during the Triassic. 1802 Palaeontologia Africana 21:133-141. 
1803 Grine FE. 1977. Postcanine tooth function and jaw movement in the gomphodont cynodont 1804 Diademodon (Reptilia; Therapsida). Palaeontologia Africana 20:123-135.

1805 Grine FE. 1978. Postcanine dental structure in the mammal-like reptile Diademodon 1806 (Therapsida; Cynodontia). Proceedings, Electron Microscopy Society of Southern Africa $1807 \quad 8: 123-124$.

1808 Groenewald GH., Welman J., Maceachern JA. 2001. Vertebrate burrow complexes from the 1809 Early Triassic Cynognathus Zone (Driekoppen Formation, Beaufort Group) of the Karoo 1810 Basin, South Africa. Palaios 16:148-160. DOI: 10.1669/0883$1811 \quad$ 1351(2001)016<0148:VBCFTE $>2.0 . C O ; 2$.

1812 Hammer WR. 1995. New therapsids from the upper Fremouw Formation (Triassic) of 1813 Antarctica. Journal of Vertebrate Paleontology 15:105-112. DOI: $1814 \quad 10.1080 / 02724634.1995 .10011210$.

1815 Haughton SH. 1924. A bibliographic list of pre-Stormberg Karroo Reptilia, with a table of 1816 horizons. Transactions of the Royal Society of South Africa 12:51-104.

1817 Hendrickx C., Abdala F., Choiniere JN. in preparation. Evolutionary transformations in the 1818 dentition of gomphodont cynodonts.

1819 Hendrickx C., Abdala F., Choiniere J. 2016. Postcanine microstructure in Cricodon metabolus, a 1820 Middle Triassic gomphodont cynodont from south-eastern Africa. Palaeontology $1821 \quad$ 59:851-861. DOI: 10.1111/pala.12263.

1822 Hendrickx C., Choiniere J., Abdala F. in preparation. Dental morphology in Traversodontidae 1823 (Cynodontia: Gomphodontia). 
1824 Hendrickx C., Mateus O., Araújo R. 2015. A proposed terminology of theropod teeth

1825 (Dinosauria, Saurischia). Journal of Vertebrate Paleontology 35:e982797. DOI:

$1826 \quad 10.1080 / 02724634.2015 .982797$.

1827 Hillson S. 2005. Teeth: Second Edition. New York: Cambridge University Press.

1828 Hopson JA. 1964. Tooth replacement in cynodont, dicynodont and therocephalian Reptiles.

1829 Proceedings of the Zoological Society of London 142:625-654. DOI: 10.1111/j.1469-

1830 7998.1964.tb04632.x.

1831 Hopson JA. 1971. Postcanine replacement in the gomphodont cynodont Diademodon. Zoological $1832 \quad$ Journal of the Linnean Society 50:1-21.

1833 Hopson JA. 1984. Late Triassic traversodont cynodonts from Nova Scotia and southern Africa.

1834 Hopson JA. 1985. Morphology and relationships of Gomphodontosuchus brasiliensis von Huene 1835 (Synapsida, Cynodontia, Tritylodontoidea) from the Triassic of Brazil. Neues Jahrbuch 1836 für Geologie und Paläontologie, Monatshefte 1985:285-299.

1837 Hopson JA. 2005. A juvenile gomphodont cynodont specimen from the Cynognathus Assemblage Zone of South Africa: implications for the origin of gomphodont postcanine morphology. Palaeontologia Africana 41:53-66.

1840 Hopson JA. 2014. The traversodontid cynodont Mandagomphodon hirschsoni from the Middle Triassic of the Ruhuhu Valley, Tanzania. In: Kammerer CF, Angielczyk KD, Fröbisch J eds. Early Evolutionary History of the Synapsida. Vertebrate Paleobiology and

1844 Hopson JA., Kitching JW. 1972. A revised classification of cynodonts (Reptilia; Therapsida). Palaeontologia Africana 14:71-75. 
1846 Hopson JA., Sidor CA. 2015. A juvenile specimen of the trirachodontid Cricodon metabolus

1847 from the Luangwa Basin of Zambia: implications for tooth replacement in gomphodont 1848 cynodonts and for trirachodontid systematics. 75th Annual Meeting Society of Vertebrate 1849 Paleontology, Dallas, Texas, USA. (October 14-17, 2015), Program and Abstracts:147.

1850 Hopson JA., Sues H-D. 2006. A traversodont cynodont from the Middle Triassic (Ladinian) of 1851 Baden-Württemberg (Germany). Paläontologische Zeitschrift 80:124-129. DOI: 1852

Illiger JKW. 1811. Prodromus Systematis Mammalium et Avium: Additis Terminis Zoographicis Utriusque Classis, Eorumque Versione Germanica. Salfeld.

Ivakhnenko MF. 2011. Permian and Triassic Therocephals (Eutherapsida) of Eastern Europe. Paleontological Journal 45:981-1144. DOI: 10.1134/S0031030111090012.

1857 Kammerer CF., Flynn JJ., Ranivoharimanana L., Wyss AR. 2008. New material of Menadon besairiei (Cynodontia: Traversodontidae) from the Triassic of Madagascar. Journal of Vertebrate Paleontology 28:445-462. $\quad$ DOI: $\quad 10.1671 / 0272-$ 4634(2008)28[445:NMOMBC]2.0.CO;2.

1861 Kammerer CF., Flynn JJ., Ranivoharimanana L., Wyss AR. 2012. Ontogeny in the Malagasy traversodontid Dadadon isaloi and a reconsideration of its phylogenetic relationships. Fieldiana Life and Earth Sciences:112-125. DOI: 10.3158/2158-5520-5.1.112.

1864 Kemp TS. 1980. Aspects of the structure and functional anatomy of the Middle Triassic cynodont Luangwa. Journal of Zoology 191:193-239.

1866 Keyser AW. 1973. A new Triassic vertebrate fauna from South West Africa. Palaeontologia Africana 16:1-15. 
1868 Kitching JW. 1977. The distribution of the Karoo vertebrate fauna. Johannesburg: Bernard Price 1869 Institute for Palaeontological Research, University of the Witwatersrand.

1870 Langer MC., Ferigolo J. 2013. The Late Triassic dinosauromorph Sacisaurus agudoensis 1871 (Caturrita Formation; Rio Grande do Sul, Brazil): anatomy and affinities. Geological 1872 Society, London, Special Publications 379:353-392. DOI: 10.1144/SP379.16.

1873 Liu J. 2007. New traversodontid materials from North Carolina, United States and the taxonomy, 1874 phylogeny of Traversodontidae (Synapsida: Cynodontia). Ph.D. Dissertation Thesis. New York, New York: Columbia University.

Liu J., Abdala F. 2014. Phylogeny and taxonomy of the Traversodontidae. In: Kammerer CF, Angielczyk KD, Fröbisch J eds. Early Evolutionary History of the Synapsida. Vertebrate Paleobiology and Paleoanthropology. Springer Netherlands, 255-279.

Liu J., Powell J. 2009. Osteology of Andescynodon (Cynodontia: Traversodontidae) from the Middle Triassic of Argentina. American Museum Novitates:1-19. DOI: 10.1206/606.1.

1881 Liu J., Ramezani J., Li L. 2018. High-precision temporal calibration of Middle Triassic vertebrate biostratigraphy: U-Pb zircon constraints for the Sinokannemeyeria Fauna and Yonghesuchus. Vertebrata PalAsiatica 56:16-24.

1884 Liu J., Sues H-D. 2010. Dentition and tooth replacement of Boreogomphodon (Cynodontia:

1885 Traversodontidae) from the Upper Triassic of North Carolina, USA. Vertebrata 1886 PalAsiatica 48:169-184.

1887 Lucas SG., Estep JW., Heckert AB., Hunt AP. 1999. Cynodont teeth from the Upper Triassic of 1888 New Mexico, USA. Neues Jahrbuch fur Geologie und Palaontologie-Monatshefte 1889 1999:331-344. 
1890 Marsicano CA., Irmis RB., Mancuso AC., Mundil R., Chemale F. 2016. The precise temporal 1891 calibration of dinosaur origins. Proceedings of the National Academy of Sciences 1892 113:509-513. DOI: 10.1073/pnas.1512541112.

1893 Martin RE. 1999. Taphonomy: a process approach. Cambridge, England; New York: Cambridge $1894 \quad$ University Press.

1895 Martinelli AG. 2010. On the postcanine dentition of Pascualgnathus polanskii Bonaparte 1896 (Cynodontia, Traversodontidae) from the Middle Triassic of Argentina. Geobios 43:6291897 638. DOI: $10.1016 /$ j.geobios.2010.03.006.

1898 Martinelli AG., de la Fuente M., Abdala F. 2009. Diademodon tetragonus Seeley, 1894 1899 (Therapsida: Cynodontia) in the Triassic of South America and its biostratigraphic 1900 implications. Journal of Vertebrate Paleontology 29:852-862. DOI: 1901 10.1671/039.029.0315.

1902 Martinelli AG., Kammerer CF., Melo TP., Neto VDP., Ribeiro AM., Da-Rosa ÁA., Schultz CL., 1903 Soares MB. 2017. The African cynodont Aleodon (Cynodontia, Probainognathia) in the 1904 Triassic of southern Brazil and its biostratigraphic significance. PloS one 12:e0177948.

1905 Martinelli AG., Soares MB., Schwanke C. 2016. Two new cynodonts (Therapsida) from the 1906 Middle-Early Late Triassic of Brazil and comments on South American 1907 probainognathians. PloS One 11:e0162945. DOI: 10.1371/journal.pone.0162945.

1908 Martínez RN., Fernández E., Alcober OA. 2013. A new non-mammaliaform eucynodont from 1909 the Carnian-Norian Ischigualasto Formation, northwestern Argentina. Revista Brasileira 1910 de Paleontologia 16:61-76.

1911 McGraw-Hill 2003. Dictionary of Bioscience. New York, New York: McGraw-Hill Professional 1912 Publishing, McGraw-Hill Companies, The Distributor. 
1913 Melo TP. 2014. Sobre a presença de Menadon besairiei (Synapsida: Traversodontidae) na zona1914 associação de Santacruzodon, triássico superior da supersequência Santa Maria, Brasil. 1915 Master Thesis Thesis. Porte Alegre, Rio Grande do Sul, Brazil: Universidade Federal do 1916 Rio Grande do Sul. Instituto de Geociências. Programa de Pós-Graduação em 1917 Geociências.

1918 Melo TP., Abdala F., Soares MB. 2015. The Malagasy cynodont Menadon besairiei 1919 (Cynodontia; Traversodontidae) in the Middle-Upper Triassic of Brazil. Journal of 1920 Vertebrate Paleontology 35:e1002562. DOI: 10.1080/02724634.2014.1002562.

1921 Melo TP., Martinelli AG., Soares MB. 2017. A new gomphodont cynodont (Traversodontidae) 1922 from the Middle-Late Triassic Dinodontosaurus Assemblage Zone of the Santa Maria 1923 Supersequence, Brazil. Palaeontology 60:571-582. DOI: 10.1111/pala.12302.

1924 Niu Y., Liu C., Shi GR., Lu J., Xu W., Shi J. 2018. Unconformity-bounded Upper Paleozoic 1925 megasequences in the Beishan Region (NW China) and implications for the timing of the Paleo-Asian Ocean closure. Journal of Asian Earth Sciences. DOI:

1931 Osborn JW. 1974. On tooth succession in Diademodon. Evolution 28:141-157.

1932 Osborn JW., Hillman J. 1979. Enamel structure in some therapsids and Mesozoic mammals. $1933 \quad$ Calcified Tissue International 29:47-61.

1934 Ottone EG., Monti M., Marsicano CA., de la Fuente MS., Naipauer M., Armstrong R., Mancuso 1935 AC. 2014. A new Late Triassic age for the Puesto Viejo Group (San Rafael depocenter, 
1936

1937

1938

1939

1940

1941

1942

1943

1944

1945

1946

1947

1948

1950

1951

1952

1953

1954

1955

1956

1957

1958

Argentina): SHRIMP U-Pb zircon dating and biostratigraphic correlations across southern Gondwana. Journal of South American Earth Sciences 56:186-199. DOI: 10.1016/j.jsames.2014.08.008.

Owen R. 1840. Odontography; or, A treatise on the comparative anatomy of the teeth; their physiological relations, mode of development, and microscopic structure, in the vertebrate animals. London, H. Baillière.

Pacheco CP., Martinelli AG., Pavanatto AEB., Soares MB., Dias-da-Silva S. 2018. Prozostrodon brasiliensis, a probainognathian cynodont from the Late Triassic of Brazil: second record and improvements on its dental anatomy. Historical Biology 30:475-485. DOI: 10.1080/08912963.2017.1292423.

Peecook BR., Steyer JS., Tabor NJ., Smith RMH. 2018. Updated geology and vertebrate paleontology of the Triassic Ntawere Formation of northeastern Zambia, with special emphasis on the archosauromorphs. Journal of Vertebrate Paleontology 37:8-38. DOI: 10.1080/02724634.2017.1410484.

Ranivoharimanana L., Kammerer CF., Flynn JJ., Wyss AR. 2011. New material of Dadadon isaloi (Cynodontia, Traversodontidae) from the Triassic of Madagascar. Journal of Vertebrate Paleontology 31:1292-1302. DOI: 10.1080/039.031.0619.

Rauhut OWM., Werner C. 1995. First record of the family Dromaeosauridae (Dinosauria: Theropoda) in the Cretaceous of Gondwana (Wadi Milk Formation, northern Sudan). Paläontologische Zeitschrift 69:475-489. DOI: 10.1007/BF02987808.

Reisz RR., Sues H-D. 2000. Herbivory in late Paleozoic and Triassic terrestrial vertebrates. In: Sues H-D ed. Evolution of Herbivory in Terrestrial Vertebrates. New York: Cambridge University Press, 9-41. 
1959 Romer AS. 1967. The Chañares (Argentina) Triassic reptile fauna. III. Two new gomphodonts, 1960 Massetognathus pascuali and M. teruggii. Breviora 264:1-25.

1961 Rubidge BS. 2005. 27th Du Toit Memorial Lecture Re-uniting lost continents - Fossil reptiles 1962 from the ancient Karoo and their wanderlust. South African Journal of Geology 108:135172. DOI: $10.2113 / 108.1 .135$.

1964 Sander PM. 1997a. Prismless enamel in amniotes: terminology, function, and evolution. In: 1965 Koenigswald W v., Sander PM eds. Tooth Enamel Microstructure. Rotterdam; 1966 Brookfield, VT: CRC Press, 92-106.

1967 Sander PM. 1997b. Non-mammalian synapsid enamel and the origin of mammalian enamel prisms: the bottom-up perspective. In: Koenigswald W v., Sander PM eds. Tooth Enamel Microstructure. Rotterdam; Brookfield, VT: CRC Press, 41-62.

Sander PM. 1997c. Teeth and jaws. In: Currie PJ, Padian K eds. Encyclopedia of Dinosaurs. San Diego, California: Academic Press, 717-725.

Sander PM. 1999. The microstructure of reptilian tooth enamel: terminology, function, and phylogeny. Münchner Geowissenschaftliche Abhandlungen, Reihe A 38:1-102.

Schwenk K. 2000. Feeding: Form, Function and Evolution in Tetrapod Vertebrates. Academic Press.

Seeley HG. 1894. Researches on the structure, organization, and classification of the fossil Reptilia. Part IX., Section 3. On Diademodon. Philosophical Transactions of the Royal Society of London. B 185:1029-1041.

1979 Seeley HG. 1895. Researches on the structure, organization, and classification of the fossil 1980 Reptilia. Part IX., Section 4. On the Gomphodontia. Philosophical Transactions of the 1981 Royal Society of London. B 186:1-57. 
1982 Seeley HG. 1908. Additional evidence as to the dentition and structure of the skull in the South 1983 African fossil reptile genus Diademodon. Proceedings of the Zoological Society of 1984 London 78:611-617. DOI: 10.1111/j.1469-7998.1908.tb07394.x.

1985 Sidor CA., Hopson JA. 2018. Cricodon metabolus (Cynodontia: Gomphodontia) from the 1986

Smith JB., Vann DR., Dodson P. 2005. Dental morphology and variation in theropod dinosaurs: 2001 2002 2003 Implications for the taxonomic identification of isolated teeth. The Anatomical Record Part A: Discoveries in Molecular, Cellular, and Evolutionary Biology 285A:699-736.

Smith R., Swart R. 2002. Changing fluvial environments and vertebrate taphonomy in response to climatic drying in a Mid-Triassic rift valley fill: The Omingonde Formation (Karoo Supergroup) of Central Namibia. PALAIOS 17:249-267. DOI: 10.1669/08831351(2002)017<0249:CFEAVT>2.0.CO;2. 
2004 Soares MB., Martinelli AG., Oliveira TV. 2014. A new prozostrodontian cynodont (Therapsida) 2005 from the Late Triassic Riograndia Assemblage Zone (Santa Maria Supersequence) of 2006 2007 2008 central New Mexico: The Characteristic Assemblage of the Apachean Land-vertebrate Faunachron: Bulletin 55. New Mexico Museum of Natural History and Science 55:1-119. Spielmann JA., Lucas SG. 2012. Tetrapod Fauna of the Upper Triassic Redona Formation Eastjeffersoni (Cynodontia: Gomphodontia) from the Upper Triassic of Virginia. Journal of Vertebrate Paleontology 30:1202-1220. DOI: 10.1080/02724634.2010.483545.

Sues H-D., Hopson JA., Shubin NH. 1992. Affinities of?Scalenodontoides plemmyridon Hopson, 1984 (Synapsida: Cynodontia) from the Upper Triassic of Nova Scotia. Journal of Vertebrate Paleontology 12:168-171. DOI: 10.1080/02724634.1992.10011447.

Sues H-D., Olsen PE., Carter JG. 1999. A Late Triassic traversodont cynodont from the Newark Supergroup of North Carolina. Journal of Vertebrate Paleontology 19:351-354. DOI: 10.1080/02724634.1999.10011146.

Sun A. 1988. Additional study on Sinognathus gracilis (Cynodontia; Reptilia). Vertebrata Palasiatica 26:173-180.

Tatarinov LP. 2002. Gomphodont cynodonts (Reptilia, Theriodontia) from the Middle Triassic of the Orenburg region. Paleontological Journal 36:176-179.

Valencio DA., Mendía J., Vilas JF. 1975. Palaeomagnetism and K-Ar ages of triassic igneous rocks from the Ischigualasto-Ischichuca Basin and Puesto Viejo Formation, Argentina. Earth and Planetary Science Letters 26:319-330. DOI: 10.1016/0012-821X(75)90007-2. 
2026 Watson DMS. 1911. XL.-The skull of Diademodon, with notes on those of some other 2027 Cynodonts. Annals and Magazine of Natural History 8:293-330. DOI: $10.1080 / 00222931108693034$.

2029

2030

2031 2032 2033 2034 2035 2036 2037 2038 2039

2040 Figure captions

2041 Figure 1. Phylogeny and geographic and stratigraphic distribution of cynodont clades. A, Tree 2042 topology based on the results of the cladistic analyses of Liu \& Abdala (2014) for cynognathians 2043 and Martínez, Fernandez \& Alcober (2013) and Martinelli, Soares \& Schwanke (2016) for 2044

Watson DMS. 1913. I.- On a new cynodont from the Stormberg. Geological Magazine 10:145148. DOI: $10.1017 / \mathrm{S} 0016756800126032$.

Wynd BM., Peecook BR., Whitney MR., Sidor CA. 2018. The first occurrence of Cynognathus crateronotus (Cynodontia: Cynognathia) in Tanzania and Zambia, with implications for the age and biostratigraphic correlation of Triassic strata in southern Pangea. Journal of Vertebrate Paleontology 37:228-239. DOI: 10.1080/02724634.2017.1421548.

Young C. 1959. Note on the first cynodont from the Sinokannemeyeria faunas in Shansi, China. Vertebrata PalAsiatica 3:124-132.

Ziegler AC. 1969. A theoretical determination of tooth succession in the therapsid Diademodon. Journal of Paleontology 43:771-778. probainognathians. Titanogomphodon, considered to be a close relative of Diademodon by Keyser (1973) and Martinelli, de la Fuente \& Abdala (2009), is placed among Diademodontidae. Node 1, Eucynodontia; Node 2, Probainognathia; Node 3, Cynognathia; Node 4, Gomphodontia; Node 5, Diademodontidae; and Node 6, Trirachodontidae. Arrows indicate that the clades extend beyond the Lower Jurassic. B, Stratigraphic distribution of Diademodontidae (in yellow) and Trirachodontidae (in blue-purple), with Diademodon in pale yellow, Titanogomphodon in dark yellow, Langbergia in pale blue, Cricodon in blue sky, Trirachodon in dark blue, Sinognathus in light purple and Beishanodon in dark purple. Stratigraphic extension of geological units based on 
2052 Liu et al. (2018) for the Ermaying Formation, Gao et al. (2010) and Niu et al. (2018) for the

2053 Hongyanjing Formation, Rubidge et al. (2005) for the Cynognathus Assemblage Zone, Wynd et

2054 al. (2018) for the Manda Beds and the Upper Omingonde, Ntawere and Fremouw formations, 2055 and Ottone et al. (2014) for the Río Seco de la Quebrada Formation. Stars denote the U-PB 2056 geochronologic ages of 243.53 Ma from Liu et al. (2018) for the upper Ermaying Formation in 2057 China, and 235.82 Ma from Ottone et al. (2014) for the Rio Seco de la Quebrada Formation in 2058 Argentina. Wavy lines indicate unconformities and diagonal lines formational interfingering, 2059 whereas dashed lines, indicates an unclear relationship to the geologic time scale. Age of the 2060 Triassic stage limits based on Cohen et al. (2018). Abbreviations: CAZ, Cynognathus 2061 Assemblage Zone; E, Early Triassic; Fm, Formation; M, Middle Triassic; Ma, million years;

2062 Pr., Province. Ottone et al.'s (2014) hypothesis refers to the Carnian dating for levels of the Río 2063 Seco de la Quebrada Formation. Black silhouettes credit: Sergey Meleshin (Sinognathus), José 2064 Eduardo Camargo Martínez (all others), used with permission.

2065

2066

Figure 2. Dental terminology used in this study. A-B, Diademodon rostrum in A, palatal and $\mathbf{B}$,

2067 labial views; $\mathbf{C}, \mathbf{F}$, idealized right upper gomphodont postcanine in $\mathbf{C}$, apical and $\mathbf{F}$, distal views 2068 (based on the upper gomphodont postcanine of Scalenodon angustifrons by Hopson, 2005; modified); $\mathbf{D}, \mathbf{G}$, idealized left lower gomphodont postcanine in $\mathbf{D}$, apical and $\mathbf{G}$, distal views (based on the lower gomphodont postcanine of Scalenodon angustifrons by Hopson, 2005; modified); E, upper right gomphodont postcanine of Menadon besairiei (UA 10601) in apical view; H, upper right gomphodont postcanine of Diademodon tetragonus (SAM-PK-571) in

2073 apical view; I, idealized sectorial postcanine of Diademodon tetragonus in lingual view (based on the second right upper sectorial postcanine of Diademodon tetragonus $\mathrm{BP} / 1 / 4529)$; $\mathbf{J}$, apex of main cusp of an upper sectorial postcanine of Diademodon tetragonus with close up on the denticles, in labial view; $\mathbf{K}$, close up on the enamel surface texture of the second right upper sectorial postcanine of Diademodon tetragonus (BP/1/4529). Abbreviations: c, canine; ca, carina; cap, crown apex; cc, central cusp (in green); cev, central valley; ci, cingulum; cic, cingular cuspules; clar, centrolabial ridge; clir, centrolingual ridge; co, crown; cos, concave surface; cpc, conical postcanine; cri, central ridge; cu, cusp; db, distal basin; dac, distal accessory cusp; dad, distal accessory cusp; dar, distal accessory ridge; dea, distal carina; dec, 2082 distal cingular cuspule; dci, distal cingulum (in violet); de, denticle; dia, diastema; dmc, distal 
2083 main cusp; dri, distal ridge; dv, distal valley; ec, ectopterygoid; ent, enamel texture; gpc,

2084 gomphodont postcanine; i, incisor; j, jugal; lac, labial cusp (in red); lacc, labial cingular cusp;

2085 laci, labial cingulum (in orange); lacr, labiocentral ridge; ladc, labiodistal accessory cusp; ladr,

2086 labiodistal ridge; lamr, labiomesial ridge; lar, labial ridge; lav, labial valley; lic, lingual cusp (in

2087 blue); licc, lingual cingular cuspule; lici, lingual cingulum (in turquoise); licr, linguocentral

2088 ridge; lidc, linguodistal accessory cusp; lidr, linguodistal ridge; limc, linguomesial accessory

2089 cusp; limr, linguomesial ridge; lir, lingual ridge; liv, lingual valley; lri, longitudinal ridge; mac,

2090 mesial accessory cusp; mar, mesial accessory ridge; mb, mesial basin; mc, main cusp; mca,

2091 mesial carina; mcc, mesial cingular cuspule; mci, mesial cingulum (in beige); mmc, mesial main

2092 cusp; mri, mesial ridge; mv, mesial valley; mx, maxilla; pal, palatine; pc, postcanine; pcf,

2093 postcanine fossa; pmx, premaxilla; ro, root; se, serration; spc, sectorial postcanine; tc, transverse

2094 crest (in yellow); tpc, transitional postcanine; tun, transverse undulation.

2095

2096 Figure 3. Dentition of non-traversodontid Gomphodontia. A, Upper gomphodont postcanine

2097 (SAM-PK-571a); and B, cranial dentition (mainly based on BSP 1934 VIII 14) of Diademodon

2098 tetragonus in apical and palatal views, respectively; C, last right upper gomphodont postcanine;

2099 and D, cranial dentition of Titanogomphodon crassus (GSN R322) in apical and palatal views,

2100 respectively; E, upper gomphodont postcanine (reconstruction based on the fourth and third left

2101 upper gomphodont teeth of NMQR 3251 and 3255, respectively); and $\mathbf{F}$, cranial dentition

2102 (NMQR 3255) of Langbergia modisei in apical and palatal views, respectively; G, last right

2103 upper gomphodont postcanine (UMCZ T905); and H, cranial dentition (reconstruction based on

$2104 \mathrm{BP} / 1 / 6102$ and UMCZ T905 for the anterior and posterior portions of the cranium, respectively,

2105 and NHCC LB28 for the anterior postcanine dentition) of Cricodon metabolus in apical and

2106 palatal views, respectively (the dashed-line represents the lateral margin of the cranium of

2107 NHCC LB28); I-J, antepenultimate right upper gomphodont postcanines (NHM PV R3307,

2108 Trirachodon 'kannemeyeri' morphotype, and BSP 1934 VIII 21, Trirachodon berryi

2109 morphotype, for $\mathbf{I}$ and $\mathbf{J}$, respectively); and $\mathbf{K}$, cranial dentition (BP/1/4658) of Trirachodon

2110 berryi in apical and palatal views, respectively; L, fourth right upper gomphodont postcanine;

2111 and M, cranial dentition of Beishanodon youngi (PKUP V3007) in apical and palatal views,

2112 respectively; N, lower gomphodont postcanine (left anterior tooth of SAM-PK-571b); and $\mathbf{O}$,

2113 mandibular dentition (reconstruction based on MBR 1004 for the mandible, incisor and canine 
2114 morphology, SAM-PK-571b and AM 3753 for the anterior postcanine dentition, and SAM-PK-

$2115 \mathrm{~K} 177$ for the posterior postcanine dentition) of Diademodon tetragonus in apical and dorsal

2116 views, respectively; P-S, upper sectorial postcanines of P, Diademodon tetragonus (MB R1004);

2117 Q, Langbergia modisei (NMQR 3251); R, Trirachodon berryi (SAM-PK-4801); and S,

2118 Cricodon metabolus (UMCZ T905) in labial view; T, lower gomphodont postcanine (third right

2119 tooth of NMQR 5251); and U, mandibular dentition (NMQR 3251) of Langbergia modisei in

2120 apical and dorsal views, respectively; V, lower gomphodont postcanine (last right tooth of

2121 UMCZ T905); and W, mandibular dentition (based on SAM-PK-5881a and UMCZ T905 for the

2122 anterior and posterior dentitions, respectively) of Cricodon metabolus in apical and dorsal views,

2123 respectively; $\mathbf{X}$, lower gomphodont postcanine (antepenultimate right gomphodont tooth of

2124 SAM-PK-K4801); and Y, mandibular dentition (BP/1/4658) of Trirachodon berryi in apical and

2125 dorsal views, respectively; $\mathbf{Z}$, lower gomphodont postcanine (sixth and antepenultimate right

2126 gomphodont tooth of SAM-PK-K171); and a, mandibular dentition (SAM-PK-K171) of

2127 Trirachodon berryi (T. 'kannemeyeri' morphotype) in apical and dorsal views, respectively.

2128 Abbreviations: c, canine (in orange); cpc, conical postcanine (in yellow); dac, distal accessory

2129 cusp; dar, distal accessory ridge; dcc, distal cingular cuspule; gpc, gomphodont postcanine (in

2130 violet); i, incisor (in blue); licc, lingual cingular cuspule; lici, lingual cingulum; mar, mesial

2131 accessory ridge; mc, main cusp; mcc, mesial cingular cuspule; mmc, mesial main cusp; pcf,

2132 postcanine fossa; spc, sectorial postcanine (in green); tpc, transitional postcanine (in red).

2133

2134 Figure 4. Dentition of Diademodon tetragonus. A, Isolated upper incisor (first left incisor?) of

2135 BSP 1934 VIII 14, with B, close up on the distal denticles, in labial view; C, Isolated upper

2136 incisor (first or second right incisor?) of BSP 1934 VIII 14, with D, close up on the mesial

2137 denticles, in lingual view; E, Isolated canine of SAM-PK-571b, with F, close up on the distal

2138 denticles, in lingual? view; G, First to third right upper conical postcanines of MB R1004 in

2139 labial view; H, Fifth right upper conical postcanine of BSP 1934 VIII 14 in apicolabial view; I,

$2140 \mathbf{J}$, Third and fourth left lower conical postcanines of AM 458 in I, labial and $\mathbf{J}$, lingual views; K,

2141 Second to fourth left lower conical postcanines of SAM-PK-5877 in labial view; L, M, Isolated

2142 upper gomphodont postcanine of SAM-PK-571a in L, apical and M, mesial views; N, O, Second

2143 and third right upper gomphodont postcanines of SAM-PK-571a in N, apical and O, distal view;

2144 P, Fourth right upper gomphodont postcanine of BSP 1934 VIII 14 in apical view. 
2145 Abbreviations: cc, central cusp; cic, cingular cuspules; dac, distal accessory cusp; dar, distal 2146 accessory ridge; dca, distal carina; dcc, distal cingular cuspule; dci, distal cingulum; dde, distal

2147 denticle; lac, labial cusp; ladc, labiodistal accessory cusp; lic, lingual cusp; limc, linguomesial

2148 accessory cusp; lri, longitudinal ridge; mar, mesial accessory ridge; mca, mesial carina; mcc,

2149 mesial cingular cuspule; mci, mesial cingulum; mde, mesial denticle; tc, transverse crest.

2150

2151

2152

2153

2154

2155

2156

2157

2158

2159

2160

2161

2162

2163

2164

2165

2166

2167

2168

2169

2170

2171

2172

2173

2174

Figure 5. Dentition of Diademodon tetragonus. A-C, E, Lower gomphodont postcanine from the posterior portion of the mandible of SAM-PK-571b in A, apical, B, labial, $\mathbf{C}$, distal views, and E, close up on the labial cusp of the distal postcanine,; D, distalmost right lower gomphodont postcanine of SAM-PK-5877 in apical view; F, Sixth? gomphodont, first and second transitional, and first sectorial postcanines from the left mandible of SAM-PK-K177 in apical view; G, First transitional and first sectorial postcanines of the right mandible of MB R1004 in apical view; H, Transitional, first and second left upper sectorial postcanines of MB R1004 in labial view (photo credit: Christian Kammerer); I-K, Second right upper sectorial postcanine of BP/1/4529, with close up on $\mathbf{J}$, showing the first distal accessory cusp, and $\mathbf{K}$, the mesial denticles, in labial view. Abbreviations: cc, central cusp; dac, distal accessory cusp; dar, distal accessory ridge; dcc, distal cingular cuspule; dci, distal cingulum; dde, distal denticle; de, denticle; dmc, distal main cusp; lac, labial cusp; ladc, labiodistal accessory cusp; lic, lingual cusp; licc, lingual cingular cuspule; limc, linguomesial accessory cusp; lir, lingual ridge; mar, mesial accessory ridge; mc, main cusp; mcc, mesial cingular cuspule; mci, mesial cingulum; mde, mesial denticle; mmc, mesial main cusp; tc, transverse crest.

Figure 6. Dentition of Titanogomphodon crassus. A-C, E. Right upper gomphodont, transitional and sectorial postcanines of GSN R322, with close up on B, the penultimate gomphodont, $\mathbf{C}$, mesial accessory ridge of the distalmost gomphodont, and $\mathbf{E}$, distalmost sectorial postcanine in apical view; D-F, left mesialmost preserved upper gomphodont postcanine of GSN R322 in D, apical and F, mesial views. Abbreviations: lac, labial cusp; lamc, labiomesial accessory cusp; lic, lingual cusp; mar, medial accessory ridge; mcc, mesial cingular cusp; spc, sectorial postcanine; tc, transverse cusp; tpc, transitional postcanine. 
2175 Figure 7. Dentition of Langbergia modisei. A-B, First left lower incisor of NMQR 3251, with B,

2176 close up on the distal carina in labial view; $\mathbf{C}$, close up on the distal carina of the fourth left

2177 upper incisor of NMQR 3281 in labial view; D, F-G, right lower canine of NMQR 3251, with

2178 close up on the $\mathbf{F}$, distal and $\mathbf{G}$, mesial carina, in labial view; $\mathbf{E}$, cross-sectional outline of the

2179 right upper canine of SAM-PK-11481 in apical view (labial and mesial sides to the top and the

2180 right, respectively); H, right upper canine of BP/1/5362 in labial view; $\mathbf{I}$, centromesial portion of

2181 the erupting left upper canine of NMQR 3268 in labial view; J, fourth and fifth left upper

2182 gomphodont postcanines of NMQR 3251 in apical view; $\mathbf{K}$, third left upper postcanine of

2183 NMQR 3255 in apical view; L, close up on the fourth left upper postcanine of NMQR 3251 in

2184 mesial view (crown upside down); M, third and fourth right lower gomphodont postcanine of

2185 NMQR 3251 in apical view; N, first left lower gomphodont postcanine of NMQR 3251 in

2186 apicodistal view; O, first and second right upper sectorial postcanine of NMQR 3251 in labial

2187 view; P, first right upper sectorial postcanine of BP/1/5362 in labial view; $\mathbf{Q}$, second left upper

2188 sectorial postcanine of NMQR 3255 in linguomesial view. Abbreviations: cc, central cusp; dac,

2189 distal accessory cusp; db, distal basin; dcc, distal cingular cuspule; dci, distal cingulum; dde,

2190 distal denticle; de, denticle; dmc, distal main cusp; lac, labial cusp; ladc, labiodistal accessory

2191 cusp; lamc, labiomesial accessory cusp; lic, lingual cusp; licc, lingual cingular cuspule; lidc,

2192 linguodistal accessory cusp; limc, linguomesial accessory cusp; lri, longitudinal ridge; mac,

2193 mesial accessory cusp; mb, mesial basin; mc, main cusp; mcc, mesial cingular cuspule; mci,

2194 mesial cingulum; mde, mesial denticle; mmc, mesial main cusp; tc, transverse crest. Elongation

2195 axes of the crown and the central cusp in green and red, respectively.

2196

2197 Figure 8. Dentition of Cricodon metabolus. A-B, First left lower incisor of UMCZ T905 in A,

2198 labial and B, labiodistal views; C-D, fourth left upper incisor of BP/1/6102, with D, close up on

2199 the distal denticles, in labial view; E-F, left lower canine of SAM-PK-5881 $a$, in E, lingual view;

2200 with $\mathbf{F}$, cross-sectional outline at mid-crow apical view; $\mathbf{G}$, centromesial and $\mathbf{H}$, centrodistal

2201 denticles of the right upper canine of BP/1/6102 in labial view; I, centrodistal denticles of the

2202 right upper canine of BP/1/5540 in labial view; J, eight? and nine? right upper gomphodont

2203 postcanines of UMCZ T905 in apical view; K, eight and nine right lower gomphodont

2204 postcanines of UMCZ T905 in apical view; L, first left lower gomphodont postcanine of SAM-

2205 PK-5881 $a$ in apical view; M, last right upper gomphodont postcanine of SAM-PK-5881 $b$ in 
2206 distal view; N, last left upper gomphodont postcanine of UMCZ T905; O, close up on the

2207 denticles on the labiodistal ridge of an isolated left upper postcanine of UMCZ T905 in

2208 labiodistal view; P-Q, ninth right upper sectorial postcanine of UMCZ T905 in P, labial and $\mathbf{Q}$,

2209 apical views. Abbreviations: cac, central accessory cusp; cc, central cusp; cos, concave surface;

2210 dac, distal accessory cusp; db, distal basin; dec, distal cingular cuspule; dei, distal cingulum;

2211 dde, distal denticle; de, denticle; dmc, distal main cusp; ent, enamel surface texture; lac, labial

2212 cusp; ladc, labiodistal accessory cusp; lic, lingual cusp; lidc, linguodistal accessory cusp; limc,

2213 linguomesial accessory cusp; Iri, longitudinal ridge; mb, mesial basin; mc, main cusp; mcc,

2214 mesial cingular cuspule; mci, mesial cingulum; mde, mesial denticle; mmc, mesial accessory

2215 cusp; tc, transverse crest; tun, transverse undulation. The red lines highlight the angular

2216 labiodistal margin of the lower postcanines.

2217

2218 Figure 9. Dentition of Trirachodon berryi I. A-C, First? left upper incisor, with close up on B,

2219 mesial and C, distal denticles of SAM-PK-12168 in labial view; D, first left and right upper and

2220 E, first right lower incisors of BP/1/4658 in apical views; F-G, right upper canine of BP/1/4661

2221 with $\mathbf{G}$, close up on the centrodistal part of the crown, in labial view; $\mathbf{H}$, distal denticles of the

2222 right lower canine of BP/1/4658 in labial view; I, fifth and sixth right upper gomphodont

2223 postcanines of SAM-PK-K171 ('T. kannemeyeri’ morphotype) in apical view; J, tenth and

2224 eleventh left (reversed) upper gomphodont postcanines of BSP 1934 VIII 21 (T. berryi

2225 morphotype) in apical view; K, penultimate right upper gomphodont postcanine of SAM-PK-

2226 K4801 ('T. kannemeyeri' morphotype) in apical view; M, penultimate left upper gomphodont

2227 postcanine of NHMUK PV R3307 ('T. kannemeyeri' morphotype) in apical view; N, tenth left

2228 upper gomphodont postcanine of BSP 1934 VIII 21 (T. berryi morphotype) in apical view; O,

2229 partially erupted twelfth (and last) upper gomphodont postcanine of BSP 1934 VIII 21 in distal

2230 view. Abbreviations: cc, central cusp; dac, distal accessory cusp; db, distal basin; dec, distal

2231 cingular cuspule; dci, distal cingulum; ent, enamel surface texture; lac, labial cusp; ladc,

2232 labiodistal accessory cusp; lamc, labiomesial accessory cusp; lic, lingual cusp; lidc, linguodistal

2233 accessory cusp; limc, linguomesial accessory cusp; lri, longitudinal ridge; mb, mesial basin; mc,

2234 main cusp; mcc, mesial cingular cuspule; mci, mesial cingulum; tc, transverse crest; tun,

2235 transverse undulation.

2236

PeerJ reviewing PDF | (2018:02:25716:2:0:NEW 28 Feb 2019) 
2237 Figure 10. Dentition of Trirachodon berryi II. A, fifth and sixth right lower gomphodont 2238 postcanines of SAM-PK-K171 in apical view; B, penultimate and C, ultimate (and basolingually rotated) right lower gomphodont postcanines of SAM-PK-K4801 in apical view; D, first left

2240 lower gomphodont postcanine of BP/1/4658 in apical view; E, fifth (bottom) and sixth (top) right 2241 lower gomphodont postcanines of SAM-PK-K171 in apicomesial view; F, first (left) and second 2242 (right) right upper sectorial postcanines of SAM-PK-K4801 in labial view; G-H, first right lower 2243 sectorial postcanine of SAM-PK-K4801 in G, labial and H, lingual views; I-J, first and second 2244 (erupted and replacing tooth) right lower sectorial postcanines of BP/1/4658 in $\mathbf{I}$, labial and $\mathbf{J}$, 2245 apical views. Abbreviations: cc, central cusp; dac, distal accessory cusp; db, distal basin; dcc, 2246 distal cingular cuspule; dci, distal cingulum; dde, distal denticle; de, denticle; dmc, distal main 2247 cusp; ent, enamel surface texture; lac, labial cusp; lacc, labial cingular cuspule; laci, labial 2248 cingulum; lic, lingual cusp; licc, lingual cingular cuspules; lici, lingual cingulum; mac, mesial 2249 accessory cusp; mb, mesial basin; mc, main cusp; mca, mesial carina; mcc, mesial cingular 2250 cuspule; mci, mesial cingulum; mmc, mesial main cusp.

2251

2252 Figure 11. Dentition of Sinognathus gracilis (IVPP V2339). A, second left upper incisor in labial 2253 view; B, fourth left upper incisor, with C, close up on basodistal denticles, in labial views; D, 2254 basal root cross-sectional outline of the first left upper incisor in apical view; E, left and F, right 2255 lower canines in labial view; $\mathbf{H}$, first to sixth upper and lower left gomphodont postcanines 2256 (sagittal cross-section through mid-crown), with close up on the fourth upper gomphodont 2257 postcanine, in labial view; J, right second to sixth upper (bottom) and second to seventh lower 2258 (top) gomphodont postcanines in linguodistal view (and apicodistal and basodistal views for the 2259 upper and lower gomphodont postcanines, respectively); K-L, third right upper gomphodont 2260 postcanine in $\mathbf{K}$, apicodistal and $\mathbf{L}$, apicolingual views; $\mathbf{M}$, third right lower gomphodont 2261 postcanine in labial view; $\mathbf{N}$, fourth left lower gomphodont postcanine in labial view; O-P, sixth 2262 (and last) upper gomphodont postcanine in $\mathbf{O}$, linguodistal and $\mathbf{P}$, apicolingual views.

2263 Abbreviations: cc, central cusp; dci, distal cingulum; de, denticle; lac, labial cusp; lic, lingual 2264 cusp; limc, linguomesial accessory cusp; mci, mesial cingulum; mde, mesial denticle; ro, root; 2265 tc, transverse crest; I-VI, first to sixth gomphodont postcanines. 
2267 Figure 12. Comparison of skull length (i.e., distance measured from the anteriormost point of the 2268 snout to the posteriormost point of the occipital condyles) and widest upper gomphodont 2269 postcanine labiolingual width in gomphodont cynodonts, with linear regression trendlines for 2270 gomphodont taxa (in black) and Diademodon (in yellow). Diademodon I, II and III refer to 2271 specimens BSP 1934 VIII 14, MB R1004 and BSP 1934 VIII 19, respectively, Andescynodon I 2272 and II to specimens PVL 3836 and PVL 3894-1, Pascualgnathus I and II to specimens PVL 22734416 and MLP 65-VI-18-1, and Massetognathus I, II, III and IV to specimens BP/1/4245, PVL 2274 4729, PVL 4727 and PVL 4613, respectively. Abbreviations: CBW, crown base width. 


\section{Figure 1}

Phylogeny and geographic and stratigraphic distribution of cynodont clades.

A, Tree topology based on the results of the cladistic analyses of Liu \& Abdala (2014) for cynognathians and Martínez, Fernandez \& Alcober (2013) and Martinelli, Soares \& Schwanke (2016) for probainognathians. Titanogomphodon, considered to be a close relative of Diademodon by Keyser (1973) and Martinelli, de la Fuente \& Abdala (2009) , is placed among Diademodontidae. Node 1, Eucynodontia; Node 2, Probainognathia; Node 3, Cynognathia; Node 4, Gomphodontia; Node 5, Diademodontidae; and Node 6, Trirachodontidae. Arrows indicate that the clades extend beyond the Lower Jurassic. B, Stratigraphic distribution of Diademodontidae (in yellow) and Trirachodontidae (in blue-purple), with Diademodon in pale yellow, Titanogomphodon in dark yellow, Langbergia in pale blue, Cricodon in blue sky, Trirachodon in dark blue, Sinognathus in light purple and Beishanodon in dark purple. Stratigraphic extension of geological units based on Liu et al. (2018) for the Ermaying Formation, Gao et al. (2010) and Niu et al. (2018) for the Hongyanjing Formation, Rubidge et al. (2005) for the Cynognathus Assemblage Zone, Wynd et al. (2018) for the Manda Beds and the Upper Omingonde, Ntawere and Fremouw formations, and Ottone et al. (2014) for the Río Seco de la Quebrada Formation. Stars denote the U-PB geochronologic ages of $243.53 \mathrm{Ma}$ from Liu et al. (2018) for the upper Ermaying Formation in China, and 235.82 Ma from Ottone et al. (2014) for the Rio Seco de la Quebrada Formation in Argentina. Wavy lines indicate unconformities and diagonal lines formational interfingering, whereas dashed lines, indicates an unclear relationship to the geologic time scale. Age of the Triassic stage limits based on Cohen et al. (2018) . Abbreviations: CAZ, Cynognathus Assemblage Zone; E, Early Triassic; Fm, Formation; M, Middle Triassic; Ma, million years; Pr., Province. Ottone et al.'s (2014) hypothesis refers to the Carnian dating for levels of the Río Seco de la Quebrada Formation. Black silhouettes credit: Sergey Meleshin (Sinognathus), José Eduardo Camargo Martínez (all 
others), used with permission.

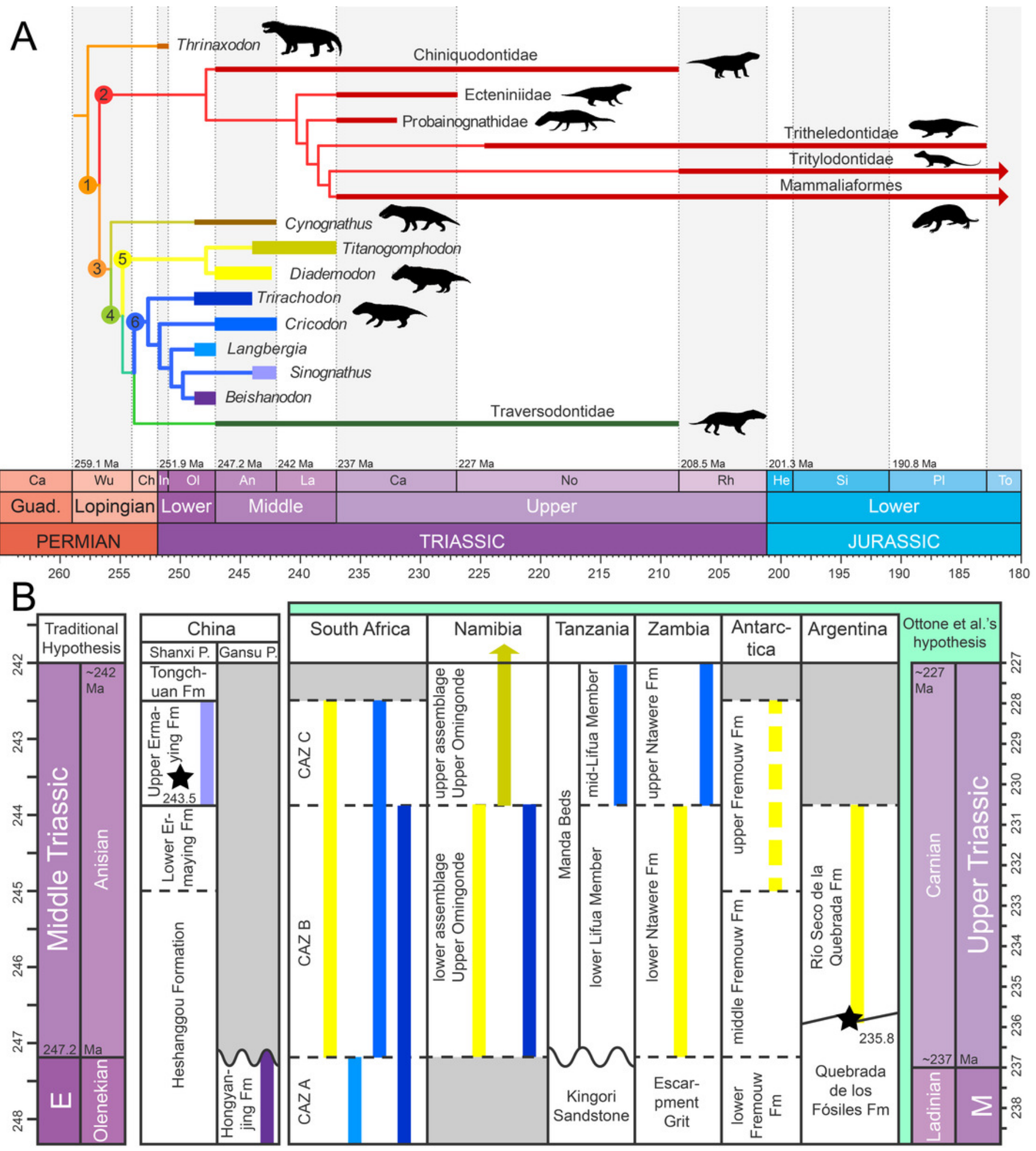




\section{Figure 2}

Dental terminology used in this study.

A-B, Diademodon rostrum in A, palatal and B, labial views; C, F, idealized right upper gomphodont postcanine in $\mathbf{C}$, apical and $\mathbf{F}$, distal views (based on the upper gomphodont postcanine of Scalenodon angustifrons by Hopson, 2005 ; modified); D, G, idealized left lower gomphodont postcanine in $\mathbf{D}$, apical and $\mathbf{G}$, distal views (based on the lower gomphodont postcanine of Scalenodon angustifrons by Hopson, 2005 ; modified); E, upper right gomphodont postcanine of Menadon besairiei (UA 10601) in apical view; H, upper right gomphodont postcanine of Diademodon tetragonus (SAM-PK-571) in apical view; I, idealized sectorial postcanine of Diademodon tetragonus in lingual view (based on the second right upper sectorial postcanine of Diademodon tetragonus BP/1/4529); J, apex of main cusp of an upper sectorial postcanine of Diademodon tetragonus with close up on the denticles, in labial view; $\mathbf{K}$, close up on the enamel surface texture of the second right upper sectorial postcanine of Diademodon tetragonus (BP/1/4529). Abbreviations: c, canine; ca, carina; cap, crown apex; cc, central cusp (in green); cev, central valley; ci, cingulum; cic, cingular cuspules; clar, centrolabial ridge; clir, centrolingual ridge; co, crown; cos, concave surface; cpc, conical postcanine; cri, central ridge; cu, cusp; db, distal basin; dac, distal accessory cusp; dad, distal accessory cusp; dar, distal accessory ridge; dca, distal carina; dcc, distal cingular cuspule; dci, distal cingulum (in violet); de, denticle; dia, diastema; dmc, distal main cusp; dri, distal ridge; dv, distal valley; ec, ectopterygoid; ent, enamel texture; gpc, gomphodont postcanine; i, incisor; $\mathbf{j}$, jugal; lac, labial cusp (in red); lacc, labial cingular cusp; laci, labial cingulum (in orange); lacr, labiocentral ridge; ladc, labiodistal accessory cusp; ladr, labiodistal ridge; lamr, labiomesial ridge; lar, labial ridge; lav, labial valley; lic, lingual cusp (in blue); licc, lingual cingular cuspule; lici, lingual cingulum (in turquoise); licr, linguocentral ridge; lidc, linguodistal accessory cusp; lidr, linguodistal ridge; limc, 
linguomesial accessory cusp; limr, linguomesial ridge; lir, lingual ridge; liv, lingual valley; Iri, longitudinal ridge; mac, mesial accessory cusp; mar, mesial accessory ridge; $\mathbf{m b}$, mesial basin; mc, main cusp; mca, mesial carina; mcc, mesial cingular cuspule; mci, mesial cingulum (in beige); $\mathbf{m m c}$, mesial main cusp; $\mathbf{m r i}$, mesial ridge; $\mathbf{m v}$, mesial valley; $\mathbf{m} \mathbf{x}$, maxilla; pal, palatine; pc, postcanine; pcf, postcanine fossa; pmx, premaxilla; ro, root; se, serration; spc, sectorial postcanine; tc, transverse crest (in yellow); tpc, transitional postcanine; tun, transverse undulation. 

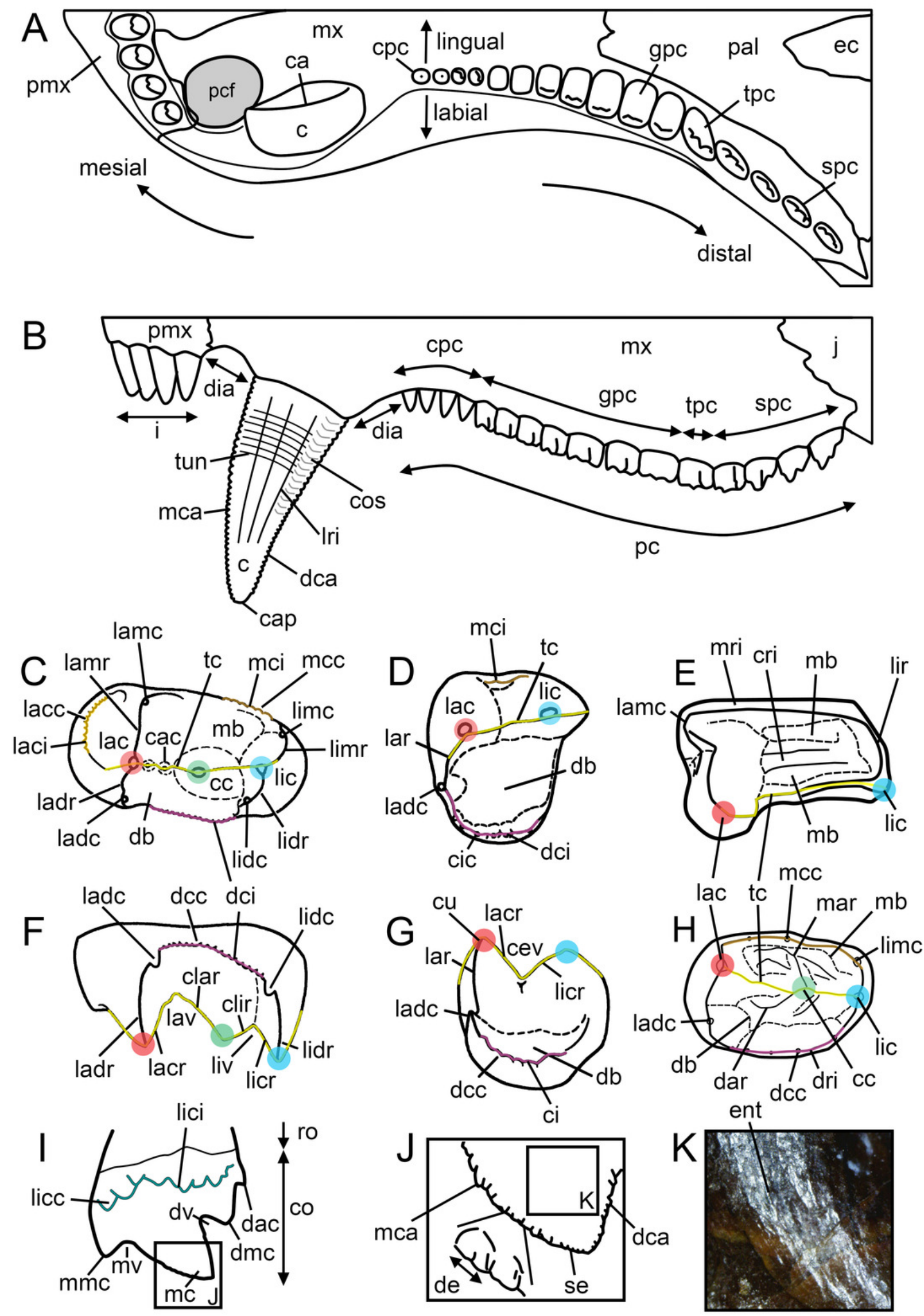


\section{Figure 3}

Figure 3. Dentition of non-traversodontid Gomphodontia.

A, Upper gomphodont postcanine (SAM-PK-571a); and B, cranial dentition (mainly based on BSP 1934 VIII 14) of Diademodon tetragonus in apical and palatal views, respectively; C, last right upper gomphodont postcanine; and $\mathbf{D}$, cranial dentition of Titanogomphodon crassus (GSN R322) in apical and palatal views, respectively; E, upper gomphodont postcanine (reconstruction based on the fourth and third left upper gomphodont teeth of NMQR 3251 and 3255, respectively); and $\mathbf{F}$, cranial dentition (NMQR 3255) of Langbergia modisei in apical and palatal views, respectively; G, last right upper gomphodont postcanine (UMCZ T905); and $\mathbf{H}$, cranial dentition (reconstruction based on BP/1/6102 and UMCZ T905 for the anterior and posterior portions of the cranium, respectively, and NHCC LB28 for the anterior postcanine dentition) of Cricodon metabolus in apical and palatal views, respectively (the dashed-line represents the lateral margin of the cranium of NHCC LB28); I-J, antepenultimate right upper gomphodont postcanines (NHM PV R3307, Trirachodon 'kannemeyeri' morphotype, and BSP 1934 VIII 21, Trirachodon berryi morphotype, for I and J, respectively); and $\mathbf{K}$, cranial dentition (BP/1/4658) of Trirachodon berryi in apical and palatal views, respectively; L, fourth right upper gomphodont postcanine; and $\mathbf{M}$, cranial dentition of Beishanodon youngi (PKUP V3007) in apical and palatal views, respectively; $\mathbf{N}$, lower gomphodont postcanine (left anterior tooth of SAM-PK-571b); and $\mathbf{0}$, mandibular dentition (reconstruction based on MBR 1004 for the mandible, incisor and canine morphology, SAMPK-571b and AM 3753 for the anterior postcanine dentition, and SAM-PK-K177 for the posterior postcanine dentition) of Diademodon tetragonus in apical and dorsal views, respectively; P-S, upper sectorial postcanines of $\mathbf{P}$, Diademodon tetragonus (MB R1004); Q, Langbergia modisei (NMQR 3251); R, Trirachodon berryi (SAM-PK-4801); and S, Cricodon metabolus (UMCZ T905) in labial view; T, lower gomphodont postcanine (third right tooth of 
NMQR 5251); and $\mathbf{U}$, mandibular dentition (NMQR 3251) of Langbergia modisei in apical and dorsal views, respectively; V, lower gomphodont postcanine (last right tooth of UMCZ T905); and $\mathbf{W}$, mandibular dentition (based on SAM-PK-5881a and UMCZ T905 for the anterior and posterior dentitions, respectively) of Cricodon metabolus in apical and dorsal views, respectively; $\mathbf{X}$, lower gomphodont postcanine (antepenultimate right gomphodont tooth of SAM-PK-K4801); and Y, mandibular dentition (BP/1/4658) of Trirachodon berryi in apical and dorsal views, respectively; $\mathbf{Z}$, lower gomphodont postcanine (sixth and antepenultimate right gomphodont tooth of SAM-PK-K171); and $\mathbf{a}$, mandibular dentition (SAM-PK-K171) of Trirachodon berryi (T. 'kannemeyeri' morphotype) in apical and dorsal views, respectively. Abbreviations: c, canine (in orange); cpc, conical postcanine (in yellow); dac, distal accessory cusp; dar, distal accessory ridge; dcc, distal cingular cuspule; gpc, gomphodont postcanine (in violet); i, incisor (in blue); licc, lingual cingular cuspule; lici, lingual cingulum; mar, mesial accessory ridge; mc, main cusp; $\mathbf{m c c}$, mesial cingular cuspule; $\mathbf{m m c}$, mesial main cusp; pcf, postcanine fossa; spc, sectorial postcanine (in green); tpc, transitional postcanine (in red). 

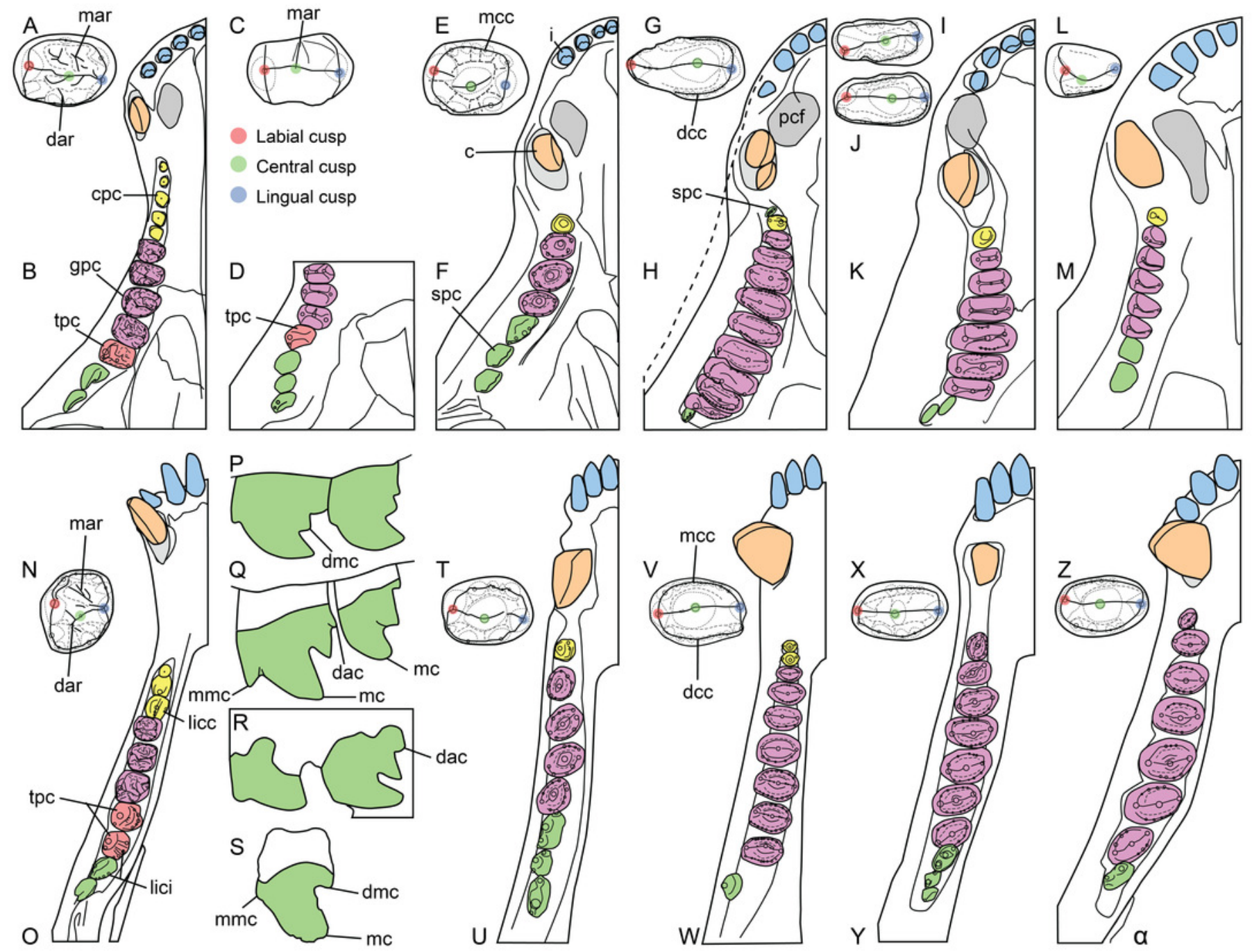


\section{Figure 4}

Dentition of Diademodon tetragonus.

A, Isolated upper incisor (first left incisor?) of BSP 1934 VIII 14, with B, close up on the distal denticles, in labial view; C, Isolated upper incisor (first or second right incisor?) of BSP 1934 VIII 14, with D, close up on the mesial denticles, in lingual view; E, Isolated canine of SAMPK-571b, with F, close up on the distal denticles, in lingual? view; G, First to third right upper conical postcanines of MB R1004 in labial view; H, Fifth right upper conical postcanine of BSP 1934 VIII 14 in apicolabial view; I, J, Third and fourth left lower conical postcanines of AM 458 in I, labial and J, lingual views; $\mathbf{K}$, Second to fourth left lower conical postcanines of SAMPK-5877 in labial view; L, M, Isolated upper gomphodont postcanine of SAM-PK-571 in L, apical and $\mathbf{M}$, mesial views; $\mathbf{N}, \mathbf{O}$, Second and third right upper gomphodont postcanines of SAM-PK-571 in N, apical and $\mathbf{0}$, distal view; P, Fourth right upper gomphodont postcanine of BSP 1934 VIII 14 in apical view. Abbreviations: cc, central cusp; cic, cingular cuspules; dac, distal accessory cusp; dar, distal accessory ridge; dca, distal carina; dcc, distal cingular cuspule; dci, distal cingulum; dde, distal denticle; lac, labial cusp; ladc, labiodistal accessory cusp; lic, lingual cusp; limc, linguomesial accessory cusp; Iri, longitudinal ridge; mar, mesial accessory ridge; mca, mesial carina; mcc, mesial cingular cuspule; mci, mesial cingulum; mde, mesial denticle; tc, transverse crest. 


\section{Diademodon tetragonus}

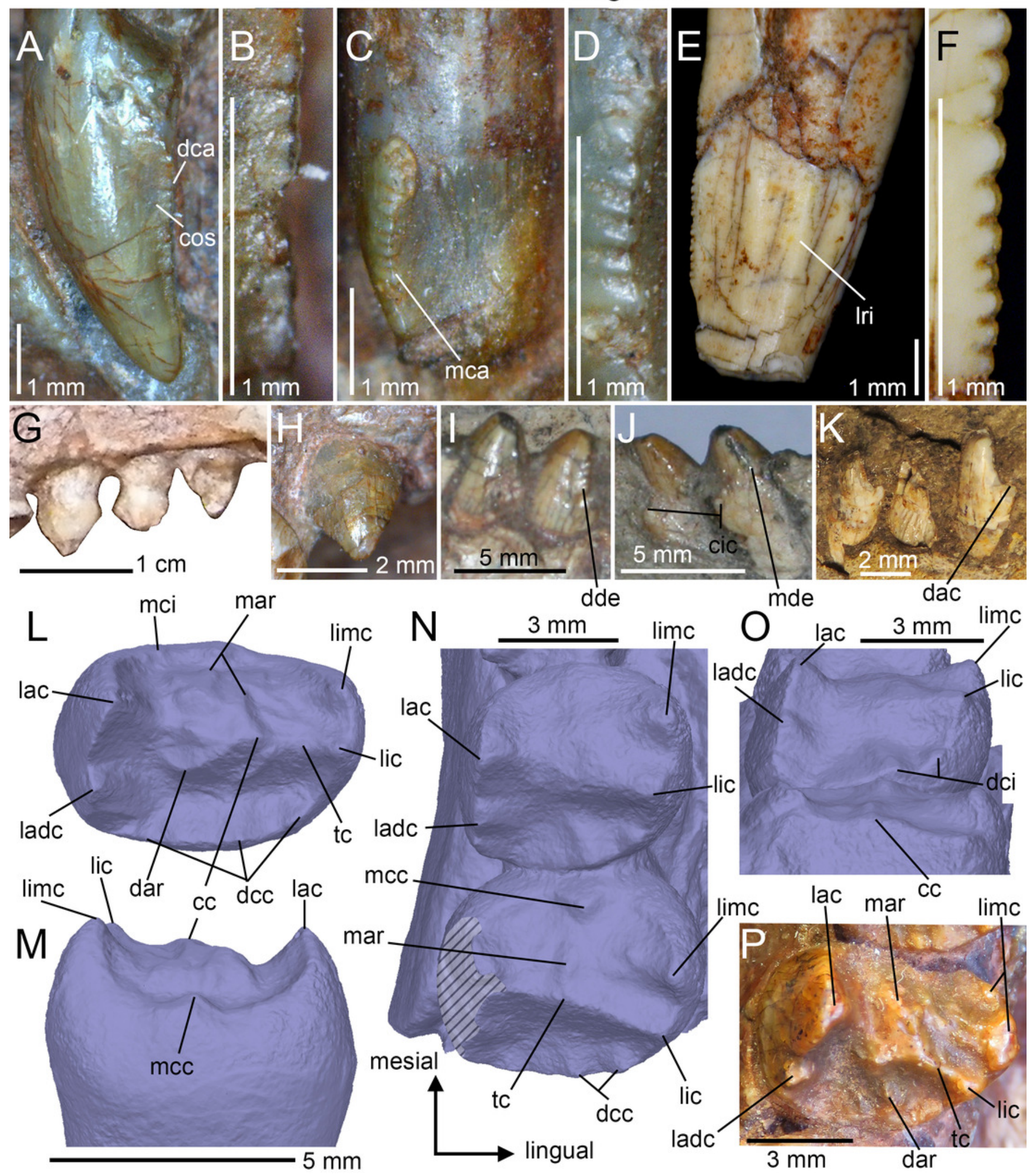




\section{Figure 5}

Dentition of Diademodon tetragonus

A-C, E, Lower gomphodont postcanine from the posterior portion of the mandible of SAM-

PK-571b in A, apical, B, labial, C, distal views, and E, close up on the labial cusp of the distal postcanine,; $\mathbf{D}$, distalmost right lower gomphodont postcanine of SAM-PK-5877 in apical view;

F, Sixth? gomphodont, first and second transitional, and first sectorial postcanines from the left mandible of SAM-PK-K177 in apical view; G, First transitional and first sectorial postcanines of the right mandible of MB R1004 in apical view; H, Transitional, first and second left upper sectorial postcanines of MB R1004 in labial view (photo credit: Christian Kammerer); I-K, Second right upper sectorial postcanine of BP/1/4529, with close up on J, showing the first distal accessory cusp, and $\mathbf{K}$, the mesial denticles, in labial view.

Abbreviations: cc, central cusp; dac, distal accessory cusp; dar, distal accessory ridge; dcc, distal cingular cuspule; dci, distal cingulum; dde, distal denticle; de, denticle; dmc, distal main cusp; lac, labial cusp; ladc, labiodistal accessory cusp; lic, lingual cusp; licc, lingual cingular cuspule; limc, linguomesial accessory cusp; lir, lingual ridge; mar, mesial accessory ridge; mc, main cusp; $\mathbf{m c c}$, mesial cingular cuspule; $\mathbf{m c i}$, mesial cingulum; mde, mesial denticle; $\mathbf{m m c}$, mesial main cusp; tc, transverse crest. 

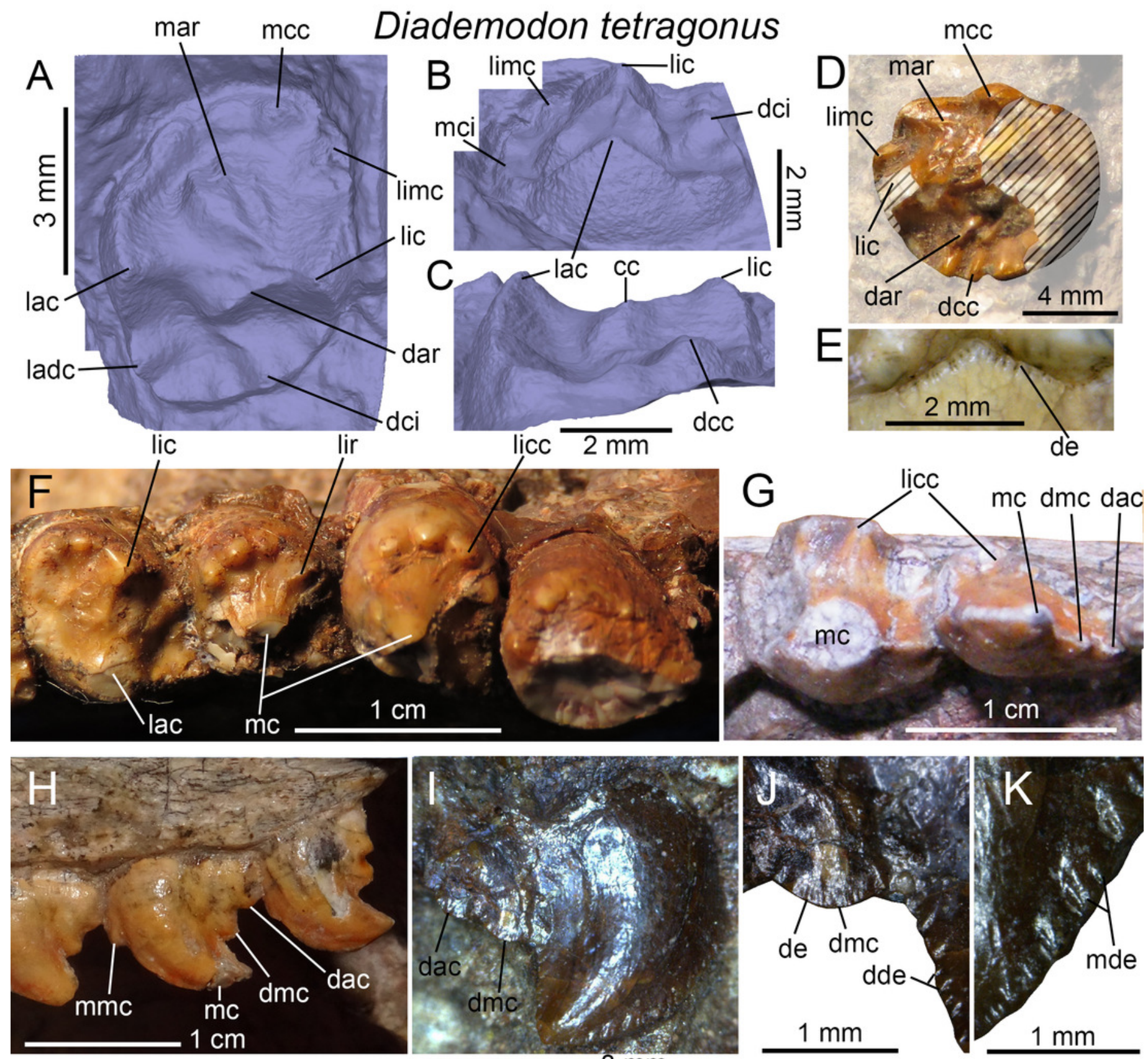


\section{Figure 6}

Dentition of Titanogomphodon crassus.

A-C, E. Right upper gomphodont, transitional and sectorial postcanines of GSN R322, with close up on B, the penultimate gomphodont, $\mathbf{C}$, mesial accessory ridge of the distalmost gomphodont, and $\mathbf{E}$, distalmost sectorial postcanine in apical view; D-F, left mesialmost preserved upper gomphodont postcanine of GSN R322 in D, apical and F, mesial views. Abbreviations: lac, labial cusp; lamc, labiomesial accessory cusp; lic, lingual cusp; mar, medial accessory ridge; $\mathbf{m c c}$, mesial cingular cusp; spc, sectorial postcanine; tc, transverse cusp; tpc, transitional postcanine. 


\section{Titanogomphodon crassus}

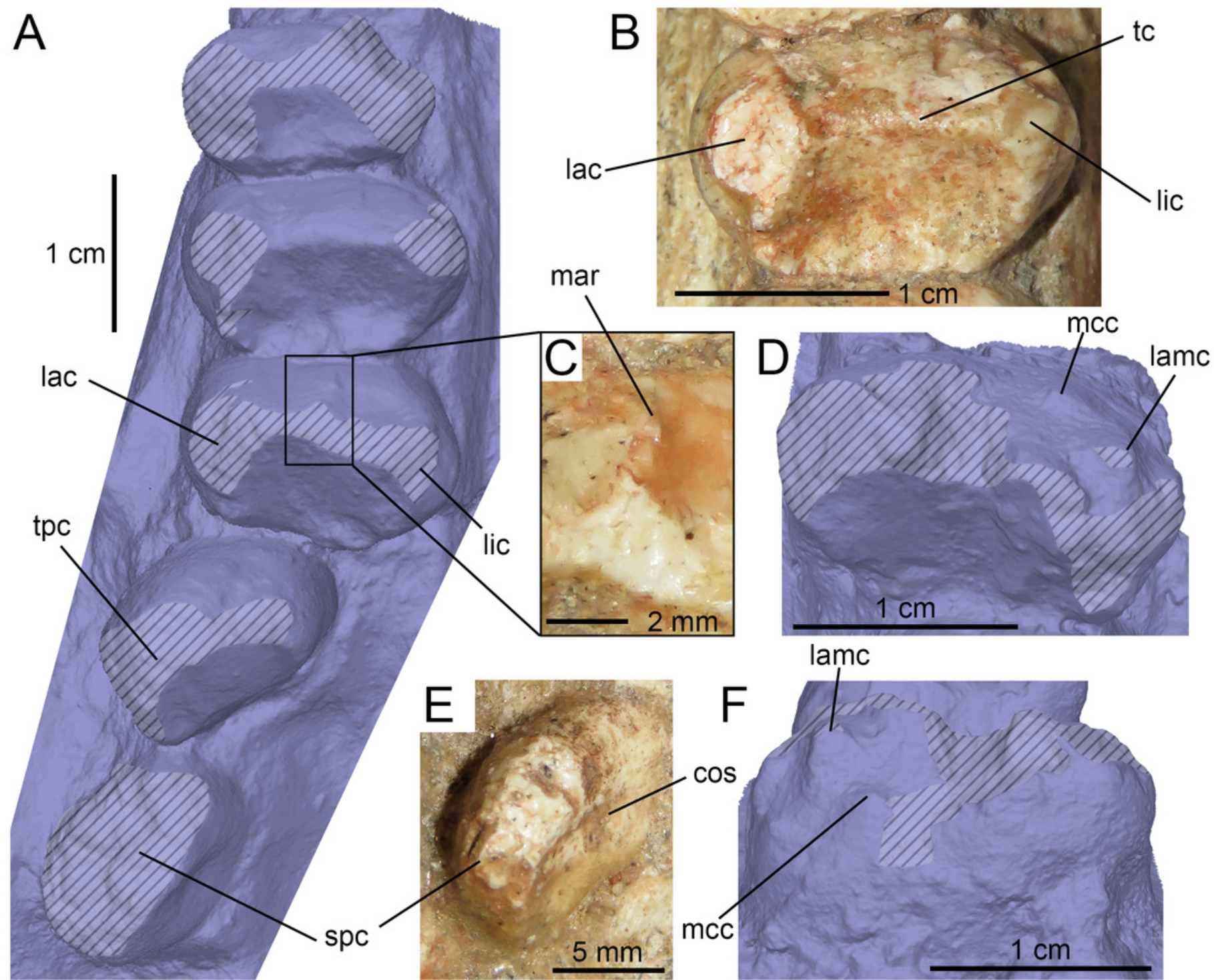




\section{Figure 7}

\section{Dentition of Langbergia modisei}

A-B, First left lower incisor of NMQR 3251, with B, close up on the distal carina in labial view; C, close up on the distal carina of the fourth left upper incisor of NMQR 3281 in labial view; D, F-G, right lower canine of NMQR 3251, with close up on the $\mathbf{F}$, distal and $\mathbf{G}$, mesial carina, in labial view; $\mathbf{E}$, cross-sectional outline of the right upper canine of SAM-PK-11481 in apical view (labial and mesial sides to the top and the right, respectively); $\mathbf{H}$, right upper canine of $\mathrm{BP} / 1 / 5362$ in labial view; I, centromesial portion of the erupting left upper canine of NMQR 3268 in labial view; J, fourth and fifth left upper gomphodont postcanines of NMQR 3251 in apical view; K, third left upper postcanine of NMQR 3255 in apical view; L, close up on the fourth left upper postcanine of NMQR 3251 in mesial view (crown upside down); $\mathbf{M}$, third and fourth right lower gomphodont postcanine of NMQR 3251 in apical view; N, first left lower gomphodont postcanine of NMQR 3251 in apicodistal view; $\mathbf{0}$, first and second right upper sectorial postcanine of NMQR 3251 in labial view; $\mathbf{P}$, first right upper sectorial postcanine of BP/1/5362 in labial view; Q, second left upper sectorial postcanine of NMQR 3255 in linguomesial view. Abbreviations: cc, central cusp; dac, distal accessory cusp; db, distal basin; dcc, distal cingular cuspule; dci, distal cingulum; dde, distal denticle; de, denticle; dmc, distal main cusp; lac, labial cusp; ladc, labiodistal accessory cusp; lamc, labiomesial accessory cusp; lic, lingual cusp; licc, lingual cingular cuspule; lidc, linguodistal accessory cusp; limc, linguomesial accessory cusp; Iri, longitudinal ridge; mac, mesial accessory cusp; mb, mesial basin; mc, main cusp; mcc, mesial cingular cuspule; mci, mesial cingulum; mde, mesial denticle; mmc, mesial main cusp; tc, transverse crest. Elongation axes of the crown and the central cusp in green and red, respectively. 


\section{Langbergia modisei}
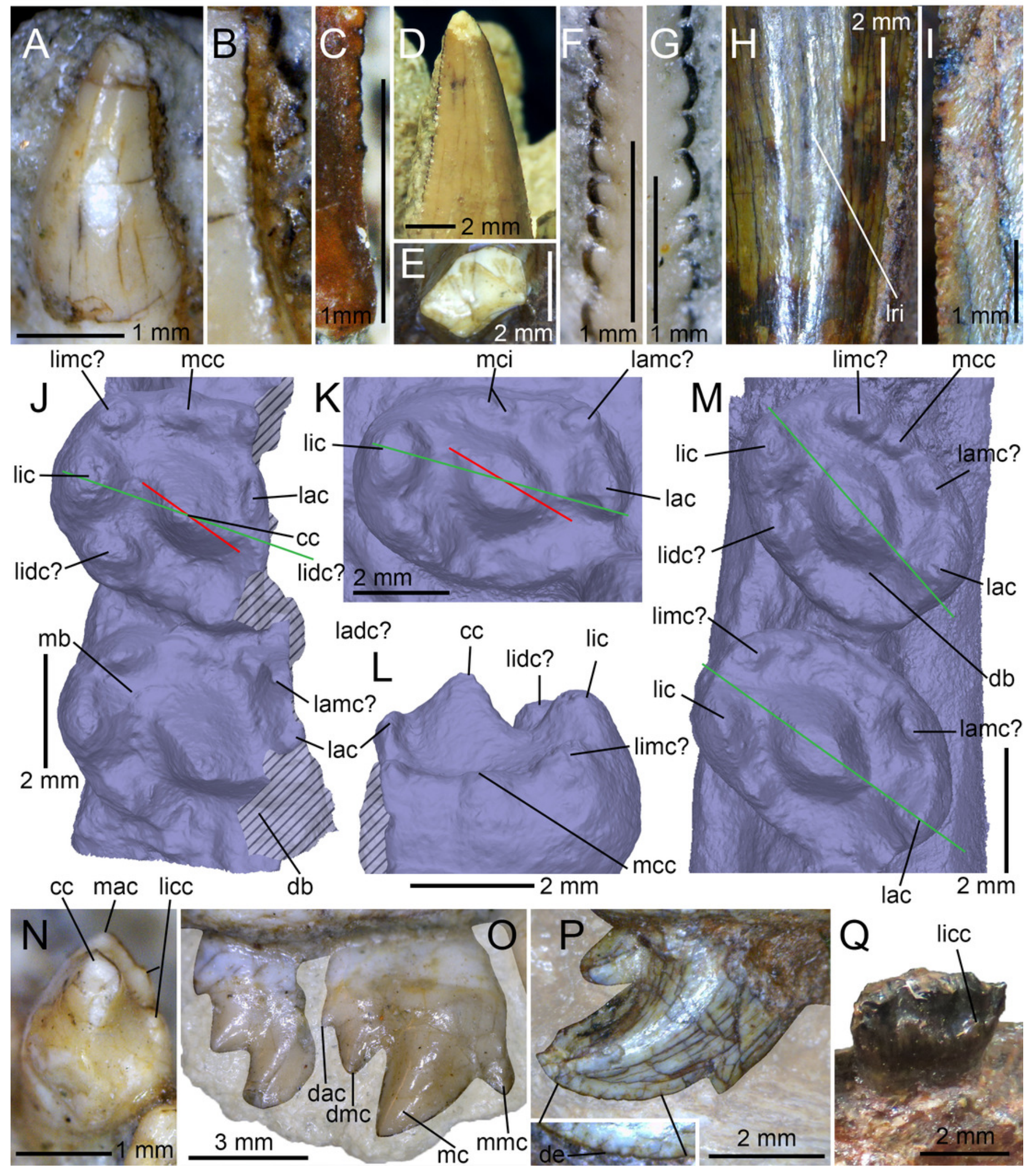


\section{Figure 8}

Dentition of Cricodon formosus

Dentition of Cricodon metabolus. A-B, First left lower incisor of UMCZ T905 in A, labial and B, labiodistal views; C-D, fourth left upper incisor of BP/1/6102, with $\mathbf{D}$, close up on the distal denticles, in labial view; E-F, left lower canine of SAM-PK-5881a, in E, lingual view; with F, cross-sectional outline at mid-crow apical view; $\mathbf{G}$, centromesial and $\mathbf{H}$, centrodistal denticles of the right upper canine of BP/1/6102 in labial view; I, centrodistal denticles of the right upper canine of BP/1/5540 in labial view; J, eight? and nine? right upper gomphodont postcanines of UMCZ T905 in apical view; K, eight and nine right lower gomphodont postcanines of UMCZ T905 in apical view; L, first left lower gomphodont postcanine of SAMPK-5881a in apical view; $\mathbf{M}$, last right upper gomphodont postcanine of SAM-PK-5881b in distal view; $\mathbf{N}$, last left upper gomphodont postcanine of UMCZ T905; $\mathbf{0}$, close up on the denticles on the labiodistal ridge of an isolated left upper postcanine of UMCZ T905 in labiodistal view; P-Q, ninth right upper sectorial postcanine of UMCZ T905 in P, labial and $\mathbf{Q}$, apical views. Abbreviations: cac, central accessory cusp; cc, central cusp; cos, concave surface; dac, distal accessory cusp; db, distal basin; $\mathbf{d c c}$, distal cingular cuspule; dci, distal cingulum; dde, distal denticle; de, denticle; dmc, distal main cusp; ent, enamel surface texture; lac, labial cusp; ladc, labiodistal accessory cusp; lic, lingual cusp; lidc, linguodistal accessory cusp; limc, linguomesial accessory cusp; Iri, longitudinal ridge; mb, mesial basin; mc, main cusp; mcc, mesial cingular cuspule; mci, mesial cingulum; mde, mesial denticle; mmc, mesial accessory cusp; tc, transverse crest; tun, transverse undulation. The red lines highlight the angular labiodistal margin of the lower postcanines. 


\section{Cricodon metabolus}

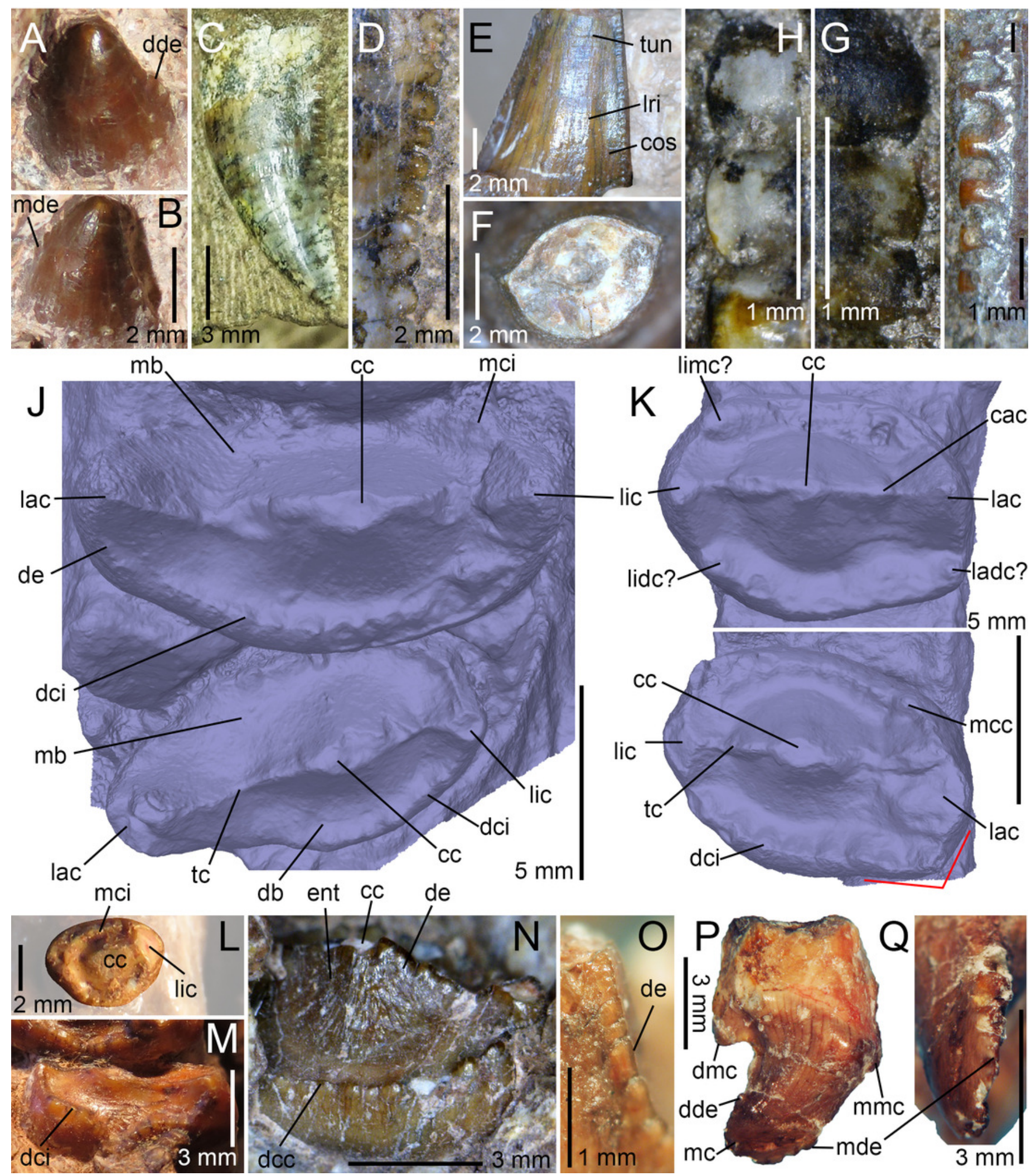




\section{Figure 9}

Dentition of Trirachodon berryi

A-C, First? left upper incisor, with close up on B, mesial and $\mathbf{C}$, distal denticles of SAMPK-12168 in labial view; D, first left and right upper and E, first right lower incisors of $\mathrm{BP} / 1 / 4658$ in apical views; F-G, right upper canine of BP/1/4661 with $\mathbf{G}$, close up on the centrodistal part of the crown, in labial view; $\mathbf{H}$, distal denticles of the right lower canine of BP/1/4658 in labial view; I, fifth and sixth right upper gomphodont postcanines of SAM-PKK171 ('T. kannemeyeri' morphotype) in apical view; J, tenth and eleventh left (reversed) upper gomphodont postcanines of BSP 1934 VIII 21 (T. berryi morphotype) in apical view; K, penultimate right upper gomphodont postcanine of SAM-PK-K4801 ('T. kannemeyeri' morphotype) in apical view; $\mathbf{M}$, penultimate left upper gomphodont postcanine of NHMUK PV R3307 ('T. kannemeyeri' morphotype) in apical view; $\mathbf{N}$, tenth left upper gomphodont postcanine of BSP 1934 VIII 21 (T. berryi morphotype) in apical view; O, partially erupted twelfth (and last) upper gomphodont postcanine of BSP 1934 VIII 21 in distal view.

Abbreviations: cc, central cusp; dac, distal accessory cusp; db, distal basin; dcc, distal cingular cuspule; dci, distal cingulum; ent, enamel surface texture; lac, labial cusp; ladc, labiodistal accessory cusp; lamc, labiomesial accessory cusp; lic, lingual cusp; lidc, linguodistal accessory cusp; limc, linguomesial accessory cusp; Iri, longitudinal ridge; mb, mesial basin; mc, main cusp; mcc, mesial cingular cuspule; $\mathbf{m c i}$, mesial cingulum; tc, transverse crest; tun, transverse undulation. 
Trirachodon berryi
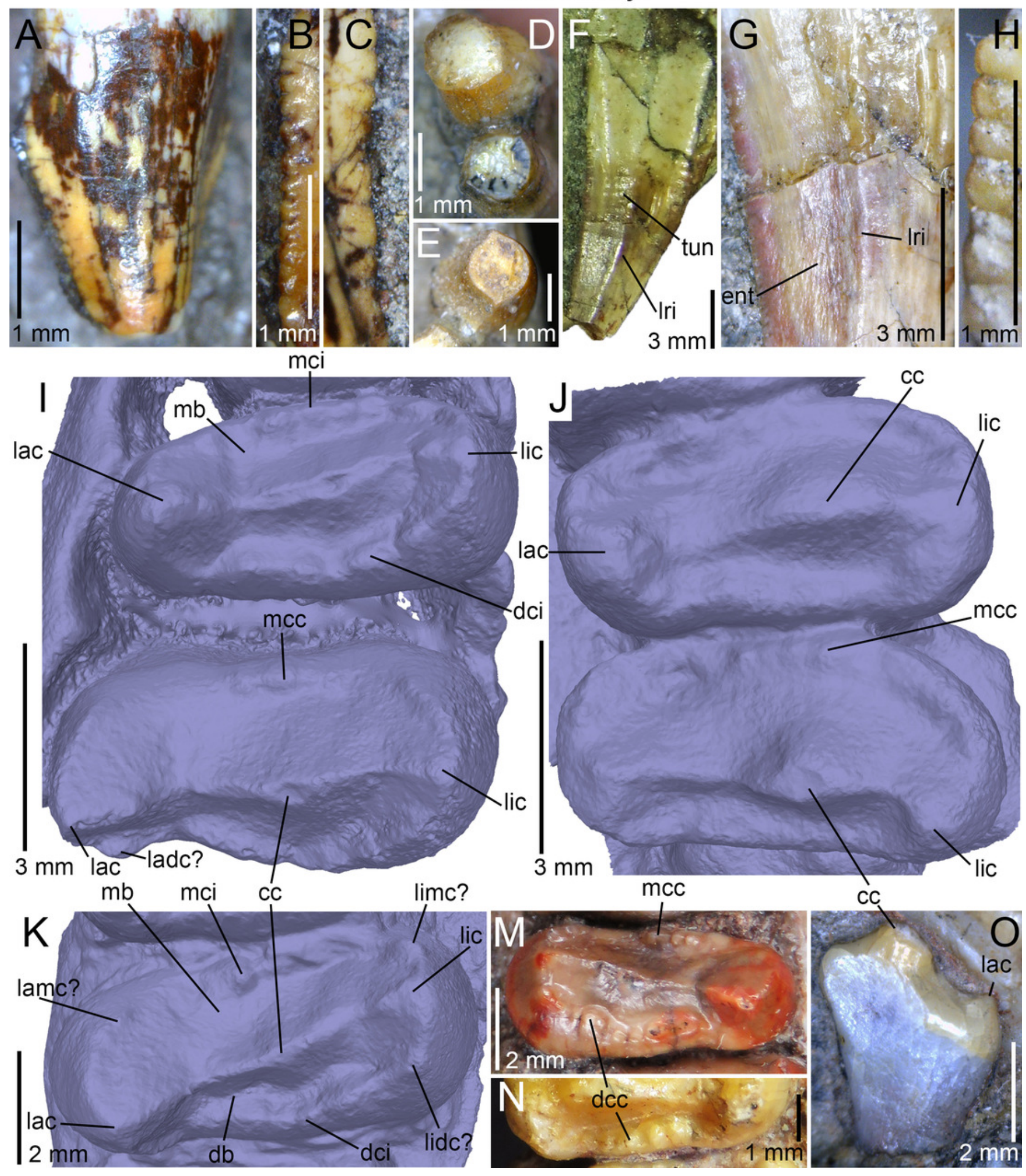


\section{Figure 10}

Dentition of Trirachodon berryi

A, fifth and sixth right lower gomphodont postcanines of SAM-PK-K171 in apical view; B, penultimate and $\mathbf{C}$, ultimate (and basolingually rotated) right lower gomphodont postcanines of SAM-PK-K4801 in apical view; $\mathbf{D}$, first left lower gomphodont postcanine of BP/1/4658 in apical view; E, fifth (bottom) and sixth (top) right lower gomphodont postcanines of SAM-PKK171 in apicomesial view; F, first (left) and second (right) right upper sectorial postcanines of SAM-PK-K4801 in labial view; G-H, first right lower sectorial postcanine of SAM-PK-K4801 in G, labial and $\mathbf{H}$, lingual views; I-J, first and second (erupted and replacing tooth) right lower sectorial postcanines of BP/1/4658 in I, labial and J, apical views. Abbreviations: cc, central cusp; dac, distal accessory cusp; db, distal basin; dcc, distal cingular cuspule; dci, distal cingulum; dde, distal denticle; de, denticle; dmc, distal main cusp; ent, enamel surface texture; lac, labial cusp; lacc, labial cingular cuspule; laci, labial cingulum; lic, lingual cusp; licc, lingual cingular cuspules; lici, lingual cingulum; mac, mesial accessory cusp; mb, mesial basin; mc, main cusp; mca, mesial carina; mcc, mesial cingular cuspule; mci, mesial cingulum; mmc, mesial main cusp. 

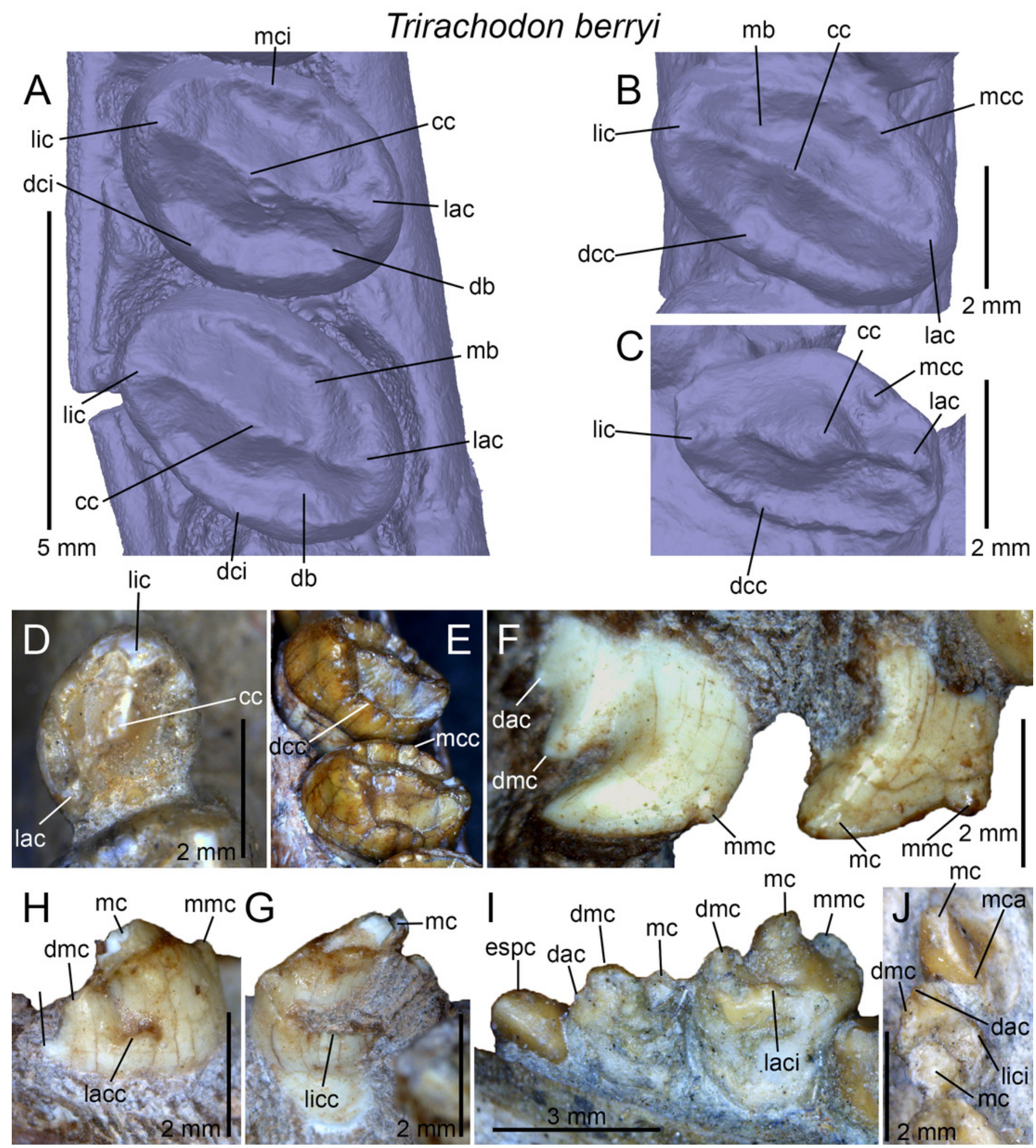


\section{Figure 11}

Dentition of Sinognathus gracilis (IVPP V2339)

A, second left upper incisor in labial view; B, fourth left upper incisor, with $\mathbf{C}$, close up on basodistal denticles, in labial views; D, basal root cross-sectional outline of the first left upper incisor in apical view; $\mathbf{E}$, left and F, right lower canines in labial view; $\mathbf{H}$, first to sixth upper and lower left gomphodont postcanines (sagittal cross-section through mid-crown), with close up on the fourth upper gomphodont postcanine, in labial view; J, right second to sixth upper (bottom) and second to seventh lower (top) gomphodont postcanines in linguodistal view (and apicodistal and basodistal views for the upper and lower gomphodont postcanines, respectively); $\mathbf{K}-\mathbf{L}$, third right upper gomphodont postcanine in $\mathbf{K}$, apicodistal and $\mathbf{L}$, apicolingual views; $\mathbf{M}$, third right lower gomphodont postcanine in labial view; $\mathbf{N}$, fourth left lower gomphodont postcanine in labial view; O-P, sixth (and last) upper gomphodont postcanine in $\mathbf{O}$, linguodistal and $\mathbf{P}$, apicolingual views. Abbreviations: cc, central cusp; dci, distal cingulum; de, denticle; lac, labial cusp; lic, lingual cusp; limc, linguomesial accessory cusp; mci, mesial cingulum; mde, mesial denticle; ro, root; tc, transverse crest; I-VI, first to sixth gomphodont postcanines. 


\section{Sinognathus gracilis}
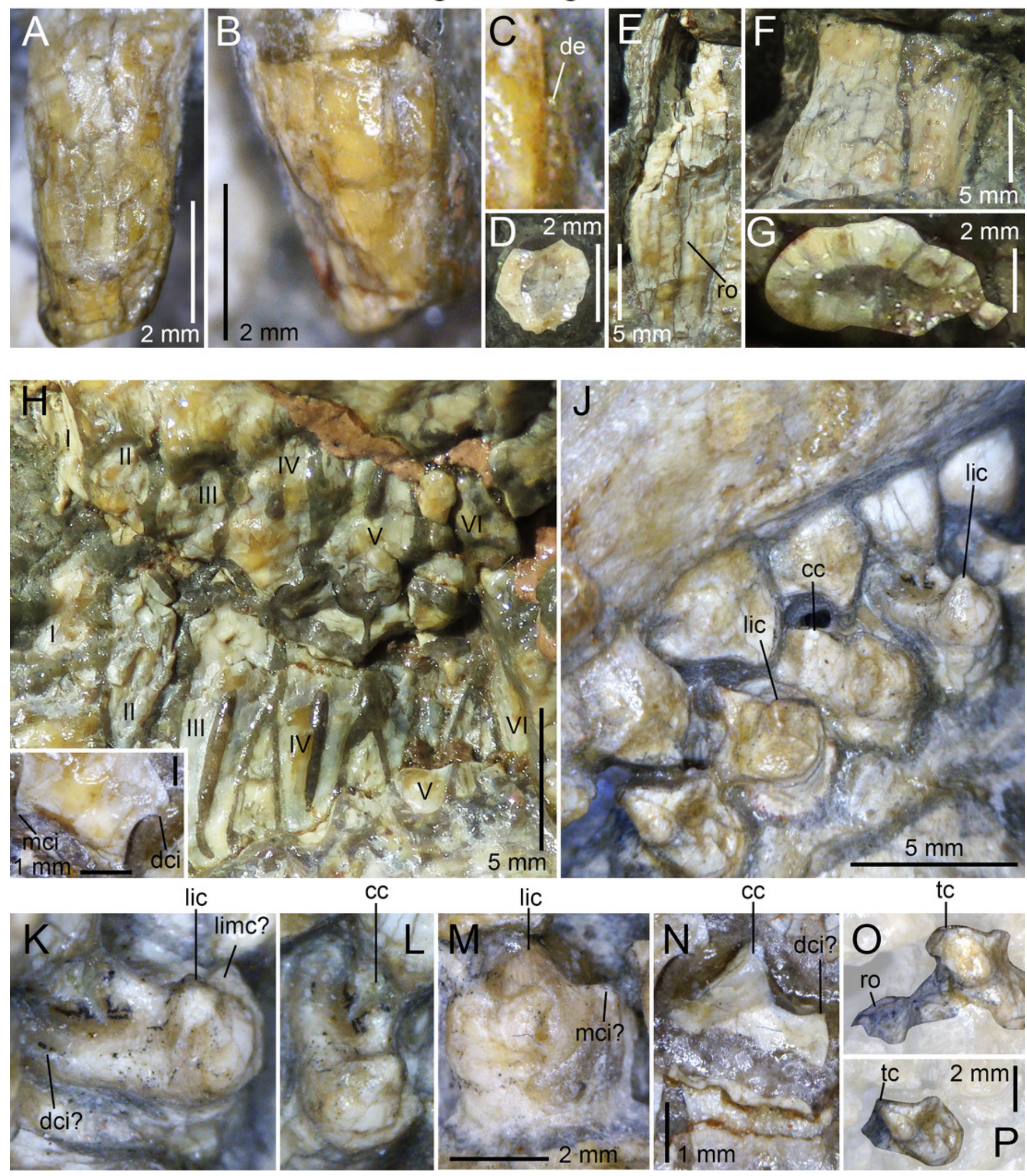


\section{Figure 12}

Comparison of skull length and widest upper gomphodont postcanine labiolingual width in gomphodont cynodonts, with linear regression trendlines for gomphodont taxa (in black) and Diademodon (in yellow).

Diademodon I, II and III refer to specimens BSP 1934 VIII 14, MB R1004 and BSP 1934 VIII 19, respectively, Andescynodon I and II to specimens PVL 3836 and PVL 3894-1, Pascualgnathus I and II to specimens PVL 4416 and MLP 65-VI-18-1, and Massetognathus I, II, III and IV to specimens BP/1/4245, PVL 4729, PVL 4727 and PVL 4613, respectively. Abbreviations:

CBW, crown base width.

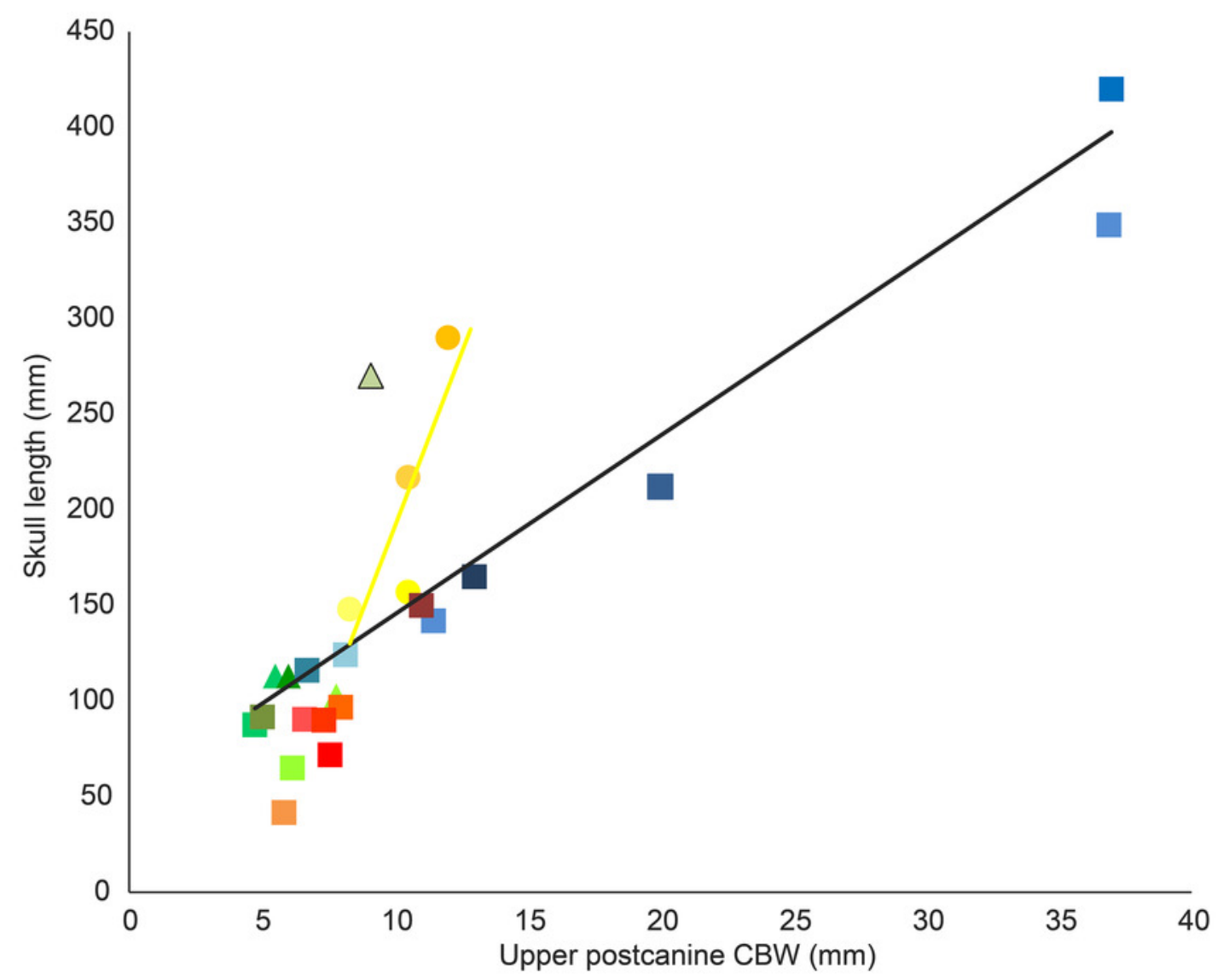

Diademodon I

Diademodon II

Diademodon III

Diademodon IV

- Langbergia

Trirachodon

- Sinognathus

$\triangle$ Beishanodon

CGP JSM 100

Andescynodon I

Andescynodon II

Rusconiodon

Pascualgnathus I

Pascualgnathus II

Luangwa

Dadadon

Massethognathus I

- Massethognathus II

- Massethognathus III

- Massethognathus IV

- Protuberum

Menadon

Exaeretodon I

Exaeretodon II 


\section{Table $\mathbf{1}$ (on next page)}

List of specimens of non-traversodontid gomphodonts examined in this study.

Specimens with the best-preserved dentition are underlined, and holotypic specimens are in bold. 


\section{Table}

2 Table 1: List of specimens of non-traversodontid gomphodonts examined in this study.

3 Specimens with the best-preserved dentition are underlined, and holotypic specimens are in bold. 4

Taxa

Diademodon tetragonus

Titanogomphodon crassus

Langbergia modisei

Cricodon metabolus

Trirachodon berryi

Sinognathus gracilis
Specimens

SAM-PK-571, 4002, 5877, 6216, 6218, 6219, 11265, K175, K177, K180, K183, ?K4660, ?K4661, K5223, K5266, K8971, K9968, K9969; AM 458, 3753;

BP/1/2522, 3639, 3756, 4529, 4669 , 4677; BSP 1934 VIII 14, 15, 16, 19, 20, 505; MB R1004; NHMUK PV R3303, R3588, R3765; GSN R321, RK3

\section{GSN R323}

NMQR 3255, 3251, 3256, 3268, 3280, 3281 ; BP/1/5362, 5363; SAM-PK-

$\underline{11481}$

UMZC T905; 6159; NHMUK PV R3722, K36800;

SAM-PK-6212, $\underline{\mathrm{K} 5881 a, b}$

NHMUK PV R3579, R2807, R3306, R3307, R3350, R3721; AM 434, 461;

BP/1/4258, 4658, 4661; $\underline{\text { BSP } 1934 \text { VIII }}$ 21, 22, 23; CGP INN 2000-7-2A, CGP unnumbered; NMQR 1399; SAM-PK987, 5880, K142, K170, K171, K4801, K4803, K5821 (=12168?), K7888, K10157, K10161, K10176, K10207, K10411

\section{IVPP V2339}


